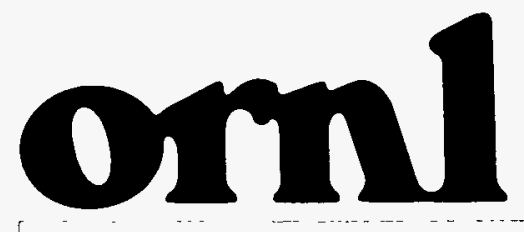

OAK RIDGE

NATIONAL

LABORATORY

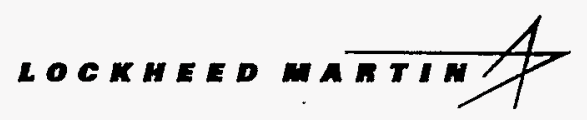

RECRVED

ORNL/TM-13241

\section{ALKALINE-SIDE EXTRACTION OF TECHNETIUM FROM TANK WASTE USING CROWN ETHERS AND OTHER EXTRACTANTS}

\author{
Peter V. Bonnesen \\ Bruce A. Moyer \\ Derek J. Presley \\ Virginia S. Armstrong \\ Tamara J. Haverlock \\ Robert M. Counce
}

Richard A. Sachleben
MANAGED ANO OPERATED BY LOCKHEED MARTIN ENERGY RESEARCH CORPORATION FOR THE UNTED STATES DEPARTMENT OF ENERGY 
This report has been reproduced directly from the best available copy.

Available to DOE and DOE contractors from the Office of Scientific and Technical Information, P.O. Box 62, Oak Ridge, TN 37831; prices available from (615) 576-8401, FTS 626-8401.

Available to the public from the National Technical Information Service, U.S. Department of Commerce, 5285 Port Royal Rd., Springfield, VA 22161.

This report was prepared as an account of work sponsored by an agency of the United States Government. Neither the United States Government nor any agency thereof, nor any of their employees, makes any warranty, express or implied, or assumes any legal liability or responsibility for the accuracy, completeness, or usefulness of any information, apparatus, product, or process disclosed, or represents that its use would not infringe privately owned rights. Reference herein to any specific commercial product, process, or service by trade name, trademark, manufacturer, or otherwise, does not necessarily constitute or imply its endorsement, recommendation, or favoring by the United States Government or any agency thereof. The views and opinions of authors expressed herein do not necessarily state or reflect those of the United States Government or any agency thereof. 


\section{DISCLAIMER}

Portions of this document may be illegible in electronic image products. Images are produced from the best available original document. 
Chemical and Analytical Sciences Division

\section{ALKALINE-SIDE EXTRACTION OF TECHNETIUM FROM TANK WASTE USING CROWN ETHERS AND OTHER EXTRACTANTS.}

Peter V. Bonnesen ${ }^{1}$, Bruce A. Moyer ${ }^{1}$, Derek J. Presley, ${ }^{1}$ Virginia S. Armstrong ${ }^{2}$, Tamara J. Haverlock ${ }^{1}$, Robert M. Counce ${ }^{3}$, and Richard A. Sachleben ${ }^{1}$

${ }^{1}$ Chemical and Analytical Sciences Division,

Oak Ridge National Laboratory P.O. Box 2008, Oak Ridge, TN 37831-6119

${ }^{2}$ Current address: Galbraith Laboratories, Inc., P.O. Box 51610, Knoxville, TN 37950

${ }^{3}$ Chemical Technology Division, Oak Ridge National Laboratory, P.O. Box 2008, Oak Ridge, TN 37831-6044, and Department of Chemical Engineering, The University of Tennessee, Knoxville, TN 37996

Date Published_June 1996

Prepared for the

U. S. Department of Energy, Office of Environmental Management, Office of Science and Technology, Efficient Separations and Processing Cross-Cutting Program

Prepared by the

OAK RIDGE NATIONAL LABORATORY

Oak Ridge, Tennessee 37831-6119

managed by

LOCKHEED MARTIN ENERGY RESEARCH CORP

for the

U. S. DEPARTMENT OF ENERGY

under contract DE-AC05-96OR22464 


\section{CONTENTS}

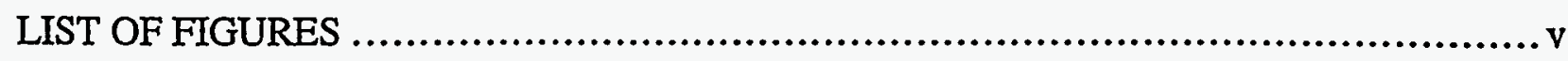

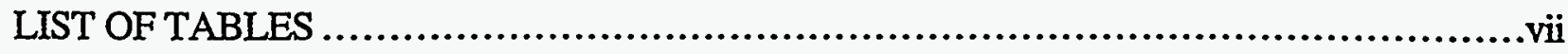

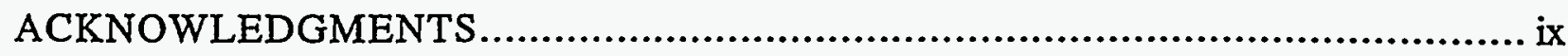

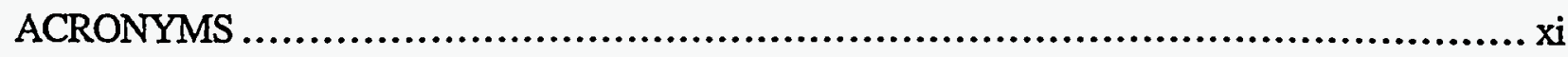

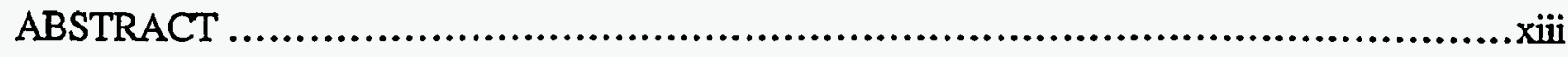

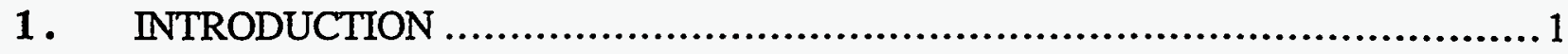

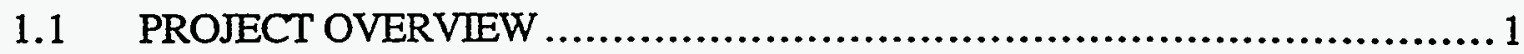

1.2 SOLVENT EXTRACTION OF PERTECHNETATE ............................2

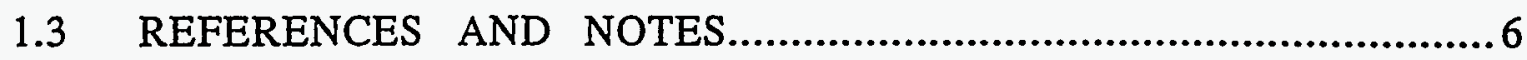

2. EVALUATION OF EXTRACTANTS ............................................ 8

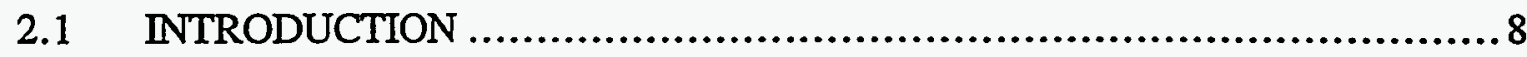



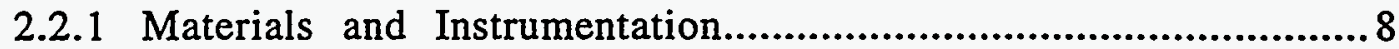

2.2.2 Quaternary Ammonium Nitrates..........................................11

2.2.3 Contacting Procedures............................................12



2.3.1 Initial Screening of Crown Ethers.......................................12

2.3.2 Effect of Crown Ether, Nitrate, and Hydroxide Concentration..............18

2.3.3 Effect of Diluent ........................................................18

2.3.4 Stripping Experiments with Selected Systems............................21

2.3.5 Comparison to Quatemary Ammonium Compounds .......................24

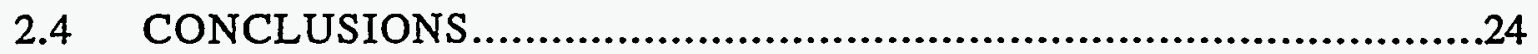

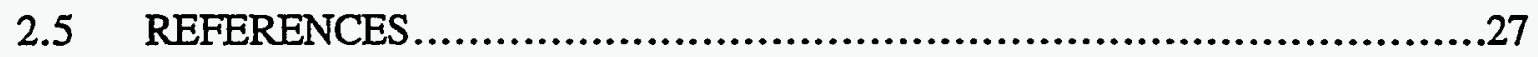

3. OPTIMIZATION OF CROWN ETHER AND DILUENT: ESTABLISHING AN

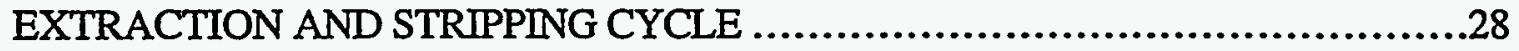

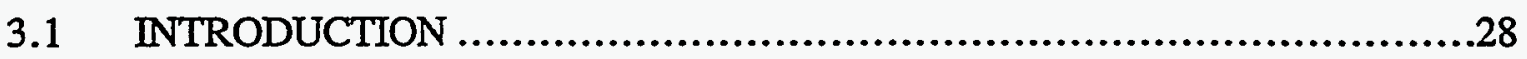

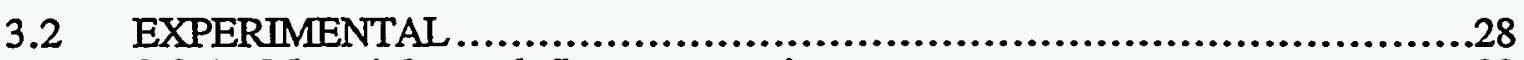

3.2.1 Materials and Instrumentation.............................................28

3.2.2 Hanford Tank Waste Simulants ...........................................29

3.2.3 General Two-Extraction/Two-Strip Contacting Procedure....................30 


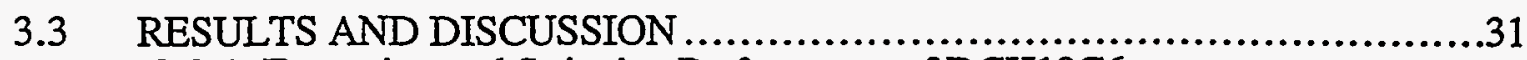

3.3.1 Extraction and Stripping Performance of DCH18C6

in Selected Diluents ..................................................... 31

3.3.2 Performance of Selected Synthetic and Commercial Crown Ethers in Various Waste Simulants (Simple, NCAW, and DSSF-7).....................37

3.3.3 Extraction/Stripping Cycling of Selected Systems .........................42

3.3.4 Evaluation of Other Stripping Methods ................................42

3.3.5 Effect of Diluent on Solvent Selection .................................45

3.3.6 Comparison of di-t-BuCH18C6 with cis-BOB 14C4-bis(oxyacetone).......47

3.3.7 The Effect of Temperature, Contact Time, and Tc Concentration ...........49

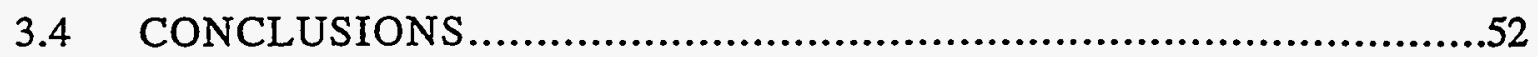



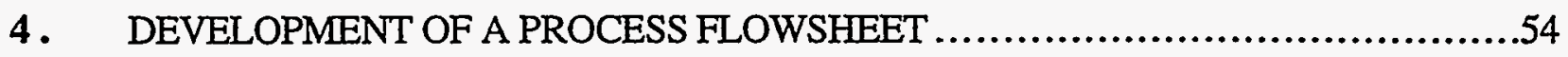

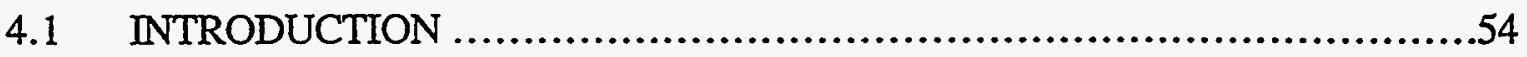

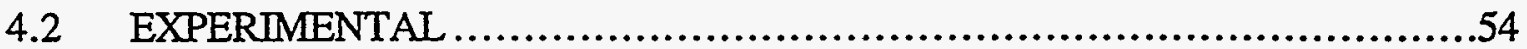



4.2.2 Actual and Simulated Waste................................................55

4.2.3 Batch-Equilibrium Three-Stage Counter-Current Contacting Procedure ....57

4.2.4 Extraction/Stripping Cycling of Candidate Systems .......................57

4.3 RESULTS AND DISCUSSION ...........................................59

4.3.1 Selection of Final Candidate Solvents ......................................59

4.3.2 Batch-Equilibrium Three-Stage Counter-Current Test..........................61

4.3.3 Technetium Extraction and Stripping Experiments with Actual MVST W-29 Supernate ..........................................64

4.3.4 Effect of Sodium and Potassium Concentration on Stripping Efficiency...68

4.3.5 Extraction/Stripping Cycling of Candidate Systems .........................70

4.3.6 Strontium and Technetium Extraction and Stripping Experiments ..........85

4.4 CONCLUSIONS AND RECOMMENDATIONS …...........................87

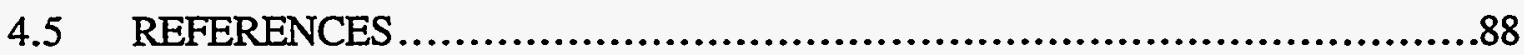

Appendix A. WORKSHEET FOR PREPARING MELTON VALLEY STORAGE TANK W-29 SIMULANT 


\section{LIST OF FIGURES}

1.1 Simplified hypothetical mechanism of extraction of pertechnetate by a crown ether from a waste stream containing alkali metal ions; stripping may be effected by backextraction with water.

2.1 14-crown-4 and 15-crown-5 ethers examined in this study ...........................13

2.218 -crown-6 and 21-crown-7 ethers examined in this study ...............................14

2.3 Extraction of pertechnetate by selected crown ethers in 1-octanol $(0.025 \mathrm{M})$ at $25^{\circ} \mathrm{C}$.......15

2.4 Extraction of pertechnetate by selected crown ethers in 1-octanol $(0.025 \mathrm{M})$..............17

2.5 Extraction of pertechnetate by DCH18C6 at $0.025,0.10$, and $0.25 \mathrm{M}$ in 1-octanol........19

2.6 Extraction of pertechnetate by $0.10 \mathrm{M} \mathrm{DCH} 18 \mathrm{C} 6$ in 1-octanol from $5.1 \mathrm{M} \mathrm{Na}\left(\mathrm{OH}+\mathrm{NO}_{3}\right)$

2.7 Extraction of pertechnetate by $\mathrm{DCH} 18 \mathrm{C} 6(0.10 \mathrm{M})$ in various diluents from $\mathrm{NaNO}_{3}$ as shown.

2.8 Extraction of pertechnetate from $0.10 \mathrm{M} \mathrm{NaOH}, 5 \mathrm{M} \mathrm{NaNO}_{3}$ solutions by

DCH18C6 $(0.10 \mathrm{M})$ in various diluents, and stripping by back-extraction into water......23

2.9 Pertechnetate extraction by selected quaternary ammonium nitrates $(0.025$ and $0.10 \mathrm{M}$ in o-xylene)

2.10 Comparison of pertechnetate extraction by Aliquat ${ }^{\circledR} 336$ Nitrate $(0.025$ and $0.10 \mathrm{M})$

in 1-octanol vs. o-xylene

3.1 ORNL-synthesized crown ethers used in this study

3.2 Diagram of two-extraction, two-strip contacting procedure

3.3 Pertechnetate/nitrate selectivity $\left(\mathrm{D}_{\mathrm{NaTcO}_{4}} / \mathrm{D}_{\mathrm{NaNO}_{3}}\right)$ for extraction by DCH18C6

$(0.10 \mathrm{M})$ in various diluents

3.4 Extraction of sodium pertechnetate and nitrate by DCH18C6 (0.10 M) in various diluents(corrected for diluent)

3.5 Extraction of pertechnetate from "simple," NCAW, and DSSF-7 waste simulants by selected crown ethers $\left(0.04 \mathrm{M}\right.$ in 2:1 2-octanone/Isopar $\left.{ }^{\circledR} \mathrm{M}\right)$ .38

3.6 Stripping of pertechnetate from 2:1 vol/vol 2-octanone//sopar ${ }^{\circledR} \mathrm{M}$ solutions after two extraction contacts with "simple", NCAW, and DSSF-7 waste simulants

3.7 Technetium distribution ratio as a function of temperature .................................50

3.8 Technetium distribution ratio as a function of $\mathrm{Tc}$ concentration. ...........................51 
4.1 Contacting procedure for batch-equilibrium extraction to approach three-stage countér-current.

4.2 Contacting procedure for batch-equilibrium stripping to approach three-stage counter-current. .58

4.3 Diagram of one-extraction, three-strip contacting procedure with solvent and stripping water recycle used to test the efficiency of the strip cycle

4.4 Tc extraction and stripping ratios for $1: 1 \mathrm{vol} / \mathrm{vol}$ TBP/Isopar ${ }^{\circledR} \mathrm{M}$ as a function of di-t-BuCH18C6 concentration $(0.04,0.02$, and $0.01 \mathrm{M})$.

4.5 Tc extraction and stripping ratios for $0.02 \mathrm{M}$ di-t-BuCH18C6 in TBP/Isopar ${ }^{\circledR} \mathrm{M}$ blends as a function of vol\% TBP $(67,50,25 \mathrm{vol} \%)$

4.6 Technetium distribution ratio as a function of crown ether concentration for extraction from DSSF-7 simulant using di-t-BuCH18C6 in 1:1 vol/vol TBP//sopar ${ }^{\circledR} \mathrm{M}$

4.7 Equilibrium data for three stage extraction of Tc using $0.02 \mathrm{M}$ di-t-BuCH18C6 in 1:1 TBP/Isopar ${ }^{\circledR} \mathrm{M}$

4.8 Technetium stripping efficiency from Tc-laden solvent as a function of the initial stripping-phase sodium or potassium nitrate concentration

4.9 [Tc] org following extraction and stripping for each solvent as a function of cycle\# (cycle \#1 omitted)

$4.10[\mathrm{Tc}]$ org following extraction contact for each solvent as a function of cycle number........74

$4.11[\mathrm{Tc}]_{\mathrm{aq}} /[\mathrm{Tc}]_{\text {org }}$ vs. $[\mathrm{M}]_{\text {total }}(\mathrm{M}=\mathrm{Na}$ or $\mathrm{K})$ in stripping or extraction contact for solvent $\mathrm{A}\left(0.04 \mathrm{M}\right.$ di-t-BuCH18C6 in 1:1 TBP/Isopar $\left.{ }^{\circledR} \mathrm{M}\right)$.

$4.12[\mathrm{Tc}]_{\mathrm{aq}} /[\mathrm{Tc}]_{\text {org }}$ vs. $[\mathrm{M}]_{\text {total }}(\mathrm{M}=\mathrm{Na}$ or $\mathrm{K})$ in stripping or extraction contact for solvent $B\left(0.02 \mathrm{M}\right.$ di-t-BuCH18C6 in 2:1 TBP/1sopar $\left.{ }^{\circledR} \mathrm{M}\right)$.

$4.13[\mathrm{Tc}]_{\mathrm{aq}} /[\mathrm{Tc}]_{\text {org }}$ vs. $[\mathrm{M}]_{\text {total }}(\mathrm{M}=\mathrm{Na}$ or $\mathrm{K})$ in stripping or extraction contact for solvent C (Pure TBP).

4.14 Ratio of total $[\mathrm{Na}]$ to total $[\mathrm{K}]$ in stripping contact for Solvent $\mathrm{A}$

(0.04 $\mathrm{M}$ di-t-BuCH18C6 in 1:1 $\left.\mathrm{TBP}^{-1 s o p a r}{ }^{\circledR} \mathrm{M}\right)$.

4.15 Ratio of total [Na] to total [K] in stripping contact for Solvent B (0.02 $\mathrm{M}$ di-t-BuCH18C6 in 2:1 $\mathrm{TBP}^{\mathrm{As}} \mathrm{spar}^{\circledR} \mathrm{M}$ ).

4.16 Ratio of total [Na] to total [K] in stripping contact for Solvent $\mathrm{C}$ (TBP). .81

4.17 Technetium removal step: simplified conceptual process flowsheet .83 


\section{LIST OF TABLES}

3.1 Composition of Hanford waste simulants and "simple simulant" used in this study.........30

3.2 Extraction of pertechnetate by $\mathrm{DCH} 18 \mathrm{C} 6(0.1 \mathrm{M})$ in various diluents from $0.1 \mathrm{M} \mathrm{NaOH}, 5.0 \mathrm{M}$ sodium nitrate, and stripping by back-extraction using water

3.3 Extraction of sodium and technetium by selected diluents with and without crown ether (DCH18C6 at $0.1 \mathrm{M}$ ), and stripping efficiency of technetium as a function of sodium (nitrate) and technetium extractability by crown ether plus diluent, and diluent alone ......34

3.4 Solvent extraction of pertechnetate from "simple" and DSSF-7 simulants, and stripping efficiency for selected synthetic and commercial crown ethers

3.5 Pertechnetate extraction from DSSF-7 simulant and stripping over three cycles using DCH18C6 and di-t-BuCH18C6.

3.6 Stripping efficiency as a function of dissolved salts in stripping phase: comparison to deionized water. Acending total \% Tc stripped

3.7 Extraction of pertechnetate from DSSF-7 simulant by di-t-BuCH18C6 in selected diluents. Stripping by back-extraction with water. Two diluents with no crown ether for comparison

3.8 Extraction of pertechnetate from DSSF-7 waste simulant by various lots of BOB-14C4-Bis(oxyacetone) (di-t-BuCH18C6 and Aliquat ${ }^{\circledR} 336$ Nitrate also shown for comparison), and stripping by back-extraction with water

4.1 Composition of simulated MVST W-29 waste supernate, and comparison with actual waste

4.2 Extraction of pertechnetate from DSSF-7 and MVST W-29 waste simulants by di-t-BuCH18C 6 in selected diluents, and stripping by back-extraction with water

4.3 Tc extraction from actual and simulated Melton Valley Storage Tank W-29 Supernate using $0.02 \mathrm{M}$ di-t-BuCH18C6 in 1:1 TBP/Isopar ${ }^{\circledR} \mathrm{M}$ (experiments \#1-4) and pure TBP (experiments \#5-6)

4.4 Extraction, stripping, and processing data for extraction of Tc from MVST W-29 simulant (59.1 micromolar $\mathrm{Tc}$ ) using candidate solvents.

4.5 Estimated yearly expenses for the three solvent candidates for a Tc extraction process with a decontamination factor for extraction and stripping of $99 \%$ from MVST W-29 simulant (59.1 micromolar Tc)

4.6 Extraction and stripping performance for strontium ( $\mathrm{Sr}-85$ tracer) from simulated Melton Valley Storage Tank W-29 supernate using Solvents A, B, and C. 
$$
\text { - }
$$ 


\section{ACKNOWLEDGMENTS}

This research was sponsored by the Efficient Separations and Processing Cross-Cutting Program, Office of Science and Technology, Office of Environmental Management, U. S. Department of Energy, under contract number DE-AC05-96OR22464 with Oak Ridge National Laboratory, managed by Lockheed Martin Energy Research Corp.

The authors wish to thank the following people: Fred V. Sloop in the Chemical Separations Group of the ORNL Chemical and Analytical Sciences Division (CASD) for assistance with the synthesis of BOB-14C4-diol; Diadra M. Bau (co-op student during 1993), for the purification of Aliquat 336; Charles F. Coleman (retired from ORNL), for many helpful discussions and for proof-reading the manuscript; Clark D. Carlson and Gregg J. Lumetta (Pacific Northwest National Laboratory), for information regarding the composition of Hanford waste simulants; Jack L. Collins (ORNL Chemical Technology Division) for providing us with a sample of the supernatant liquid from Oak Ridge's Melton Valley Storage Tank W-29, along with analytical data; and Bill Wilkenson, Rodney Hunt, and Phil McGinnis (ORNL), for management assistance with the Technical Task Plan (TTP) and reporting. Finally, we thank Barry B. Spencer (ORNL Robotics and Process Systems Division), for technical review of the manuscript, and for many helpful suggestions and comments, and also Mary S. Fisher (ORNL Information Management Services), for editorial assistance. 
 


\section{ACRONYMS}

\begin{tabular}{|c|c|}
\hline ANL & Argonne National Laboratory \\
\hline DF & Decontamination Factor \\
\hline DOE & Department of Energy \\
\hline $\mathrm{D}_{\mathrm{M}}$ & Distribution Ratio for species $M$ \\
\hline DPM & Disintegrations per Minute \\
\hline DSSF & Double Shell Slurry Feed \\
\hline DSSF-7 & Double Shell Slurry Feed, $7 \mathrm{M} \mathrm{Na}$ \\
\hline DST & Double Shell Tank \\
\hline EPA & Environmental Protection Agency \\
\hline FY & Fiscal Year \\
\hline HLW & High Level Waste \\
\hline ICAP & Inductiveley Coupled Argon Plasma \\
\hline LANL & Los Alamos National Laboratory \\
\hline LLW & Low Level Waste \\
\hline LSC & Liquid Scintillation Counting \\
\hline $\mathrm{M} \Omega$ & Mega Ohm \\
\hline MSDS & Material Safety Data Sheet \\
\hline MVST & Melton Valley Storage Tank \\
\hline NCAW & Neutralized Current Acid Waste \\
\hline NIST & National Institute of Standards and Technology \\
\hline ORNL & Oak Ridge National Laboratory \\
\hline PNNL & Pacific Northwest National Laboratory \\
\hline RCRA & Resource Conservation and Recovery Act \\
\hline SF & Separation Factor \\
\hline $\mathrm{S}_{\mathrm{M}}$ & Stripping Ratio for species $M$ \\
\hline SRS & Savannah River Site \\
\hline SST & Single Shell Tank \\
\hline TFA & Tanks Focus Area \\
\hline TWRS & Tank Waste Remediation System \\
\hline
\end{tabular}





\begin{abstract}
The chemical development of a new crown-ether-based solvent-extraction process for the separation of technetium (Tc) from alkaline tank-waste supernate has been completed and is ready for counter-current testing. The process addresses a priority need in the proposed cleanup of Hanford and other tank wastes. This need has arisen from concerns due to the volatility of Tc during vitrification, as well as ${ }^{99}$ Tc's long half-life (213,000 years) and environmental mobility. In addressing this need, the new process offers several key advantages that make it competitive with other techniques. The advantages include: 1) direct treatability - no adjustment of the waste composition is needed; 2) economical stripping with water; 3) high efficiency - few stages needed; 4) non-RCRA chemicals - no generation of hazardous or mixed wastes; 5) co-extraction of ${ }^{90} \mathrm{Sr} ; 6$ ) optional concentration on a resin. A key concept advanced in this work entails the use of tandem techniques: solvent extraction offers high selectivity, while a subsequent column sorption process on the aqueous stripping solution serves to greatly concentrate the Tc. Optionally, the stripping solution can be evaporated to a small volume. Batch tests of the solvent-extraction and stripping components of the process have been conducted on actual Melton Valley Storage Tank (MVST) waste as well as simulants of MVST and Hanford waste (DSSF-7 and NCAW). The tandem process was demonstrated on MVST waste simulants using the three solvents that were selected as the final candidates for the process. The solvents are $0.04 \mathrm{M}$ bis- $4,4^{\prime}\left(5^{\prime}\right)[($ tertbutyl)cyclohexano]-18-crown-6 (abbreviated di-t-BuCH18C6) in a 1:1 vol/vol blend of tributyl phosphate (TBP) and Isopar ${ }^{\circledR} \mathrm{M}$ (an isoparaffinic kerosene) ("Solvent $\mathrm{A}^{\text {") }} 0.02 \mathrm{M}$ di-tBuCH18C6 in 2:1 vol/vol TBP/Isopar ${ }^{\circledR} \mathrm{M}$ ("Solvent B"); and pure TBP ("Solvent C"). The process is now ready for counter-current testing on actual Hanford tank supernates.
\end{abstract}




\section{INTRODUCTION}

\subsection{PROJECT OVERVIEW}

Objective. The primary objective of the project entitled "Alkaline-Side Extraction of Technetium from Tank Waste Using Crown Ethers and Other Extractants" was to develop an efficient solvent-extraction and stripping process utilizing crown ethers or other extractants for the removal of technetium (Tc) from alkaline tank waste containing high concentrations of sodium nitrate.

Target Problem. The problem of how to safely dispose of the large volumes of radioactive wastes is one of the largest facing the Department of Energy. ${ }^{1}$ A significant fraction of the high level waste (approximately $6 \times 10^{7}$ gallons, roughly $2 / 3$ of all high level waste) is stored in 149 single shell tanks (SSTs) and 28 double shell tanks (DSTs) at the Department of Energy's (DOE's) Hanford, Washington, site. The remainder is stored mostly at DOE's Savannah River Site (SRS) in South Carolina; smaller amounts are stored at other sites (e.g., at the Oak Ridge Reservation in Tennessee, at the Idaho National Engineering Laboratory, and at the Nuclear Fuel Services plant near West Valley, New York). ${ }^{2}$ Remediation schemes are focused on cost savings through both reduction in the volume of radionuclides that must be committed to a geologic repository and minimization of secondary waste streams. Such schemes include the efficient separation of the small amount of highly radioactive species (e.g., ${ }^{137} \mathrm{Cs},{ }^{90} \mathrm{Sr}$ ) from the larger amount of low- and non-radioactive components, to yield respectively high-level waste (HLW) and low-level waste (LLW). The current plans are to convert LLW to glass and store it on the Hanford reservation, and to vitrify $\mathrm{HLW}$ into glass logs and store the logs in a geologic repository.

Among the radionuclides being considered for separation from the tank sludges and supernates are ${ }^{137} \mathrm{Cs},{ }^{90} \mathrm{Sr},{ }^{99} \mathrm{Tc}$, and various actinides. Cesium-137 and strontium-90 are responsible for the bulk of the radiation from the tank waste, representing $40 \%$ and $25 \%$ of the total curie content respectively, ${ }^{1}$ and as such the removal of these two radionuclides from the waste is of prime importance. They pose mostly a short-term risk, as the half-lives are relatively short at 30.3 and 29.1 years, respectively. Technetium-99 is a uranium fission product with a low-energy beta emission and a half-life of $2.13 \times 10^{5}$ years. It is present in non-complexant-containing alkaline nuclear-waste media mainly in the +7 oxidation state ${ }^{3}$ as the environmentally mobile oxoanion, pertechnetate $\left(\mathrm{TcO}_{4}^{-}\right)$. An estimated 1.8 metric tons ${ }^{4}$ of technetium- 99 (most of the world's supply) is believed to be contained in the liquid and slurry phases of the high-level waste stored in the 177 waste tanks at Hanford.

How to treat and dispose of technetium has been the subject of some debate. The long half-life and environmental mobility of $\mathrm{TcO}_{4}^{-}$have been the cause of some concern regarding plans to incorporate Tc into LLW: pertechnetate could leach out of the LLW form and migrate in streams, 
run-off, etc. to other locations, posing health risks. Separation of Tc from the tank waste for incorporation into HLW is an option, but the volatility of Tc oxides creates difficulties in vitrification processes. While the current baseline remediation strategy of the new Hanford Triparty Agreement (between the Department of Energy, the Environmental Protection Agency, and Washington state) does not explicitly include a technetium removal step, these special aspects of Tc chemistry make desirable its removal from alkaline tank-waste streams and ultimately development of stable waste forms specifically suited for its containment.

There are a number of technologies currently being developed for the removal of technetium from tank waste supernate. One technology being pursued at Los Alamos National Laboratory (LANL) involves the use of the anion exchange resin Reillex ${ }^{\mathrm{TM}}$ HPQ to remove pertechnetate from Hanford tank waste. 5 Researchers at Argonne National Laboratory (ANL) have been investigating the use of polyethylene glycols and polypropylene glycols for use in a polymer-based extraction system for pertechnetate and iodide. ${ }^{6}$ Another viable separation system for pertechnetate is the work described in this report dealing with solvent extraction.

Chemistry of Technetium. For the sake of brevity, only the most salient aspects of technetium chemistry will be reported here; the reader is encouraged to refer to the many fine texts ${ }^{7,8}$ and review articles ${ }^{9}$ covering technetium chemistry. Technetium (atomic number 43 ) is a second-row transition metal element between $\mathrm{Mo}$ and $\mathrm{Ru}$ and is the second element in the $\mathrm{Mn}$ triad. The chemistry of technetium is comparable in some respects to that of $\mathrm{Mn}$ and is particularly similar to that of Re. Interestingly, there are no stable isotopes of technetium. Technetium-99 is produced mostly from the fission of $235 \mathrm{U}$ with a yield of $6 \%$. The redox behavior of technetium is such that the pertechnetate anion $\mathrm{TcO}_{4}{ }^{-}$is quite stable to reduction under the alkaline conditions present in the tank wastes; under acidic conditions, the reduction potential of the $\mathrm{TcO}_{4}-/ \mathrm{TcO}_{2}$ couple is $0.738 \mathrm{~V}$ (vs. SHE) and pertechnetate can be reduced quite easily). ${ }^{7}$ The four oxo groups are arranged tetrahedrally, and the energy of hydration is fairly low compared to other monoanions $\left(\Delta G_{\text {hydr }}=-251 \mathrm{~kJ} / \mathrm{mol}\right)_{.}{ }^{10}$ The lower hydration energy in part explains why pertechnetate transfers more readily into an organic solvent than many other monoanions, such as nitrate $\left(\Delta G_{\text {hydr }}\right.$ $=-289 \mathrm{~kJ} / \mathrm{mol}) .10$

\subsection{SOLVENT EXTRACTION OF PERTECHNETATE}

Previous Results. Solvent extraction has been employed as a method for the removal of pertechnetate from both acidic and alkaline solutions. ${ }^{11,12}$ Some reagents that have been employed in the extraction of pertechnetate from alkaline media include cyclohexanone, ${ }^{13}$ pyridines, ${ }^{14}$ lipophilic anion exchangers (such as tetraphenylarsonium chloride, 15 triphenyltetrazolium chloride, ${ }^{16}$ and tetraalkylammonium iodides ${ }^{17}$ ), polyethylene and polypropylene glycols, ${ }^{6}$ and 
crown ethers. ${ }^{18,19}$ Whereas adequate extraction of pertechnetate from alkaline media was demonstrated by each method, in every case the method described possessed some characteristic which would make it undesirable for a large-scale process. These characteristics included the use of hazardous chemicals as defined by the Resource Conservation and Recovery Act (RCRA) or difficulty in the regeneration of the extractant.

Approach. The research described here contains the results of our research efforts aimed at developing an efficient solvent-extraction process that seeks to avoid many of the problems of the previous methods. The process utilizes crown ethers for the direct extraction of pertechnetate from high-nitrate-containing alkaline nuclear-waste media. The tank wastes at the Hanford site and other locations (e.g., Oak Ridge) are typically both highly alkaline and highly concentrated in various salts (such as sodium nitrate) and thus pose special problems for current extraction technology. We investigated crown ethers as potential solvent-extraction reagents for $\mathrm{Tc}$ removal because we believed the high-salt condition would actually promote Tc extraction and because we believed an inexpensive water wash would effect stripping of the Tc from the solvent. The conceptual process is depicted in Fig. 1.1. The mechanism of extraction and stripping can most easily be described by a reversible equilibrium involving complexation of an alkali metal ion by a crown ether. The high alkali metal concentration in the aqueous phase during the extraction portion of the cycle drives the equilibrium toward formation of the crown ether-alkali metal complex. It is important to note that this is different from the usual "salting out" enhancement of extraction by increasing the activity of the entity to be extracted, with little or no effect on the extractant; aside from the possible presence of salting effects, here the enhancement results primarily from the conversion of the neutral crown ether to the effective cationic crown ether-alkali metal complex. An anion is necessary to conserve charge neutrality, and in this way the pertechnetate anion is also extracted:

$$
\mathrm{Na}^{+}+\mathrm{TcO}_{4}^{-}+\overline{\mathrm{CE}} \rightleftharpoons(\overline{\mathrm{CE}}) \mathrm{NaTcO}_{4}
$$

Here, $\mathrm{CE}$ is the crown ether, and the overbar designates organic-phase species. Stripping is accomplished by simply reversing this equilibrium. The organic solvent containing the crown ether-alkali metal-pertechnetate complex is contacted with deionized water, promoting dissociation of the complex to free alkali metal pertechnetate in the aqueous phase and free crown ether in the organic phase:

$$
\left(\overline{\mathrm{CE}) \mathrm{NaTcO}_{4}} \rightleftharpoons \mathrm{Na}^{+}+\mathrm{TcO}_{4}^{-}+\overline{\mathrm{CE}}\right.
$$




\section{EXTRACTION}

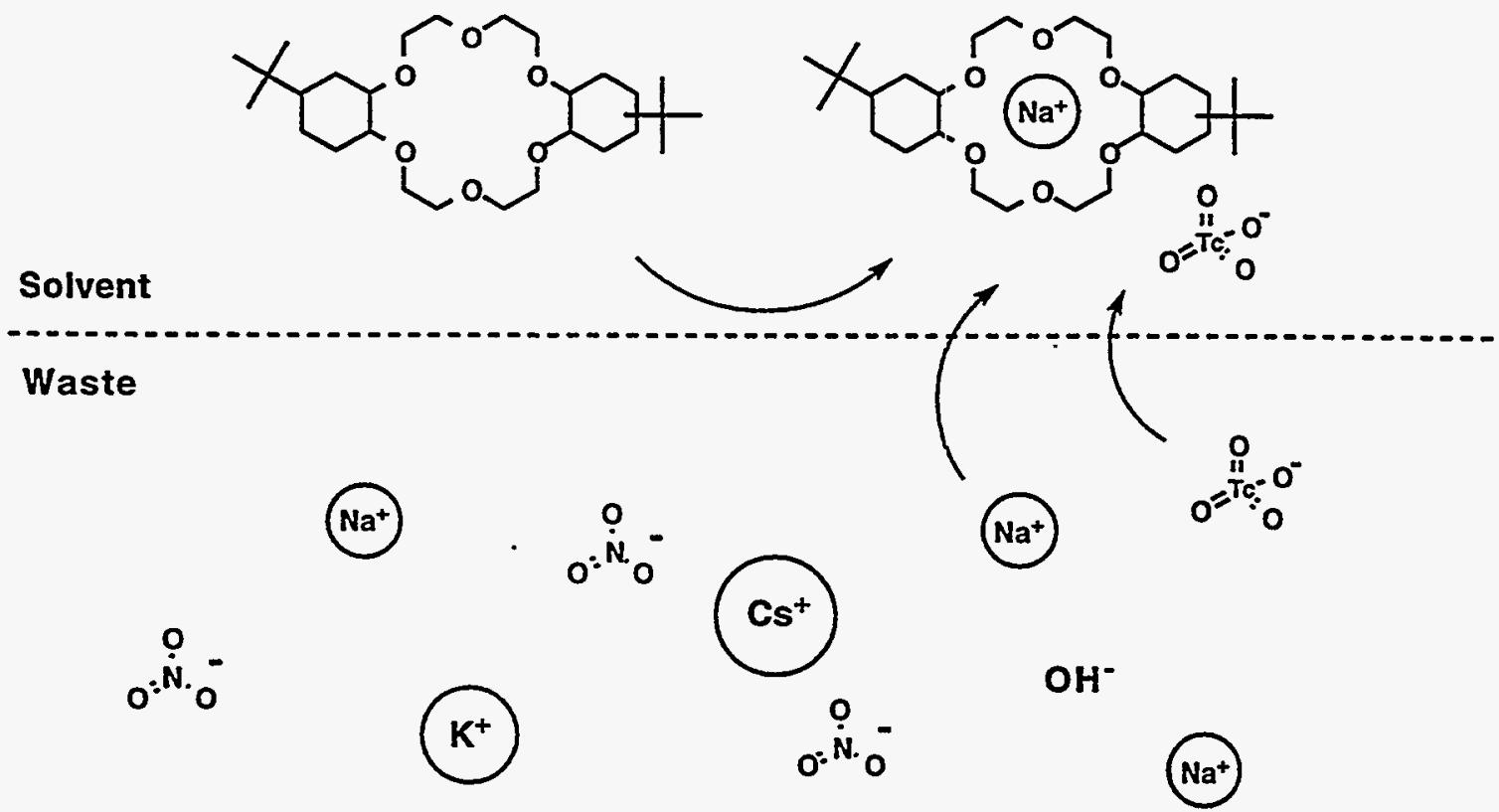

STRIPPING



Fig. 1.1. Simplified hypothetical mechanism of extraction of pertechnetate by a crown ether from a waste stream containing alkali metal ions; stripping may be effected by back-extraction with water. 
As will be discussed in this report, the extracted cation need not be $\mathrm{Na}^{+}$but can also advantageously include other cations (such as potassium and strontium) from the waste. It should be noted that Eqs. (1) and (2) represent at present only a postulated model. Detailed equilibrium studies are being conducted to test this model as well as to reveal other equilibria that may occur, especially the competing extraction of sodium nitrate.

There is some precedent for the use of crown ethers to extract technetium. The "SREX" (Strontium Extraction) process, developed by Horwitz and co-workers at Argonne National Laboratory, ${ }^{20}$ employs crown ethers to specifically extract strontium from nitric acid media; the process also co-extracts small amounts of pertechnetate. Jalhoom ${ }^{18}$ and Korpusov ${ }^{19}$ both described the use of crown ethers for extraction of pertechnetate from basic solutions, and our work largely builds on their results. Specifically, we have developed good alternatives to halogenated diluents and have demonstrated a complete solvent cycle incorporating stripping with water. We have also tailored the chemistry for efficient waste processing and have characterized process-related aspects, such as the competing effect of sodium and potassium nitrate extraction. A patent ${ }^{21}$ has been issued covering this process.

The initial stage of this project was conducted in FY 1993, and as reported in the year-end letter report, ${ }^{22}$ sufficiently high distribution and stripping coefficients using selected crown ethers were obtained under laboratory conditions to warrant proceeding to more stringent tests in FY 1994. Work completed in FY 1994 focused on developing, testing, optimizing, and defining a solvent-extraction cycle for technetium using realistic waste simulants. ${ }^{23}$ The research concentrated on the more process-oriented and environmental-, safety,- and health-oriented concerns of the solvent-extraction cycle. Crown ether/diluent/modifier systems were evaluated with regard to pertechnetate extraction and stripping performance, leading to a group of candidate systems. The best commercially available crown ether bis-4,4'(5')[(tert-butyl)cyclohexano]-18crown- 6 was identified, the range of diluents and modifiers were reduced to a select few, and information regarding the thermodynamics, concentration dependence, and kinetics of the extraction was obtained. In FY 1995, we narrowed the field of process-suitable solvents to a select few; we conducted extensive tests on both the extraction and stripping cycles using a realistic simulant for Melton Valley Storage Tank (MVST) W-29 supernate; we tested authentic MVST W29 supernate; and we outlined a new "tandem" process cycle for Tc removal and concentration from tank waste. ${ }^{24}$ The work performed in FYs 1993, 1994, and 1995, respectively, is described in Sects. 2,3, and 4 of this report.

Benefits. The Tanks Focus Area (TFA) program and the Tank Waste Remediation System (TWRS) program would receive the primary benefit from this program. The process described offers several key advantages that make it competitive with other techniques. The advantages include: (1) direct treatability-no adjustment of the waste composition is needed, (2) economical 
stripping with water, (3) high efficiency-few stages needed, (4) non-RCRA chemicals-no generation of hazardous or mixed wastes, (5) co-extraction of ${ }^{90} \mathrm{Sr}$, and (6) optional concentration on a resin. A key concept advanced in this work entails coupling a second separation technique for Tc (resin anion exchange) together with the solvent extraction separation step in a "tandem" fashion: solvent extraction offers high selectivity, while a subsequent column sorption process on the aqueous stripping solution serves to greatly concentrate the Tc. Alternatively, simple evaporation may be used to concentrate the stripping solution.

\subsection{REFERENCES AND NOTES}

1. Bunker, B., Virden, J., Kuhn, B., Quinn, R. "Nuclear Materials, Radioactive Tank Wastes," Encyclopedia of Energy Technology and the Environment, John Wiley \& Sons, Inc., New York, pp. 2023-2032 (1995).

2. "Integrated Data Base Report-1993: U.S. Spent Nuclear Fuel and Radioactive Waste Inventories, Projections, and Characteristics," DOE/RW-0006, Rev. 10, December 1994, pp.47-90.

3. (a) There is evidence that some technetium may exist in complexed form in lower oxidation states in certain tanks containing complexants. Dr. Norman C. Schroeder, Los Alamos National Laboratory, private communication. (b) The likely preference of technetium for the +7 oxidation state under conditions of interest, however, should not be assumed without caution until actual determinations have been made. For present purposes, we will base our approach on such an assumption, keeping in mind the need for additional information on the oxidation state and chemical form of technetium in the waste solutions.

4. Calculated from the Tc-99 Curie content in the liquid and slurry phases of HLW at Hanford as of Dec 31, 1993. Data taken from Table 2.16, page 82, in "Integrated Data Base Report-1993: U.S. Spent Nuclear Fuel and Radioactive Waste Inventories, Projections, and Characteristics," DOE/RW-0006, Rev. 10, December 1994.

5. Schroeder, N.C., Radzinski, S., Ashley, K.R., Ball, J., Stanmore, F., Whitener, G. "Technetium Partitioning for the Hanford Tank Waste Remediation System: Sorption of Technetium from DSS and DSSF-7 Waste Simulants Using Reillex ${ }^{\mathrm{TM}}$-HPQ Resin," Los Alamos National Laboratory Report LA-UR95-40 (1995).

6 (a) Chaiko, D.J., Vojta, Y., Takeuchi, M. Sep. Sci. Technol. 1995, 30, 1123-1137. (b) Chaiko, D.J., Mertz, C.J., Vojta, Y., Henriksen, J.L., Neff, R., Takeuchi, M. "Extraction of Long-lived Radionuclides from Caustic Hanford Tank Waste Supernatants," Argonne National Laboratory Report ANL-95/39 (1995).

7. Colton, R., The Chemistry of Rhenium and Technetium, John Wiley: London, 1965.

8. Peacock, R.D., The Chemistry of Technetium and Rhenium, Elsevier Publishing Company:Amsterdam, 1966.

9. Baldas, J. Adv. Inorg. Chem. 1994, 41, 1-123 
10. Shmidt, V.S.; Rybakov, K.A., Rubisov, V.N. Russ. J. Inorg. Chem., 1982, 27, 855-857.

11. Möbius, S. In Gmelin Handbook of Inorganic Chemistry, Tc Supplement Vol.2; SpringerVerlag: New York, 1983.

12. Pruett, D.J. "The Solvent Extraction of Hepatvalent Technetium and Rhenium by Tributyl Phosphate," Oak Ridge National Laboratory Technical Report ORNL/TM-8668 (1984).

13. Schulz, W. W. In Proceedings of the International Solvent Extraction Conference (ISEC'80); Liege, Belgium, 1980; paper \#108.

14. Zaitsev, A. A.; Lebedev, I. A.; Pirozhkov, S. V.; Yakovlev, G. N. Sov. Radiochem. $1964,6,428-431$.

15. Tribalat, S.; Beydon, J. Anal. Chim. Acta 1953, 8, 22-28.

16. Karalova, Z. K.; Lavrinovich, E. A.; Myasoedov, B. F. Sov. Radiochem. 1991, 33, 268-269.

17. Shanker, R.; Venkateswarlu, K. S.; Shanker, J. J. Less-Common Metals 1968, 15, 311-316.

18. Jalhoom, M. G. J. Radioanal. Nucl. Chem. 1986, 104, 131-139.

19. Korpusov, G. V.; Krylov, Y. S.; Tsalon, S. I. Sov. Radiochem. 1984, 26, 390-392.

20. Horwitz, E.P.; Dietz, M.L. "Process for the Extraction of Strontium from Acidic Solutions," U.S. Patent 5,344,623, Sept 6, 1994.

21. Moyer, B.A.; Sachleben, R.A.; Bonnesen, P.V. "Process for Extracting Technetium from Alkaline Solutions," U.S. Patent 5,443, 731, August 22, 1995.

22. Bonnesen, P.V.; Moyer, B.A.; Sachleben, R.A. "Alkaline-Side Extraction of Technetium from Tank Waste Using Crown Ethers and Other Extractants. FY 1993 Letter Report." September 28, 1993. Letter report to meet milestones set forth in TTP No. OR-1320-19 in support of the Efficient Separations and Processes Integrated Program, Office of Technology Development, Office of Environmental Management, US DOE.

23. Armstrong, V.S.; Bonnesen, P.V.; Haverlock, T.J.; Moyer, B.A.; Presley, D.J.; Sachleben, R.A. "Alkaline-Side Extraction of Technetium from Tank Waste Using Crown Ethers and Other Extractants. FY 1994 Letter Report." September 28, 1994. Letter report to meet milestones set forth in TTP No. OR-1320-19 in support of the Efficient Separations and Processes Integrated Program, Office of Technology Development, Office of Environmental Management, US DOE.

24. Bonnesen, P.V.; Presley, D.J.; Counce, R.M.; Moyer, B.A. "Alkaline-Side Extraction of Technetium from Tank Waste Using Crown Ethers and Other Extractants." FY 1995 Letter Report." September 28, 1995. Letter report to meet milestones set forth in TTP No. OR1320-12C in support of the Efficient Separations Cross-Cutting Program, Office of Technology Development, Office of Environmental Management, US DOE. 


\section{EVALUATION OF EXTRACTANTS}

\subsection{INTRODUCTION}

In the first year of the project (FY 1993), our main objective was to determine the feasibility of using crown ethers to extract technetium from aqueous solutions that possessed the high sodium nitrate and hydroxide concentrations that are characteristic of alkaline nuclear tank wastes. We also wished to ascertain whether the technetium extracted could be stripped out of the organic solvent using only water. In the tests reported herein, we surveyed a wide variety of variables while limiting the aqueous composition to simple solutions of the nitrate, hydroxide, and pertechnetate salts of sodium. The effects of such variables as diluent composition and electrolyte concentration were surveyed together with a variety of crown ethers, the crown ethers being selected on the basis of their ring size, availability, and properties (such as lipophilicity) of the ring appendages. Several quaternary ammonium extractants (quats) were also tested for comparison. At the close of FY 1993, it was our intention to determine whether sufficiently high distribution and stripping coefficients using selected crown ethers could be obtained under laboratory conditions to warrant proceeding to more stringent tests in FY 1994.

\subsection{EXPERIMENTAL}

\subsubsection{Materials and Instrumentation}

Reagents. All salts and solvents were reagent grade and were used as received. Deionized water was obtained from a Barnstead Nanopure filtering system (resistivity $18 \mathrm{M} \Omega$ ).

Commercially Available Crown Ethers. The crown ethers cyclohexano-15-crown-5, 4-tertbutylbenzo-15-crown-5, 4-tert-butylcyclohexano-15-crown-5, 4-tert-butylbenzo-18-crown-6, 4tert-butylcyclohexano-18-crown-6, dicyclohexano-18-crown-6 ( 1:1 ratio of cis-syn-cis and cisanti-cis isomers), and dicyclohexano-21-crown-7 were used as received from Parish Chemical. The crown ether bis-4,4'(5')[(tert-butyl)cyclohexano]-18-crown-6 (Lot 3IBD) was also used as received from Parish Chemical without further purification. This particular crown ether has a great many isomers, and the isomer ratio can vary significantly from lot to lot. Accordingly, the binding constants for sodium and potassium can vary significantly depending upon the orientation of the cavity of the particular crown isomer, and hence the performance in solvent extraction will also vary with the isomer distribution (see Horwitz ${ }^{1}$ for a more detailed discussion of this point). This particular lot was a liquid at room temperature, and as it turned out contained low concentrations of the "more effective" isomers. We have observed that lots that are semi-solids at room temperature tend to perform better, presumably due to the higher content of the preferred cis-syn isomers, which tend to be low-melting solids. Thus, it is important to use the same lot, or lots of equivalent 
performance, when making comparisons. (We subsequently obtained material of considerably better quality, which was employed in the work described in Sects. 3 and 4).

\section{Synthetic Crown Ethers}

The crown ethers cis-syn-cis-dicyclohexano-14-crown-4 and cis-sym-bis-(t-octylbenzo)14-crown-4-diol are not commercially available and were prepared in these laboratories.

Cis-syn-cis-dicyclohexano-14-crown-4 was prepared by Gregg Lumetta following the literature procedure. ${ }^{2}$ The final recrystallization was from methanol.

Cis-sym-bis-(t-octylbenzo)-14-crown-4-diol was prepared by Frederick V. Sloop as described below. Catechol $(0.10 \mathrm{~mol})$ was stirred under argon at $40^{\circ} \mathrm{C}$ for 48 hours with $0.4 \mathrm{~mol}$ epichlorohydrin and $0.4 \mathrm{~mL} 10 \mathrm{M} \mathrm{NaOH}$. The reaction was cooled to room temperature, and 42 $\mathrm{mL}$ of $5 \mathrm{M} \mathrm{NaOH}$ saturated with $\mathrm{Na}_{2} \mathrm{CO}_{3}$ was added. Stirring was continued vigorously for 20 hours, following which the reaction mixture was extracted twice with chloroform. The organic layers were combined, washed with $50 \mathrm{~mL}$ water, and the solvent volume reduced by rotary evaporation. The product 1'- (o-phenylenedioxy) bis-(2,3-epoxypropane) was fractionally distilled at $118-120^{\circ} \mathrm{C}$ at $0.01 \mathrm{~mm} \mathrm{Hg}$ pressure. (Yield: 13.5 grams, $60.7 \mathrm{mmol}, 61 \%$, of colorless material). A portion of this material $(60 \mathrm{mmol})$ was combined with catechol $(84 \mathrm{mmol}$, 1.4 equiv) and $\mathrm{LiOH}(84 \mathrm{mmol})$ in $450 \mathrm{~mL}$ t-butyl alcohol. The mixture was stirred at reflux, under argon, for 19 hours, after which a second $84 \mathrm{mmol}$ of $\mathrm{LiOH}$ was added. The reaction was refluxed under argon for an additional 60 hours, after which the solvent was removed in vacuo, and the residue dissolved in $500 \mathrm{~mL}$ chloroform. The chloroform solution was washed thrice with $200 \mathrm{~mL}$ portions of water. The aqueous washes were combined and back-extracted with chloroform, and the back-extractions combined with the first chloroform solution. The pooled organic layers were dried over $\mathrm{MgSO}_{4}$, filtered, and the solvent removed under vacuum, to give the mixed cis and trans isomers of dibenzo-14-crown-4-diol (DB-14C4-diol, 17.2 grams, 52 $\mathrm{mmol}$ ). The isomers were separated by florasil column chromatography: the mixed isomer DB14C4-diol (11.3 grams) was loaded on a flash column containing 300 grams of florasil over 10 grams silica, wet-packed in $\mathrm{MeOH}$. The trans isomer eluted with $\mathrm{MeOH}$, then the column was stripped using 7:3 MeOH/water containing $1 \% \mathrm{LiClO}_{4}$ to yield the cis isomer. The fractions containing the cis isomer were combined, filtered, and the solvent removed in vacuo. The cis isomer was crystallized from 7:3 $\mathrm{MeOH} /$ water at $0^{\circ} \mathrm{C}$ to give 2.6 grams $(8 \mathrm{mmol})$ of product. The proton and carbon NMR were consistent with the putative product, and an X-ray structure of the $\mathrm{NaClO}_{4}$ salt of the product confirmed the cis-isomer form. The tert-octyl groups were attached by Friedel-Crafts alkylation. Cis-DB-14C4-diol $(500 \mathrm{mg}, 1.5 \mathrm{mmol})$ was reacted with $1.0 \mathrm{~mL}$ (4.2 equiv.) of 2,4,4-trimethyl-1-pentene ( $\mathrm{fw}=112.22, \mathrm{~d}=0.708$ ) in $5 \mathrm{~mL} 55 \mathrm{mM}$ trifluoromethanesulfonic (triflic) acid in trifluoroacetic acid (TFA), for 1 hour with agitation. The solvent was removed, and the residue taken up in $30 \mathrm{~mL}$ ethyl ether. The ether solution was 
washed with water, saturated sodium bicarbonate, then water again to remove residual triflic acid, TFA and $\mathrm{LiClO}_{4}$. The ether layer was dried over $\mathrm{MgSO}_{4}$. Decolorizing carbon was added to the solution, which was then suction filtered. An amber wax $(532 \mathrm{mg})$ was recrystallized from petroleum ether, and thin-layer chromatography (70:30 ethyl acetate/hexanes) of the product revealed a considerable amount of a polar contaminant. A diagnostic acetylation reaction was performed to test for the presence of $-\mathrm{OH}$ groups. A small sample of the putative crown was reacted with pyridine and acetic anhydride. Thin-layer chromatography revealed the presence of acetylated product, indicating that alcohols were available to react. Carbon-13 $\mathrm{NMR}$ in $\mathrm{CDCl}_{3}$ was not determinative. The $\mathrm{CDCl}_{3}$ was evaporated, and the putative product dissolved in warm hexanes, and loaded onto 5 grams silica gel for filtration. The column was washed with $20 \mathrm{~mL}$ hexanes, and the product eluted with ethyl acetate. Thin-layer chromatography revealed removal of most of the polar contaminant. The bulk sample was then dissolved in warmed hexanes, and filtered through a silica gel column as per above. Removal of the solvent gave $295 \mathrm{mg}$ of purer product, as confirmed by proton and carbon-13 NMR.

Technetium. Technetium-99 (NIST traceable ammonium pertechnetate in water) was obtained from Isotope Products Laboratories, Burbank, CA. The solution received contained $1.023 \mathrm{mCi} \mathrm{NH}_{4}{ }^{99} \mathrm{TcO}_{4}$ in $5 \mathrm{~mL}$ of water (solution mass $5.0196 \mathrm{~g}$ ) in a flame-sealed ampoule. A $3.006 \times 10^{-3} \mathrm{M}^{99} \mathrm{TcO}_{4}\left(1.120 \times 10^{7} \mathrm{DPM} / \mathrm{ml}\right)$ working stock solution was prepared by transferring $4.9506 \mathrm{~g}$ of the solution in the ampoule to a $200.0 \mathrm{~mL}$ volumetric flask, and diluting to the mark with deionized water. Technetium- 99 was then added to the waste simulants by spiking the simulant with the appropriate amount of this working stock solution to give the desired concentration.

Instrumentation. Beta-liquid scintillation counting of ${ }^{99} \mathrm{Tc}$ in either Packard Ultima Gold ${ }^{\mathrm{TM}}$ or Packard Ultima Gold ${ }^{\mathrm{TM}}$ XR scintillation cocktails was performed using a Packard Tricarb ${ }^{\circledR}$ Model 4530 counter. Generally, $0.50 \mathrm{~mL}$ samples were added to $17.5 \mathrm{~mL}$ Ultima Gold ${ }^{\mathrm{TM}}$ cocktail (using plastic $20 \mathrm{~mL}$ scintillation vials) or $5.0 \mathrm{~mL}$ of Packard Ultima Gold ${ }^{\mathrm{TM}} \mathrm{XR}$ (extended range) cocktail (using plastic $5.5 \mathrm{~mL}$ "Pico-Hanging" vials obtained from Packard). Quench curves were constructed for each cocktail for the 5 to $292 \mathrm{keV}$ window (Emax for Tc-99 is $292 \mathrm{keV}$ ): unquenched samples had efficiences of $99.1 \%$ for Packard Ultima Gold ${ }^{\mathrm{TM}}$ and $96.3 \%$ for Packard Ultima Gold ${ }^{\mathrm{TM}} \mathrm{XR}$. Count times were 15 minutes. Centrifugations were performed using a Beckman TJ- 6 centrifuge equipped with a TH-4 hanging bucket rotor, typically for 5 minutes at 2700 RPM. 


\subsubsection{Quaternary Ammonium Nitrates}

Aliquat ${ }^{\circledR} 336$ nitrate. Aliquat ${ }^{\circledR} 336$ nitrate (tricapryl methyl quaternary ammonium nitrate) was prepared from the chloride (obtained from Henkel Corp.) following a procedure carried out by Diadra M. Bau, 3 which involved removal of the 1-2\% tricapryl amine impurity, followed by metathesis with sodium nitrate. The material is an amber, viscous oil at room temperature. Solutions of Aliquat ${ }^{\circledR} 336$ nitrate in toluene and 1-octanol $(0.10 \mathrm{M})$ were prepared by Diadra $\mathrm{M}$. Bau and were used as received or diluted to $0.025 \mathrm{M}$.

Arquad ${ }^{\circledR} 316$ nitrate. Arquad ${ }^{\circledR} 316$ chloride (tri-hexadecyl methyl quaternary ammonium chloride) was received at $90 \%$ purity as a complimentary research sample from Akzo Chemicals, Chicago, IL. This material is a white waxy solid at room temperature $\left(\mathrm{mp} 46^{\circ} \mathrm{C}\right)$, and the impurities (as given by the MSDS) are water, some alcohol, tri-hexadecyl amine $(<2 \%)$, and $\sim 2 \%$ di-hexadecyl dimethyl quaternary ammonium chloride. A $10.87 \mathrm{~g}$ sample was placed in a $300 \mathrm{~mL}$ round-bottom flask, and the volatiles removed by rotary evaporation for 30 minutes at $50-60{ }^{\circ} \mathrm{C}$; this resulted in a mass loss of $0.35 \mathrm{~g}(\sim 3 \%)$. Ortho-xylene $(100 \mathrm{~mL})$ was added to the residue in the flask, giving a solution with approximate concentration of $0.142 \mathrm{M}$ (based on a $\mathrm{MW}$ of 740.80 $\mathrm{g} / \mathrm{mol}$ ). This solution was then contacted successively with five $75 \mathrm{~mL}$ portions of $1.5 \mathrm{M}$ sodium nitrate solution in a separatory funnel to convert the quat from the chloride to nitrate form. After each contact, $2 \mathrm{~mL}$ of the aqueous phase was tested for chloride content using silver nitrate: following the fourth contact there was only a trace of silver chloride, and after the fifth contact there was no trace of silver chloride. The organic solution was then centrifuged, and the clear top organic layer was transferred to a glass bottle. The concentration of this stock solution was determined by removing the solvent from a $2.00 \mathrm{~mL}$ aliquot by oil-pump vacuum to give $0.1521 \mathrm{~g}$ of Arquad ${ }^{\circledR} 316$ nitrate, $\mathrm{MW}=767.36 \mathrm{~g} / \mathrm{mol}(0.099 \mathrm{M})$. Solutions of concentrations $0.025 \mathrm{M}$ and $0.10 \mathrm{M}$ in o-xylene were prepared by appropriate dilution of the concentrated stock solution.

Carsoquat SDQ-85 nitrate. Carsoquat SDQ-85 (stearyl dimethyl benzyl quaternary ammonium chloride, CAS No. 122-19-0) was received at $~ 90 \%$ purity as a complimentary research sample from Lonza, Fair Lawn, NJ. This material is a white solid at room temperature (mp $57^{\circ} \mathrm{C}$ ), and the main impurity (as given by the MSDS) is ethanol at $\sim 10 \%$. A $14.17 \mathrm{~g}$ sample was placed in a $300 \mathrm{~mL}$ round-bottom flask, and the volatiles removed by rotary evaporation for 30 minutes at $60-70^{\circ} \mathrm{C}$; this resulted in a mass loss of $0.76 \mathrm{~g}(\sim 5 \%)$. Ortho-xylene $(100 \mathrm{~mL})$ was added to the residue in the flask, but the material was not completely soluble. Adding more (20 $\mathrm{mL}$ ) o-xylene was necessary to dissolve the material. The approximate concentration of the 120 $\mathrm{mL}$ solution is $0.263 \mathrm{M}$ (based on a MW of $424.15 \mathrm{~g} / \mathrm{mol}$ ). This solution was then treated with $1.5 \mathrm{M}$ sodium nitrate in the same manner as above for Arquad ${ }^{\circledR} 316$. However, this material readily formed emuisions, requiring centrifugation after each sodium nitrate treatment and addition of more o-xylene $(\sim 10 \mathrm{~mL})$ to maintain clarity and solubility. No silver chloride was detected in 
the aqueous phase following the fifth contact with sodium nitrate. Following centrifugation, the straw-colored organic solution was transferred to a glass bottle. The concentration of an aliquot of this stock solution was determined as described above to be $0.236 \mathrm{M}$ for Carsoquat SDQ-85 nitrate, $\mathrm{MW}=450.70 \mathrm{~g} / \mathrm{mol}$. Solutions of concentrations $0.025 \mathrm{M}$ and $0.10 \mathrm{M}$ in o-xylene were prepared by appropriate dilution of the concentrated stock solution.

Tetraheptyl ammonium nitrate. Tetraheptyl ammonium bromide (reagent grade from Eastman Chemical, $\mathrm{mp} 87-89^{\circ} \mathrm{C}, \sim 6$ grams) was dissolved in $50 \mathrm{~mL}$ o-xylene, to give an approximate concentration of $0.245 \mathrm{M}$. The solution was contacted as prescribed above with five $50 \mathrm{~mL}$ portions of $1.5 \mathrm{M}$ aqueous sodium nitrate; the aqueous fraction following the last contact tested negative for precipitation of silver bromide. Following centrifugation, the concentration of the stock solution was found to be $0.235 \mathrm{M}$ for tetraheptyl ammonium nitrate ( $\mathrm{MW}=472.27$ $\mathrm{g} / \mathrm{mol}$ ). Solutions of concentrations $0.025 \mathrm{M}$ and $0.10 \mathrm{M}$ in o-xylene were prepared by appropriate dilution of the concentrated stock solution.

\subsubsection{Contacting Procedures}

All liquid-liquid contacts were performed in glass borosilicate vials using black phenolic screw caps with polyethylene inserts. Equal volumes of aqueous and organic phase (generally $1.00 \mathrm{~mL}$ of each) were contacted for 1 hour (to ensure achievement of equilibrium) at $25 \pm 1^{\circ} \mathrm{C}$ by end-over-end rotation at $35 \pm 5 \mathrm{RPM}$ using a Glass-Col ${ }^{\circledR}$ laboratory rotator in a temperaturecontrolled airbox. After allowing the phases to coalesce (either on their own or assisted by centrifugation as necessary), the aqueous and organic phases were subsampled and the ${ }^{99} \mathrm{Tc}$ activity in each phase determined. The distribution ratio $\mathrm{D}_{\mathrm{Tc}}$ was calculated as the ratio $[\mathrm{Tc}]_{\text {org }} /[\mathrm{Tc}]_{\text {aq }}$ after equilibrium. In the stripping tests, an aliquot of the organic phase was contacted with an equal volume of deionized water, and the activity in the phases was determined in the manner described above. Generally, all sample contacts were performed in duplicate.

\subsection{RESULTS AND DISCUSSION}

\subsubsection{Initial Screening of Crown Ethers}

Ten crown ethers $(0.025 \mathrm{M}$ in 1-octanol) were evaluated with regard to efficacy of pertechnetate $\left(1.5 \times 10^{-5} \mathrm{M}\right)$ extraction from alkaline $(0.1 \mathrm{M} \mathrm{NaOH})$ media containing sodium nitrate at concentrations of $0.0 \mathrm{M}, 0.1 \mathrm{M}$, or $5.0 \mathrm{M}$, the latter being represenative of $\mathrm{NaNO}_{3}$ concentrations in tank-waste supernate. The ten crown ethers range from 14-crown-4 to 21crown-7 in ring size and are shown in Figs. 2.1 and 2.2. The results are shown graphically in Fig. 2.3 as a plot of the log of the distribution ratio (relative to 1-octanol) obtained for each crown 
<smiles>CC(C)(C)CC(C)(C)c1ccc(OC[C@H](O)COc2ccccc2OC[C@H](O)CO)c(C(C)(C)CC(C)(C)C)c1</smiles>

cis-sym-bis-(tert-octylbenzo)-14-crown-4-diol (BOB-14C4-diol)

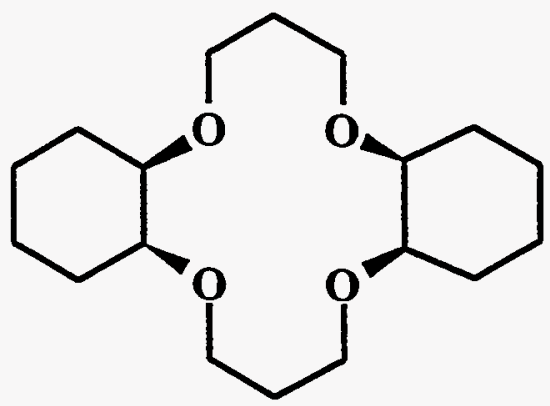

cis-syn-cis-dicyclohexano-14-crown-4 (csc-DCH14C4)<smiles>CC(C)(C)c1ccc2c(c1)OCCOCCOCCOCCO2</smiles>

4-tert-butylbenzo-15-crown-5

(4-t-BuB15C5)

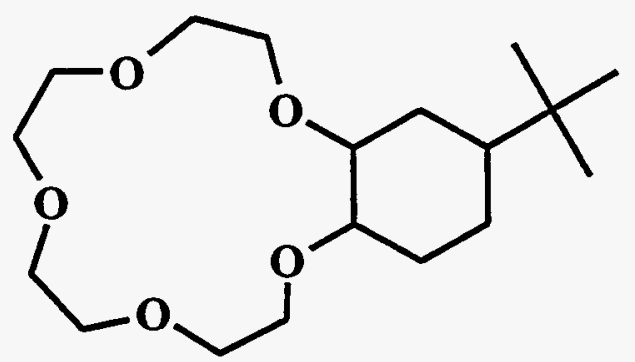

4-tert-butylcyclohexano-15-crown-5 (4-t-BuCH15C5)



cyclohexano-15-crown-5 (CH15C5)

Fig. 2.1. 14-crown-4 and 15-crown-5 ethers examined in this study. 
<smiles>CC(C)(C)C1CCC2OCCOCCOCCOCCOCCOC2C1</smiles>

4-tert-butylcyclohexano-18-crown-6 (4-t-BuCH18C6)<smiles>C1CCC2OCCOCCOC3CCCCC3OCCOCCOC2C1</smiles>

cis-dicyclohexano-18-crown-6 (DCH18C6)<smiles>CC(C)(C)c1ccc2c(c1)OCCOCCOCCOCCOCCO2</smiles>

4-tert-butylbenzo-18-crown-6 (4-t-BuB18C6)<smiles>CC(C)(C)C1CCC2OCCOCCOC3CCC(C(C)(C)C)CC3OCCOCCOC2C1</smiles>

bis-4,4'(5')[(tert-butyl)cyclohexano]-18-crown-6 (di-t-BuCH18C6)

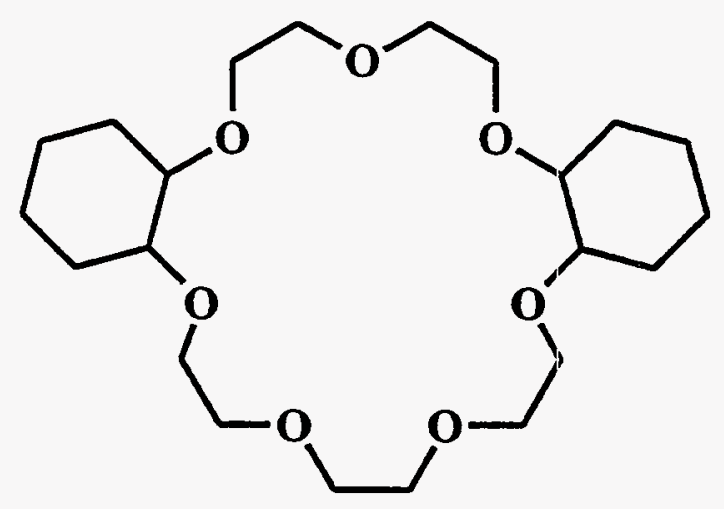

dicyclohexano-21-crown-7

(DCH21C7)

Fig. 2.2. 18-crown-6 and 21-crown-7 ethers examined in this study. 


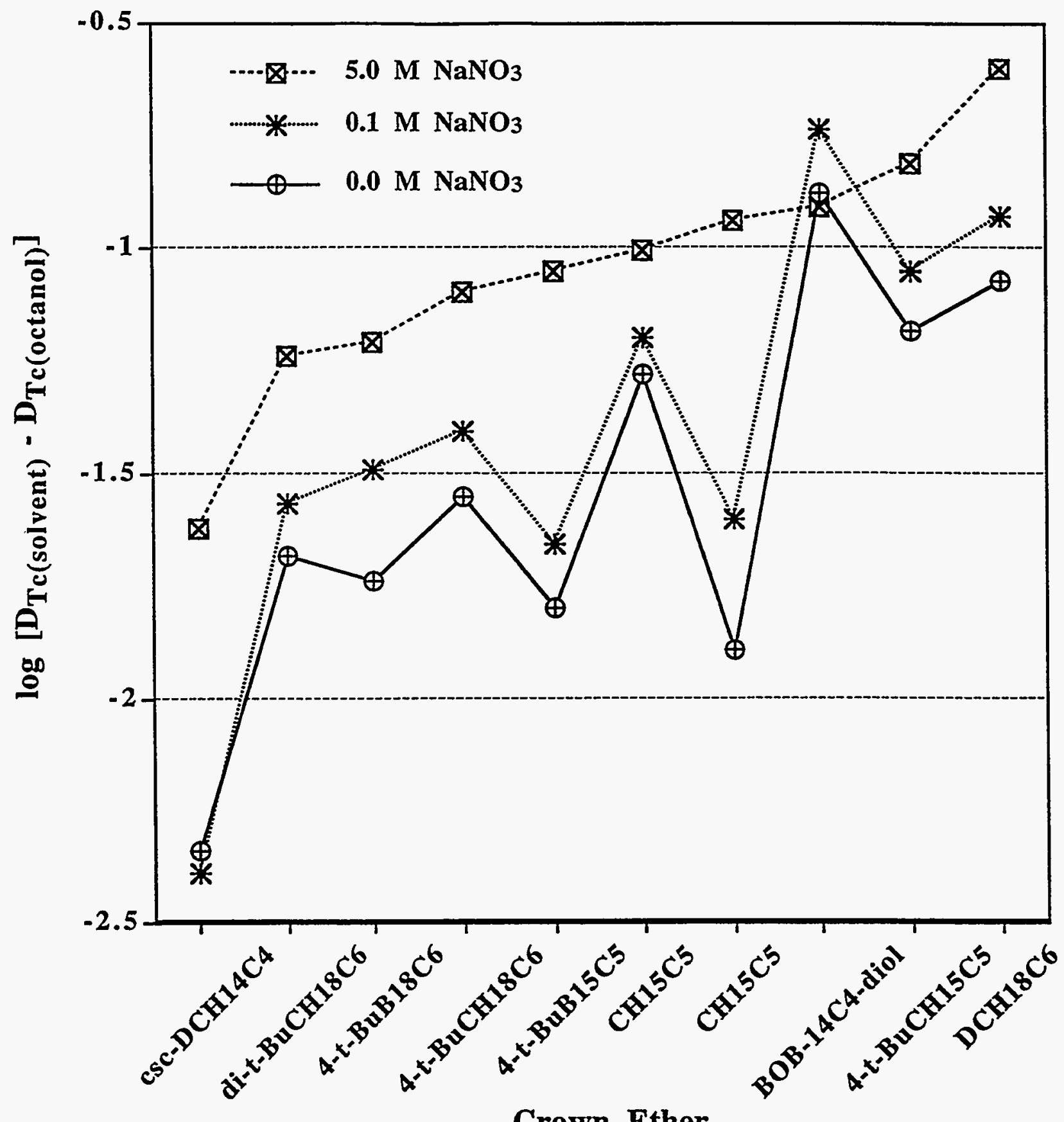

\section{Crown Ether}

Fig. 2.3. Extraction of pertechnetate by selected crown ethers in 1-octanol $(0.025 \mathrm{M})$ at $25^{\circ} \mathrm{C}$. Aqueous phase: $[\mathrm{NaOH}]=0.10 \mathrm{M},[\mathrm{Tc}]=$ $1.5 \times 10^{-5} \mathrm{M},\left[\mathrm{NaNO}_{3}\right]$ as noted. The crown ethers are ordered along the $\mathrm{x}$-axis according to increasing distribution coefficient (relative to 1-octanol) at $5.0 \mathrm{M}$ $\mathrm{NaNO}_{3}$. 
ether (ordered according to increasing distribution coefficient at 5.0 $\mathrm{M} \mathrm{NaNO}_{3}$ ), at the three different aqueous sodium nitrate concentrations. (The technetium distribution ratios afforded by 1octanol alone were $5.81 \times 10^{-3}, 6.12 \times 10^{-3}$, and $9.76 \times 10^{-3}$ respectively for the $0.0 \mathrm{M}, 0.1 \mathrm{M}$, and 5.0 M sodium nitrate concentrations.) Dicyclohexano-18-crown-6 (DCH18C6, a 1:1 mixture of the cis-syn-cis and cis-anti-cis isomers by proton NMR) was the strongest crown with regard to extraction of pertechnetate from $5.0 \mathrm{M} \mathrm{NaNO}_{3}$ solution, whereas the crown cis-sym-bis-( $t$ octylbenzo)-14-crown-4-diol (BOB-14C4-diol) was the strongest pertechnetate extractant from 0.0 $\mathrm{M}$ and $0.1 \mathrm{M} \mathrm{NaNO}_{3}$ solutions. The sensitivity of $\log \mathrm{D}$ to $\mathrm{NaNO}_{3}$ concentration varied considerably from one crown to another; $\mathrm{BOB}-14 \mathrm{C} 4$-diol was the least sensitive, and dicyclohexano-21-crown-7 (DCH21C7) was the most sensitive. Figure 2.4 presents the distribution ratio relative to 1-octanol ordered by increasing ring size (and within a given ring size, the projected increasing basicity of the ether oxygens). Relative to benzo groups, ${ }^{4}$ cyclohexano groups tend to increase the basicity of the ether oxygens and also allow the ring to have more flexibility, thus, cyclohexano crowns tend to have higher binding constants for a given alkali metal ion than their benzo counterparts. It can be seen that, for the various $15 \mathrm{C} 5$ and $18 \mathrm{C} 6$ ethers, the cyclohexano crowns provide stronger extraction than the benzo crowns. The $15 \mathrm{C} 5$ ring size is a better size match for sodium than is $18 \mathrm{C} 6$ (optimized for potassium), which may explain the stronger extraction provided by 4-t-BuCH15C5. As was mentioned in the experimental section above, di-t-BuCH18C6 has many isomers, and we believe the relatively poor performance of this lot of di-t-BuCH18C6 is likely due to material which does not contain enough of the preferred isomers. The csc-DC14C4 is somewhat too small for sodium (lithium selective), and DC21C7 is somewhat too large (prefers potassium, rubidium, and cesium); hence lower extraction results relative to the other cyclohexyl crowns. However, DC21C7 is capable of twisting so that it can wrap itself around sodium, which may in part explain the increase in extraction at the higher sodium concentrations. The extraction efficiency from low sodium-containing solutions (e.g., 0.1 $\mathrm{M} \mathrm{NaOH}, 0.0 \mathrm{M} \mathrm{NaNO}_{3}$ ) roughly follows the sodium ion-binding strength of the crowns. This indicates that BOB-14C4-diol strongly binds sodium ion and is loaded with sodium nitrate at low aqueous sodium ion concentrations. This crown is special, as it is "bibrachial", having two arms containing the hydroxyl oxygens, which together with the four ether oxygens within the ring can better surround the metal ion. For all the crowns surveyed except BOB-14C4-diol, the distribution ratios were observed to increase with increasing sodium (nitrate) concentration, implying that these crowns are not fully loaded with sodium nitrate from aqueous solutions of $0.1 \mathrm{M} \mathrm{NaOH}, 0.1 \mathrm{M}$ $\mathrm{NaNO}_{3}$. At high sodium nitrate concentrations however, competition of nitrate with pertechnetate becomes more serious, and for crowns which are already loaded with sodium nitrate, increasing the aqueous sodium nitrate concentration results in suppression of pertechnetate extraction; this is 




\section{Crown Ether}

Fig. 2.4. Extraction of pertechnetate by selected crown ethers in 1-octanol $(0.025 \mathrm{M})$. Data from Fig. 2.3 sorted by increasing ring size of crown, and basicity of ether oxygens. 
observed with BOB-14C4-diol, which peaks with regard to pertechnetate extraction at some intermediate aqueous sodium (nitrate) concentration.

On the basis of its good overall performance and accessibility, DCH18C6 was selected for use in experiments designed to investigate the effects of such variables as diluent composition and electrolyte and crown ether concentration on the extractability of technetium. These experiments are described below.

\subsubsection{Effect of Crown Ether, Nitrate, and Hydroxide Concentration}

Extraction of pertechnetate by dicyclohexano-18-crown-6 (mixed isomers) was examined at three concentrations $(0.025,0.10$, and $0.25 \mathrm{M})$ in 1-octanol. The results, shown in Fig. 2.5, reveal an essentially linear relationship between the technetium distribution ratio and the crown ether concentration. However, the slope does appear to increase beyond 1.0 at the higher crown ether concentrations, possibly indicating that more than one crown ether may be associated with the sodium pertechnetate ion pair. With regard to the magnitude of extraction, the distribution ratio for pertechnetate from 5.0 M sodium nitrate was found to vary from $0.25(0.025 \mathrm{M} \mathrm{DCH18C6)}$ to $4.72(0.25 \mathrm{M})$. The latter represents extraction of $82.5 \%$ of the pertechnetate from the aqueous phase in a single contact and shows that usable distribution ratios can be obtained for process applications.

In a separate experiment, pertechnetate extraction by $\mathrm{DCH} 18 \mathrm{C} 6(0.1 \mathrm{M}$ in 1-octanol) was examined from aqueous phases which were $5.1 \mathrm{M}$ in total sodium ion concentration, but of varying nitrate and hydroxide concentrations (hydroxide concentration varied 0.1 to $5.1 \mathrm{M}$ ). The results, plotted in Fig. 2.6, show a linear relationship between the Tc distribution ratio and the fraction of sodium that has nitrate (or hydroxide) as the counter ion. The distribution ratio varied from 3.69 in 5.1 M NaOH (0.0 M nitrate) to 1.29 in $0.1 \mathrm{M} \mathrm{NaOH}$ (5.0 M nitrate), confirming the normal expectation that nitrate is more readily extracted into organic media than hydroxide and that nitrate is a stronger competitor than hydroxide for pertechnetate.

\subsubsection{Effect of Diluent}

The nature of the diluent was shown to be by far the most influential variable in controlling the extraction efficiency, encompassing at least six orders of magnitude in the range of observed distribution ratios for pertechnetate extraction. Though some of the diluents tested are not suitable for process applications, this insight provided the means to find a suitable diluent or blend that would meet process requirements. Extraction of pertechnetate from $0.1 \mathrm{M} \mathrm{NaOH} / 0.0,0.1$, or 5.0 $\mathrm{M} \mathrm{NaNO}_{3}$ by DCH18C6 $(0.10 \mathrm{M})$ in n-octane, ortho-xylene, 1,2-dichloroethane, cyclohexanone, 




Fig. 2.5. Extraction of pertechnetate by DCH18C6 at $0.025,0.10$, and $0.25 \mathrm{M}$ in 1-octanol. Sodium nitrate concentrations as noted. [Tc] = $1.5 \times 10^{-5} \mathrm{M}$. 


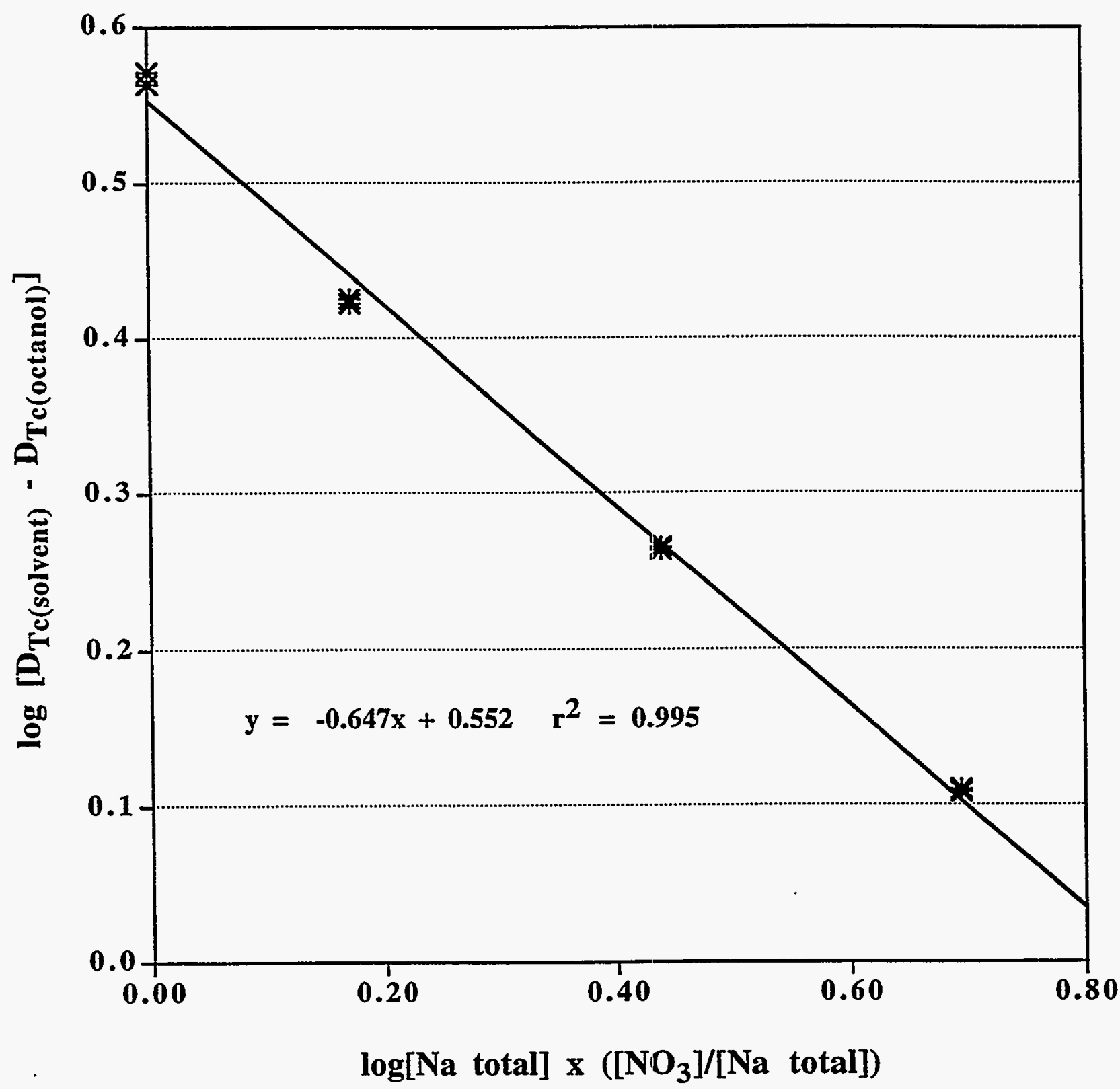

Fig. 2.6. Extraction of pertechnetate by $0.10 \mathrm{M}$ DCH18C6 in 1-octanol from 5.1 M Na(OH $\left.+\mathrm{NO}_{3}\right)$. $\log \mathrm{D}_{\mathrm{Tc}}$ vs. $\log [\mathrm{Na}$ total] $\mathrm{x}$ fraction nitrate. 
and nitrobenzene (in addition to 1-octanol) was examined to investigate the relationship between diluent properties (such as polarity) and extractability of the crown ether-sodium-pertechnetate complex. As shown in Fig. 2.7, generally, the distribution ratios increased as the empirical diluent parameter $\mathrm{DP}^{*}$ (a measure of effective diluent polarity ${ }^{5}$ ) of the solvent increased. Distribution ratios were extremely low $\left(\leq 10^{-3}\right)$ for n-octane diluent but were outstanding $\left(10^{2}\right.$ to $\geq 10^{3}$, depending on the sodium nitrate concentration) for cyclohexanone and nitrobenzene diluents. Although detailed investigation of each diluent system could not be attempted within the scope of the present work, the following interpretations are offered. The lower distribution ratios for 1octanol might be attributable to an increased affinity for nitrate extraction relative to pertechnetate (decreased pertechnetate selectivity) since octanol is a protic solvent, capable of acting as a hydrogen bond donor. It is plausible that the extraction of the smaller nitrate anion is enhanced by association with an alcohol more so than the larger pertechnetate anion. Distribution ratios increased with decreasing sodium nitrate concentration for cyclohexanone and nitrobenzene diluents; for the other diluents the opposite trend was observed. This result implies that in cyclohexanone and nitrobenzene, the crown is loaded with sodium nitrate at relatively low aqueous sodium ion concentrations and that increasing the aqueous nitrate concentration results in inhibition of the anion exchange with pertechnetate. For the other diluents, such as 1,2-dichloroethane (which gave distribution ratios of $\sim 15$ from $5.0 \mathrm{M}$ sodium nitrate), the crown was apparently not fully loaded with sodium nitrate at the lower aqueous sodium nitrate concentrations, and so increasing the sodium nitrate concentration increased the loading and thus increased the extraction of pertechnetate. Unfortunately, diluents such as nitrobenzene and chlorinated hydrocarbons are unsuitable in process applications; acceptable diluents with similar solvating properties have been tested and are described in Sects. 3 and 4.

\subsubsection{Stripping Experiments with Selected Systems}

The ability to remove ("strip") the pertechnetate from the extractant, and thus regenerate the extractant, was a key element of the process we sought to develop. Experiments were conducted in which post-extraction organic solutions containing the crown-sodium-pertechnetate complex were subjected to stripping procedures using water. The crown DCH18C6 was again examined at $0.1 \mathrm{M}$ in cyclohexanone, 1,2-dichloroethane, and 1-octanol diluents; the results are shown graphically in Fig. 2.8. While $\geq 99 \%$ pertechnetate extraction was obtained using cyclohexanone diluent after only one contact, only $\sim 2 \%$ could be stripped after two contacts. For 1,2dichloroethane and 1-octanol diluents, the results were $94 \%$ extracted $/ 42 \%$ stripped and $56 \%$ extracted/99\% stripped, respectively. When two extraction passes were employed using 1-octanol (results not shown in Fig. 2.8), 81\% of the pertechnetate was extracted; 99\% was again stripped 


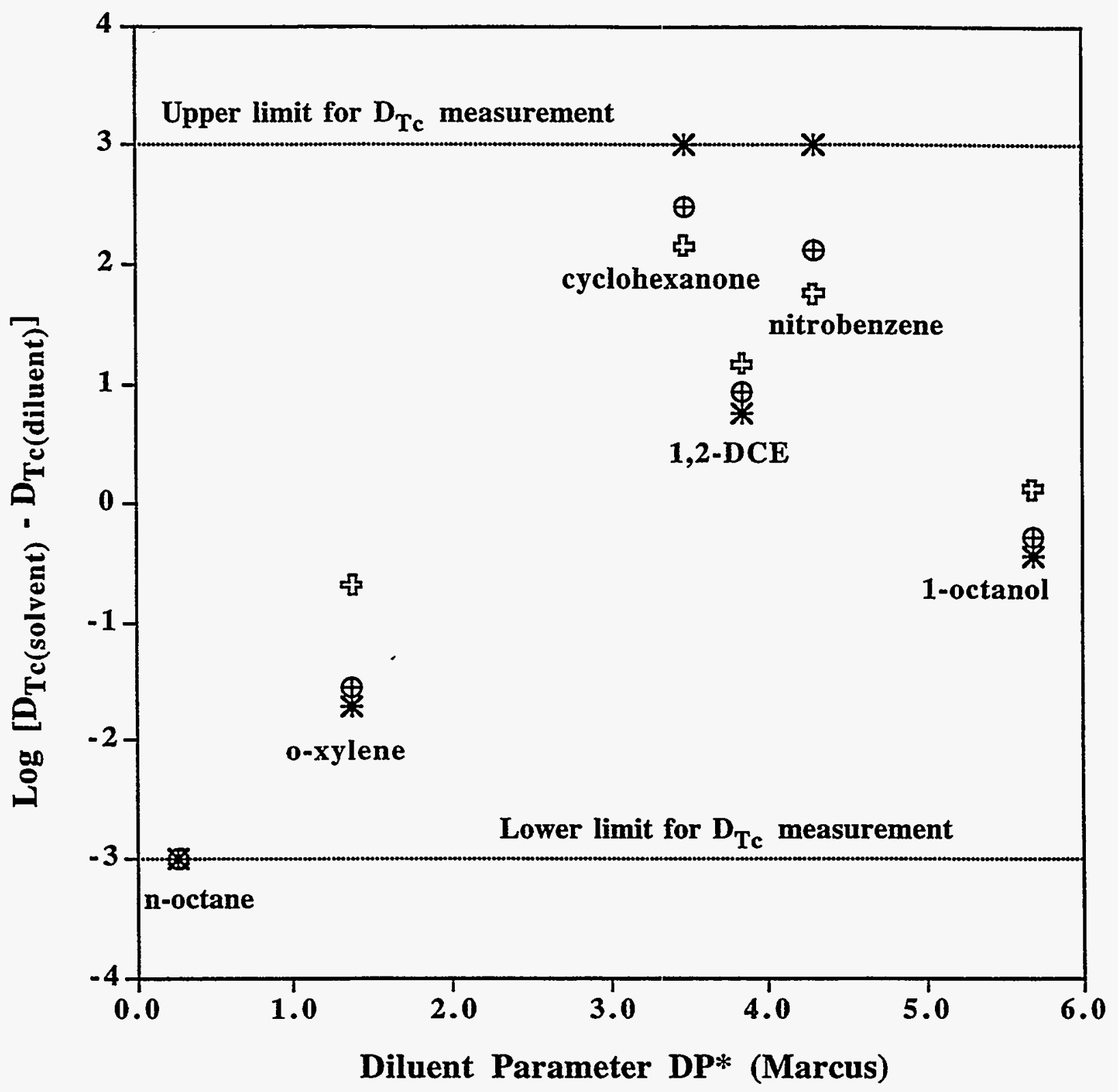

Fig. 2.7. Extraction of pertechnetate by DCH18C6 $(0.10 \mathrm{M})$ in various diluents from $\mathrm{NaNO}_{3}$ concentrations as shown.

* $\quad 0.0 \mathrm{M} \mathrm{NaNO}_{3} \oplus 0.1 \mathrm{M} \mathrm{NaNO}_{3} \uplus 5.0 \mathrm{M} \mathrm{NaNO}_{3}$ 


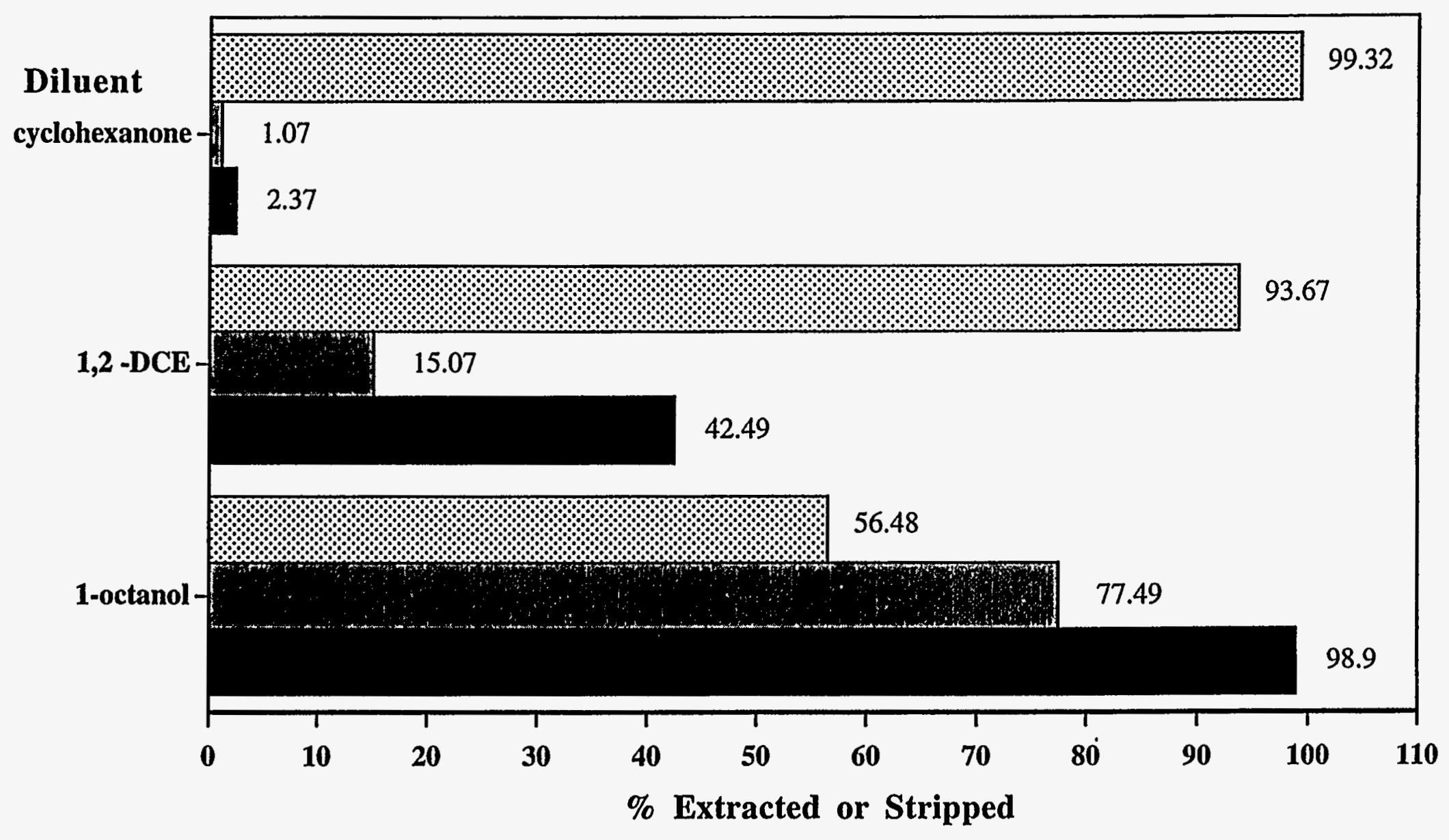

\% extracted after one pass 圈 \% stripped after one pass

Total \% stripped after two passes

Fig. 2.8. Extraction of pertechnetate from $0.1 \mathrm{M} \mathrm{NaOH}, 5.0 \mathrm{M} \mathrm{NaNO}_{3}$ solutions by DCH18C6 $(0.10 \mathrm{M})$ in various diluents, and stripping by back-extraction into water. 
after two passes. These results showed that water stripping is possible, but one obtains the normal behavior in which high distribution coefficients are associated with poor stripping.

\subsubsection{Comparison to Quaternary Ammonium Compounds}

The extraction of pertechnetate from $0.1 \mathrm{M} \mathrm{NaOH} / 0.0,0.1$, or $5.0 \mathrm{M} \mathrm{NaNO}_{3}$ by selected quaternary ammonium nitrate compounds was also examined. These materials ("quats") have been successfully utilized in the solvent extraction of anions, including pertechnetate. However, regeneration of the quat via stripping procedures is currently problematic, in that concentrated nitric or perchloric acids are required. In general, quats such as tricaprylmethyl ammonium nitrate (Aliquat ${ }^{\circledR} 336$ Nitrate) and tetraheptyl ammonium nitrate were found to be much stronger extractants than the crowns for pertechnetate when low polarity diluents (e.g. ortho-xylene) are employed. Figure 2.9 shows that for all quats except Carsoquat SDQ-85, the Tc distribution coefficient was $>1000$ for both 0.025 and $0.10 \mathrm{M}$ quat at zero sodium nitrate concentration. Distribution ratios decreased with increasing nitrate concentration but were nevertheless high $(>10$ for all except $0.025 \mathrm{M}$ Carsoquat) from $5.0 \mathrm{M}$ sodium nitrate solutions in ortho-xylene diluent. However, in 1-octanol the distribution ratios for the quats were considerably lower and on a par with the crowns (see Fig. 2.10); Aliquat ${ }^{\circledR} 336$ Nitrate at $0.1 \mathrm{M}$ gave a distribution coefficient of 1.14 whereas DCH18C6 at $0.1 \mathrm{M}$ gave a distribution coefficient of 1.30 . However, the loaded quat solution could not be stripped by the procedure used to strip the crown solutions. After two stripping contacts with water, $\ll<1 \%(\sim 0.2 \%)$ of the pertechneatte contained in the quat solution could be removed, as compared to $\geq 99 \%$ technetium rernoved from the solution containing the crown ether. It may be expected that a reductive stripping method employing the same principle used by $N$. Schroeder et al. at LANL ${ }^{6}$ for stripping anion-exchange resins could be employed. Although this option may be worth pursuing, especially in view of the high $\mathrm{D}_{\mathrm{Tc}}$ values obtained and the low cost of the reagents, we have elected herein to develop further the crown ether systems. Persuasive advantages of the crown-ether approach include water stripping and the likelihood that combined extraction of ${ }^{99} \mathrm{Tc}$ and other fission products such as ${ }^{90} \mathrm{Sr}$ and ${ }^{137} \mathrm{Cs}$ can be obtained.

\subsection{CONCLUSIONS}

In the first year of the project, the feasibility of using crown ethers to extract technetium in the form of pertechnetate from alkaline solutions which are highly concentrated in sodium nitrate (0.1 M NaOH/5.0 M NaNO3) was successfully demonstrated. The degree of extraction was dependent on such factors as the structure of the crown ether, the concentration of sodium and 


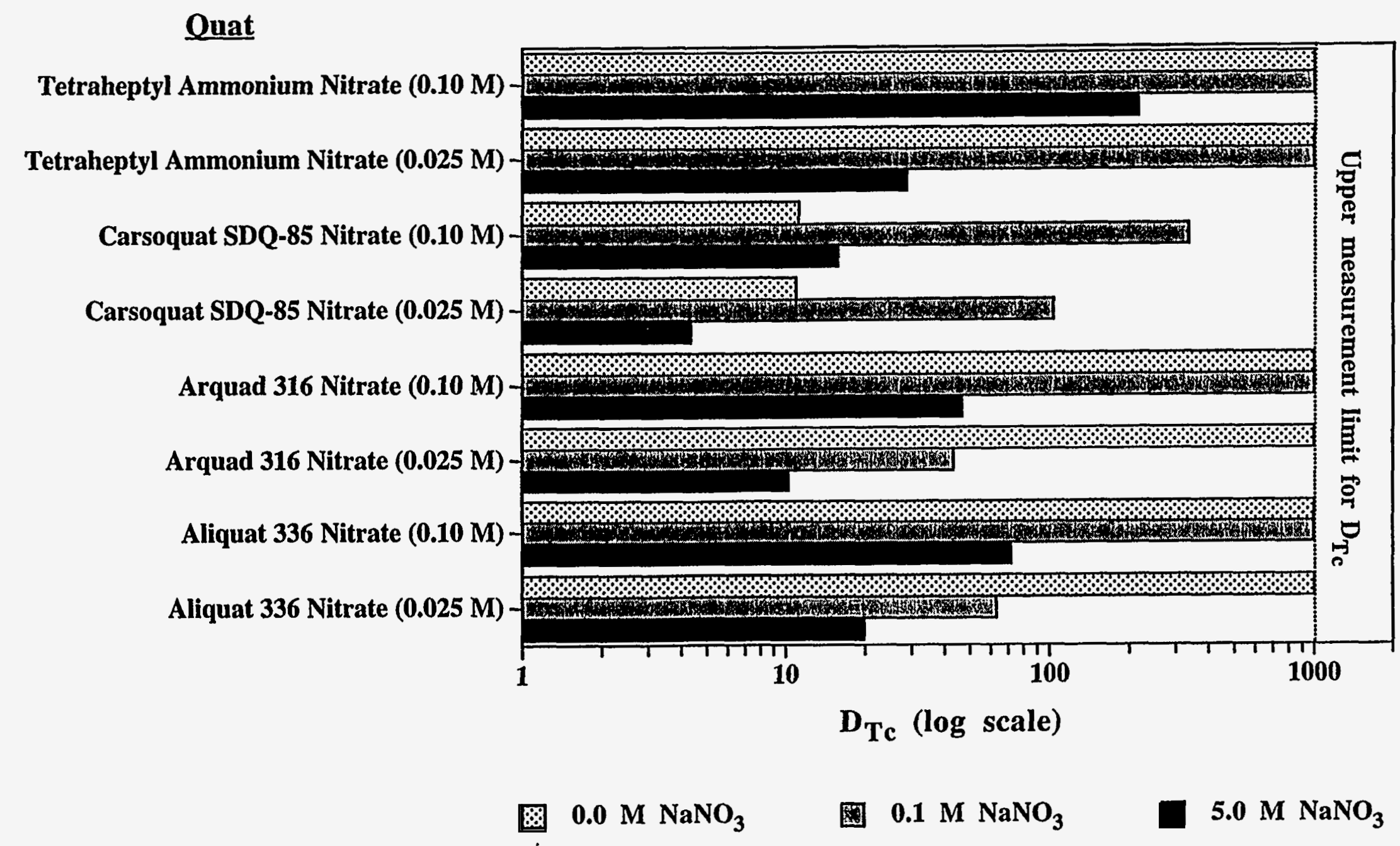

Fig. 2.9. Pertechnetate extraction by selected quaternary ammonium nitrates (0.025 and 0.10 $\mathrm{M}$ in o-xylene). Aqueous phase: $[\mathrm{NaOH}]=0.10 \mathrm{M} ;[\mathrm{Tc}]=1.5 \times 10^{-5} \mathrm{M}$; $\left[\mathrm{NaNO}_{3}\right]$ as noted. 


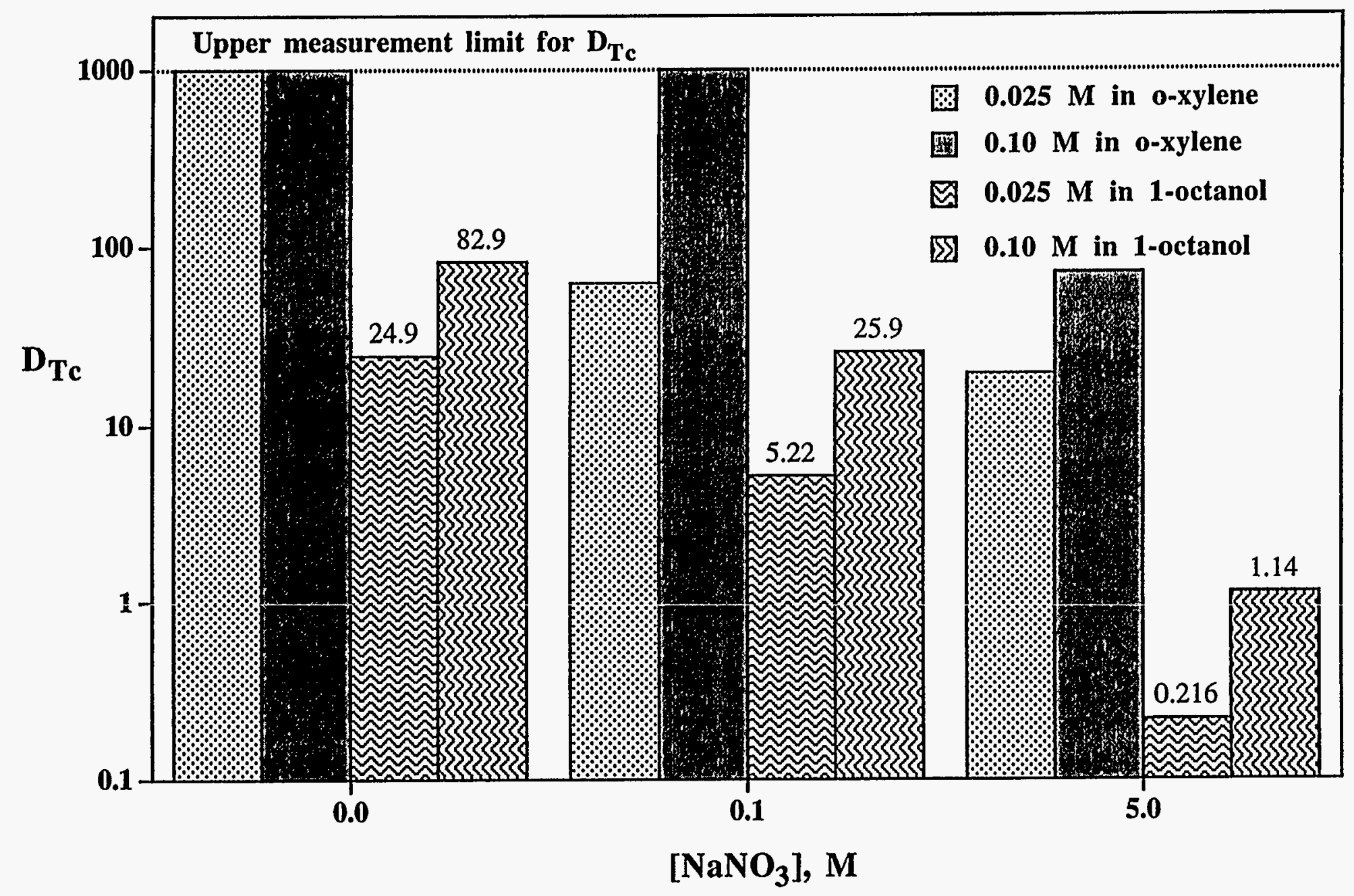

Fig. 2.10. Comparison of pertechnetate extraction by Aliquat ${ }^{\circledR} 336$ Nitrate $(0.025$ and $0.10 \mathrm{M})$ in 1-octanol vs. o-xylene. Aqueous phase: $[\mathrm{NaOH}]=0.10 \mathrm{M} ;[\mathrm{Tc}]$ $=1.5 \times 10^{-5} \mathrm{M} ;\left[\mathrm{NaNO}_{3}\right]$ as noted. 
nitrate, and the properties of the diluent employed. Efficient and economical stripping was achievable with water, but with water stripping there is a trade-off with regard to degree of extraction. The next section concerns optimization of the crown ether and diluent with regard to extraction and stripping from waste simulants and establishment of the basic extraction and stripping cycle.

\subsection{REFERENCES}

1. Horwitz, E.P.; Dietz, M.L.; Fisher, D.E. Solvent Extr. Ion Exch. 1991, 9, 1-25.

2. Buchanan, G.W.; Kirby, R.A.; Charland, J.P. J. Am. Chem. Soc. 1988, 110, 2477-2483.

3. Diadra Bau, unpublished work on purification of Aliquat 336, conducted under the SERS Program, ORNL, 1993.

4. (a) J. J. Christensen, D. J. Eatough, and R. M. Izatt, Chem. Rev. 1974, 74, 351.

(b) R. M. Izatt, J. S. Bradshaw, S. A. Nielsen, J. D. Lamb, J. J. Christensen, and

D. Sen, Chem. Rev. 1985,85, 271. (c) R. M. Izatt, K. Pawlak, J. S. Bradshaw, and R. L. Bruening, Chem. Rev.1991, 91, 1721.

5. Marcus, Y., Solvent Extr. Ion Exch. 1989, 7, 567-575.

6 Schroeder, N.C., Radzinski, S., Ashley, K.R., Ball, J., Stanmore, F., Whitener, G. "Technetium Partitioning for the Hanford Tank Waste Remediation System: Sorption of Technetium from DSS and DSSF-7 Waste Simulants Using Reillex ${ }^{\mathrm{TM}}$-HPQ Resin," Los Alamos National Laboratory Report LA-UR95-40 (1995). 


\section{OPTIMIZATION OF CROWN ETHER AND DILUENT: ESTABLISHING AN EXTRACTION AND STRIPPING CYCLE}

\subsection{INTRODUCTION}

In the second year (FY 1994) of the project, we sought to define and optimize the extraction and stripping cycle for pertechnetate from realistic waste simulants using processsuitable diluents and modifiers. The research concentrated on the more process-oriented and environmental, safety, and health concerns of the solvent-extraction cycle. Crown ether/diluent/modifier systems were evaluated with regard to pertechnetate extraction and stripping performance, leading to a group of candidate systems. The best commercially available crown ether bis- $4,4^{\prime}\left(5^{\prime}\right)[($ tert-butyl)cyclohexano]-18-crown- 6 was identified, the range of diluents and modifiers were reduced to a select few, and information regarding the thermodynamics, concentration dependence, and kinetics of the extraction was obtained.

\subsection{EXPERIMENTAL}

\subsubsection{Materials and Instrumentation}

Crown Ethers. The crown ether bis-4,4'(5')[(tert-butyl)cyclohexano]-18-crown-6 (Parish Chemical, lot \#LBM, abbreviated di-t-BuCH18C6) was used as received without further purification. A second sample, lot \#4VNH, was dissolved in acetone and filtered to remove salts. After cleanup, this material performed as well as lot \#LBM, but again it should be cautioned that performance was found to vary markedly from lot to lot. Both of these lots were semi-solids at room temperature and appeared to contain sufficient quantities of the preferred isomer, as their performance was markedly better than that of lot $¥ 3$ IBD). The crown ethers 4-tertbutylcyclohexano-15-crown-5 (4-t-BuCH15C5, lot ¥3TBB), dicyclohexano-18-crown-6 (DCH18C6, 1:1 ratio of cis-syn-cis and cis-anti-cis isomers, lot \#3KNP)) and dicyclohexano-21crown-7 (DCH21C7, lot \#3IGE) were used as received from Parish Chemical. The crown ethers cis-sym-bis-(tert-octylbenzo)-14-crown-4-diol (1), mono-methoxy-cis-sym-bis-(tert-octylbenzo)14-crown-4 (2), bis-methoxy-cis-sym-bis-(tert-octylbenzo)-14-crown-4 (3), and cis-sym-bis-(tertoctylbenzo)-14-crown-4-bis(oxyacetone) (4), (abbreviated BOB-14C4-diol, MeOBOB14C4, $(\mathrm{MeO})_{2} \mathrm{BOB} 14 \mathrm{C} 4$, and cis-BOB14C4-bis(oxyacetone), respectively) were synthesized at Oak Ridge National Laboratory as part of this research (see Fig. 3.1 below); the synthetic procedures will be published elsewhere. ${ }^{1}$ Isopar ${ }^{\circledR} \mathrm{M}$ (a completely aliphatic isoparaffinic kerosene), and Norpar 12 (a completely aliphatic normal paraffinic kerosene) were obtained from Exxon Chemical Company, Houston, Texas. Deionized water was obtained from a Barnstead Nanopure filtering system (resistivity $18 \mathrm{M} \Omega$ ). Aliquat ${ }^{\circledR} 33 \mathrm{~N}$ (Aldrich) was dried under vacuum to remove excess 
water prior to use. All other diluents, modifiers and reagents were used as received without further purification. All diluent blends were prepared on a volume basis, unless otherwise noted.

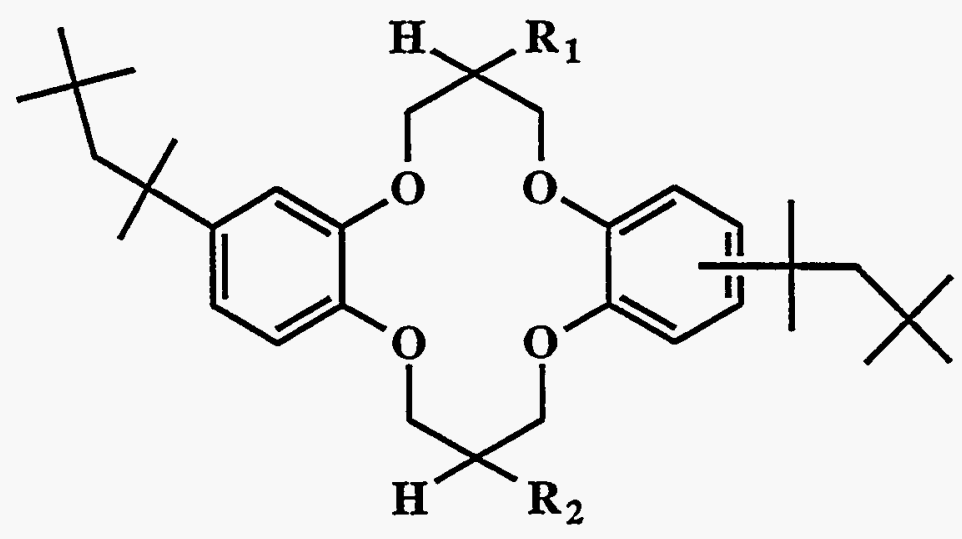

Fig. 3.1. ORNL-synthesized crown ethers used in this study.
$1 \quad R_{1}=R_{2}=-O H$

$2 \mathbf{R}_{1}=-\mathrm{H}, \mathrm{R}_{2}=-\mathrm{OCH}_{3}$

$3 \quad \mathbf{R}_{1}=\mathbf{R}_{2}=-\mathbf{O C H}_{3}$

$4 \mathrm{R}_{1}=\mathrm{R}_{2}=-\mathrm{OCH}_{2} \mathrm{C}(\mathrm{O}) \mathrm{CH}_{3}$

Radionuclides and Radiation Measurement. The ${ }^{99} \mathrm{Tc}$ stock solution as described in Sect. 2.2.1 was used to prepare all Tc-containing waste simulants. Beta-liquid scintillation counting of ${ }^{99} \mathrm{Tc}$ was performed using a Packard Tricarb ${ }^{\circledR}$ Model 4530 counter, and Packard Ultima Gold ${ }^{\mathrm{MM}}$ $\mathrm{XR}$ scintillation cocktail also as previously described in Sect. 2.2.1. Sodium-22 was obtained from DuPont New England Nuclear as a solution of $1 \mathrm{mCi} 22 \mathrm{NaCl}$ in water. Simulant solutions were generally spiked to a level of 0.4 to $0.8 \mu \mathrm{Ci} / \mathrm{mL}$. Gamma counting of ${ }^{22} \mathrm{Na}(511$ and 1022 $\mathrm{keV}$ ) was performed using a 3-inch sodium iodide well-type detector connected to an Oxford Tennelec multichannel analyzer controlled by a Macintosh Quadra 700 computer.

\subsubsection{Hanford Tank Waste Simulants}

Simulants for two different types of alkaline tank waste stored at Hanford were prepared following the procedures described by C. D. Carlson ${ }^{2}$ of Pacific Northwest Laboratories. One simulant approximates the neutralized current acid waste feed for Hanford tank 241-AZ-101, and is designated as NCAW (Neutralized Current Acid Waste). The other simulant approximates the double shell slurry feed supernate from Hanford tank 241-AW-101, but has a somewhat lower total sodium concentration than the actual AW-101 tank waste supernate ( $7 \mathrm{M}$ rather than the about $10 \mathrm{M}$ ). This simulant is designated as DSSF-7 (Double Shell Slurry Feed, 7M Na). The composition of these waste simulants are presented in Table 3.1, along with the composition of a "simple" sodium nitrate-based simulant. Pertechnetate was added to a level of $6 \times 10^{-5} \mathrm{M}$ for all simulants. 
Table 3.1. Composition of Hanford waste simulants and

"simple simulant" used in this study.

Concentration (M)

\begin{tabular}{|c|c|c|c|}
\hline Species & "Simple" Simulanta & NCAW simulant ${ }^{b}$ & DSSF-7 simulantc \\
\hline $\mathrm{Na}^{+}$ & 5.10 & 4.99 & 7.00 \\
\hline $\mathrm{K}^{+}$ & not added & $1.20 \times 10^{-1}$ & $9.45 \times 10^{-1}$ \\
\hline $\mathrm{Rb}^{+}$ & not added & $5.0 \times 10^{-5}$ & not added \\
\hline $\mathrm{Cs}^{+}$ & not added & $5.0 \times 10^{-4}$ & $7.0 \times 10^{-5}$ \\
\hline $\mathrm{Al}^{3+}$ & not added & $4.30 \times 10^{-1}$ & $7.21 \times 10^{-1}$ \\
\hline $\mathrm{OH}^{-}$(total) & $1.0 \times 10^{-1}$ & 3.40 & 4.63 \\
\hline $\mathrm{OH}^{-}$(free) & $1.0 \times 10^{-1}$ & 1.68 & 1.75 \\
\hline Theoretical $\mathrm{pH}$ & 13.0 & 14.5 & 14.6 \\
\hline $\mathrm{F}$ & not added & $1.7 \times 10^{-2}$ & not added \\
\hline $\mathrm{Cl}^{-}$ & not added & not added & $1.02 \times 10^{-1}$ \\
\hline $\mathrm{NO}_{2}^{-}$ & not added & $4.3 \times 10^{-1}$ & 1.51 \\
\hline $\mathrm{NO}_{3}^{-}$ & 5.00 & 1.67 & 3.52 \\
\hline $\mathrm{SO}_{4}^{2-}$ & not added & $1.50 \times 10^{-1}$ & $8.0 \times 10^{-3}$ \\
\hline $\mathrm{CO}_{3}^{2-}$ & not added & $2.30 \times 10^{-1}$ & $1.47 \times 10^{-1}$ \\
\hline $\mathrm{PO}_{4}^{3-}$ & not added & $2.5 \times 10^{-2}$ & $1.4 \times 10^{-2}$ \\
\hline${ }^{99} \mathrm{TcO}_{4}^{-}$ & $6.0 \times 10^{-5}$ & $6.0 \times 10^{-5}$ & $6.0 \times 10^{-5}$ \\
\hline
\end{tabular}

a"Simple" simulant is $0.10 \mathrm{M} \mathrm{NaOH}, 5.0 \mathrm{M} \mathrm{NaNO}_{3}$.

bNCAW approximates Hanford tank AZ-101 Neutralized Current Acid Waste.

cDSSF-7 approximates Hanford tank AW-101 Double-Shell Slurry Feed.

\subsubsection{General Two-Extraction/Two-Strip Contacting Procedure}

This procedure was used as a general method to screen candidate solvents for extraction and stripping efficiency. Synthetic waste solutions were contacted with equal volumes of solvent for 1 hour at $25 \pm 1^{\circ} \mathrm{C}$ in sealed borosilicate vials by end-over-end rotation at $35 \pm 5 \mathrm{RPM}$ using a Glass- $\mathrm{Col}^{\circledR}$ laboratory rotator. This contacting procedure ensures achievement of equilibrium, though kinetic tests show that $95 \%$ or more of the Tc is extracted within the first 5 minutes (see 
Sect. 3.3.7). After allowing the phases to coalesce (either on their own, or assisted by centrifugation as necessary), the aqueous and organic phases were subsampled and the ${ }^{99} \mathrm{Tc}$ activity in each phase determined. An aliquot of the aqueous phase from the first contact was subsequently contacted with an equal volume of fresh extractant solution in the manner described above and the phases subsampled to determine the ${ }^{99} \mathrm{Tc}$ activity. In the stripping tests, aliquots of the organic phases from the first and second contacts were combined and contacted with an equal volume of deionized water in the manner described above. After the phases were subsampled, the organic phase from this first stripping operation was contacted with a second equal volume of water, comprising the second strip, and the phases were again subsampled to determine the ${ }^{99} \mathrm{Tc}$ activity. The entire cross-current two-extraction, two-strip procedure is shown diagramatically in Fig. 3.2. All tests were run in duplicate, and the technetium extraction (distribution) ratios ( $[\mathrm{Tc}]_{\text {org }} /[\mathrm{Tc}]_{\mathrm{aq}}$ ) are reported as the average of those obtained in the two stages $\mathrm{E}_{1}$ and $\mathrm{E}_{2}$. In general, the value of $E_{2}$ differed insignificantly from $E_{1}$. Variations of this general procedure were also tested as will be noted specifically below.

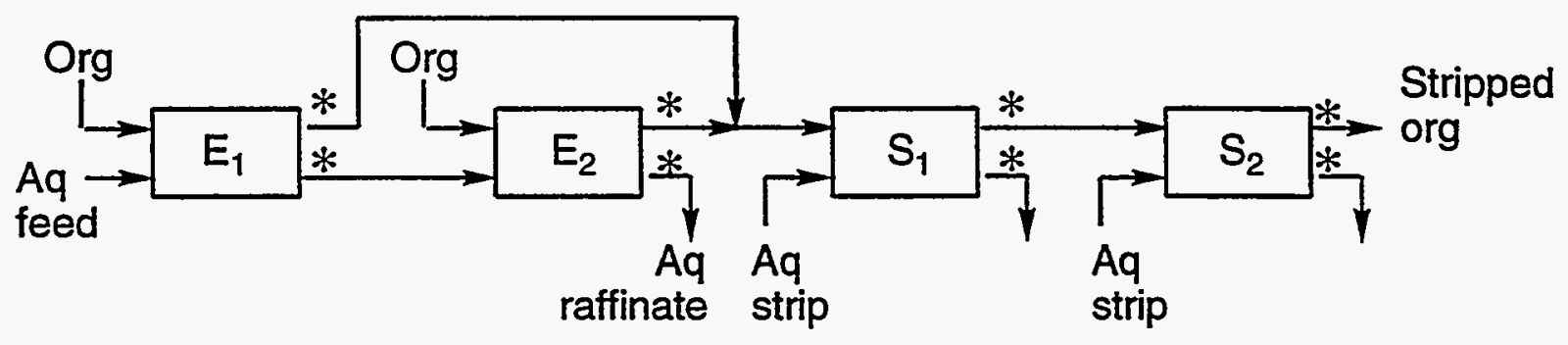

Fig. 3.2. Diagram of two-extraction, two-strip contacting procedure. The asterisk $(*)$ denotes when samples were taken for analysis. (Note: This is not meant to represent a process flowsheet).

\subsection{RESULTS AND DISCUSSION}

\subsubsection{Extraction and Stripping Performance of DCH18C6 in Selected Diluents}

Effect of Diluent on Solvent Selection. Due to the good extraction performance provided by cis-DCH18C6, and its availability, more detailed experiments were performed using it at $0.1 \mathrm{M}$ in selected diluents. The two-extraction, two-strip procedure outlined above in Fig. 3.2 was used to evaluate extraction performance from the "simple simulant" (Table 3.1), as well as stripping performance, as a function of the diluent. The results are shown in Table 3.2. All the diluents examined in this initial screening were more process-suitable, as they were non-aromatic, nonhalogenated, and all had flash points above $60^{\circ} \mathrm{C}$, (except for cyclohexanone, which is listed here 
Table 3.2. Extraction of pertechnetate by DCH18C6 $(0.1 \mathrm{M})$ in various diluents from

$0.1 \mathrm{M} \mathrm{NaOH}, 5.0 \mathrm{M}$ sodium nitrate, and stripping by back-extraction using water

(Two cross-current extraction and two cross-current stripping contacts)

\begin{tabular}{|c|c|c|c|c|c|c|c|}
\hline Diluent (blends are vol/vol) & 1-octanol & 2-octanol & 2-octanone & 3-octanone & 1:12-octanone/2-octanol & 1:1 2-octanone/Isopar M & cyclohexanone \\
\hline \multicolumn{8}{|l|}{ Extraction } \\
\hline $\begin{array}{l}\text { First contact - \% in aq phase } \\
\text { First contact - } \% \text { in org phase }\end{array}$ & $\begin{array}{l}43.40 \\
56.60\end{array}$ & $\begin{array}{l}30.59 \\
69.41\end{array}$ & $\begin{array}{c}4.37 \\
95.63\end{array}$ & $\begin{array}{c}4.73 \\
95.27\end{array}$ & $\begin{array}{c}9.46 \\
90.54\end{array}$ & $\begin{array}{l}25.25 \\
74.75\end{array}$ & $\begin{array}{r}0.79 \\
99.21\end{array}$ \\
\hline uncertainty & 0.39 & 0.12 & 0.04 & 0.04 & 0.04 & 0.11 & 0.01 \\
\hline Second contact - \% in aq phase & 43.26 & 30.03 & 4.46 & 4.40 & 9.55 & 20.51 & 0.86 \\
\hline Second contact - \% in org phase & 56.74 & 69.97 & 95.54 & 95.60 & 90.45 & 79.49 & 99.14 \\
\hline uncertainty & 0.16 & 0.21 & 0.04 & 0.05 & 0.05 & 0.04 & 0.18 \\
\hline Combined - \% in aq phase & 18.77 & 9.19 & 0.19 & 0.21 & 0.90 & 5.18 & 0.01 \\
\hline Combined - \% in org phase & 81.23 & 90.81 & 99.81 & 99.79 & 99.10 & 94.82 & 99.99 \\
\hline uncertainty & 0.18 & 0.07 & 0.00 & 0.00 & 0.01 & 0.02 & 0.00 \\
\hline Total \% Extracted 2 Contacts & $81.23 \pm 0.18$ & $90.81 \pm 0.07$ & $99.81 \pm 0.00$ & $99.79 \pm 0.00$ & $99.10 \pm 0.01$ & $94.82 \pm 0.02$ & $99.99 \pm 0.00$ \\
\hline \multicolumn{8}{|l|}{ Stripping } \\
\hline First contact - \% in aq phase & 76.69 & 83.10 & 20.48 & 37.17 & 35.94 & 96.41 & 1.05 \\
\hline First contact - $\%$ in org phase & 23.32 & 16.90 & 79.52 & 62.83 & 64.06 & 3.59 & 98.95 \\
\hline uncertainty & 0.89 & 0.15 & 0.03 & 0.47 & 0.19 & 0.04 & 0.01 \\
\hline Second contact - \% in aq phase & 97.16 & 99.18 & 48.61 & 81.98 & 60.07 & 98.52 & 1.36 \\
\hline Second contact - \% in org phase & 2.84 & 0.82 & 51.39 & 18.02 & 39.93 & 1.48 & 98.64 \\
\hline uncertainty & 0.18 & 0.01 & 2.17 & 1.31 & 0.10 & 0.24 & 0.00 \\
\hline Combined - \% in aq phase & 99.34 & 99.861 & 59.135 & 88.678 & 74.42 & 99.947 & 2.396 \\
\hline Combined - \% in org phase & 0.66 & 0.139 & 40.865 & 11.322 & 25.58 & 0.053 & 97.604 \\
\hline uncertainty & 0.05 & 0.002 & 1.726 & 0.827 & 0.10 & 0.009 & 0.010 \\
\hline Total \% Stripped 2 Contacts & $99.35 \pm 0.05$ & $99.86 \pm 0.00$ & $59.14 \pm 1.73$ & $88.68 \pm 0.83$ & $74.42 \pm 0.10$ & $99.95 \pm 0.01$ & $2.40 \pm 0.01$ \\
\hline \multicolumn{8}{|l|}{ Distribution coefricients } \\
\hline SX-1A & $1.283 \mathrm{E}+00$ & $2.256 \mathrm{E}+00$ & $2.170 \mathrm{E}+01$ & $1.997 \mathrm{E}+01$ & $9.533 \mathrm{E}+00$ & $2.944 \mathrm{E}+00$ & $1.242 E+02$ \\
\hline$S X-1 B$ & $1.325 \mathrm{E}+00$ & $2.282 \mathrm{E}+00$ & $2.210 \mathrm{E}+01$ & $2.033 \mathrm{E}+01$ & $9.619 \mathrm{E}+00$ & $2.978 \mathrm{E}+00$ & $1.273 E+02$ \\
\hline$S X-2 A$ & $1.303 \mathrm{E}+00$ & $2.307 \mathrm{E}+00$ & $2.162 \mathrm{E}+01$ & $2.200 \mathrm{E}+01$ & $9.410 \mathrm{E}+00$ & $3.865 \mathrm{E}+00$ & $7.991 \mathrm{E}+01$ \\
\hline$S X-2 B$ & $1.320 \mathrm{E}+00$ & $2.353 \mathrm{E}+00$ & $2.118 \mathrm{E}+01$ & $2.148 \mathrm{E}+01$ & $9.530 \mathrm{E}+00$ & $3.884 \mathrm{E}+00$ & $1.437 \mathrm{E}+02$ \\
\hline Average distributlon coeff. & $1.308 \mathrm{E}+00$ & $2.300 \mathrm{E}+00$ & $2.165 \mathrm{E}+01$ & $2.095 \mathrm{E}+01$ & $9.523 \mathrm{E}+00$ & $3.418 \mathrm{E}+00$ & $1.188 E+02$ \\
\hline Standard deviation & $1.900 \mathrm{E}-02$ & $4.130 \mathrm{E}-02$ & $3.772 \mathrm{E}-01$ & $9.536 \mathrm{E}-01$ & $8.590 \mathrm{E}-02$ & $5.276 \mathrm{E}-01$ & $2.729 \mathrm{E}+01$ \\
\hline
\end{tabular}


for comparison). Again, while cyclohexanone (once evaluated for a technetium extraction process ${ }^{3}$ ) exhibited excellent pertechnetate extraction, stripping was poor, even after two contacts. There is literature precedent for using other ketones ${ }^{4}$ as extractants for pertechnetate, and the ketones 2-octanone and 3-octanone were examined here. The best combined extraction and stripping results were obtained using a diluent blend of $1: 1 \mathrm{vol} / \mathrm{vol}$ 2-octanone//sopar ${ }^{\circledR} \mathrm{M}$ (where Isopar ${ }^{\circledR} \mathrm{M}$ is an isoparaffinic kerosene). The blend also exhibited excellent phase disengagement behavior (phase coalescence was essentially immediate).

Pertechnetate/Nitrate Selectivity. We were interested in the reasons why certain diluent blends gave better combined extraction and stripping results than others, and thus the extraction of sodium (using ${ }^{22} \mathrm{Na}$ tracer) was probed for all the diluents listed in Table 3.2, except the more expensive ones (2-octanol, and 3-octanone). The extraction of sodium was traced from the simple simulant which contained no added pertechnetate; since there is only a small amount of hydroxide $(0.1 \mathrm{M})$ relative to nitrate $(5.0 \mathrm{M})$, and since nitrate is a more extractable anion, the amount of sodium extracted provides a fair measure of the amount of nitrate extracted. The distribution ratios for sodium (nitrate) and pertechnetate for five diluents (both with and without crown ether), along with some pertechnetate extraction and stripping data from Table 3.2 are shown in Table 3.3. It can be seen that, generally, stripping increases as the amount of sodium nitrate extracted by both the solvent (DCH18C6 plus diluent) and the diluent alone decreases, and as the amount of pertechnetate extracted by the diluent alone decreases. Cyclohexanone is a powerful extractant in and of itself, and with the crown ether present extraction was exceptional. However, this system is essentially non-strippable using water. (Technetium can be stripped from cyclohexanone solutions containing no crown ether). Also, cyclohexanone possesses several undesirable properties which make it unsuitable for a large-scale process. These include having (1) a flash point below the $60^{\circ} \mathrm{C}\left(140^{\circ} \mathrm{F}\right)$ RCRA threshold; (2) appreciable water solubility (50 grams per liter at $30^{\circ} \mathrm{C}$ ); and (3) the tendency to form emulsions on stripping. The affinity 2-octanone alone has for pertechenate may in part explain why stripping is difficult. Diluting 2-octanone with Isopar ${ }^{\circledR} \mathrm{M}$ decreased the amount of pertechnetate extracted by the diluent alone by nearly two orders of magnitude; the amount of pertechnetate extracted by the crown solvent was decreased by only a factor of around six. One must therefore balance extraction and stripping, for if the distribution ratio is too large (above 10), stripping becomes more difficult and would require more contacts with water. Figure 3.3 shows that the pertechnetate/nitrate selectivity afforded by DCH18C6 $(0.1 \mathrm{M})$ in 1:1 2-octanone/Isopar ${ }^{\circledR} \mathrm{M}$ remains high, almost as high as that using pure 2octanone, and Fig. 3.4 shows that the extraction of sodium nitrate and sodium pertechnetate with this system falls within a workable range. 
Table 3.3. Extraction of sodiuma and technetium ${ }^{b}$ by selected diluents with and without crown ether (DCH18C6 at $0.1 \mathrm{M}$ ), and stripping efficiency of technetium as a function of sodium (nitrate) and technetium extractability by crown ether plus diluent, and diluent alone

\begin{tabular}{|c|c|c|c|c|c|c|}
\hline Diluent & $\begin{array}{c}\mathbf{D}_{\mathrm{Tc}} \\
\mathrm{CE}+\text { diluent }\end{array}$ & $\begin{array}{c}\mathrm{D}_{\mathrm{Na}} \\
\mathrm{CE}+\text { diluent }\end{array}$ & $\frac{\text { DTc }_{\text {diluent only }}}{\text { dit }}$ & $\underset{\text { diluent only }}{\text { DNa }_{\text {Na }}}$ & $\begin{array}{c}\% \text { Tc Extr. } \\
\text { (1st Contact) }\end{array}$ & $\begin{array}{l}\text { \% Tc Strip. } \\
\text { (1st Contact) }\end{array}$ \\
\hline cyclohexanone & 119 & $1.93 \times 10^{-2}$ & 4.61 & $1.28 \times 10^{-3}$ & 99.2 & 1.05 \\
\hline 2-octanone & 21.6 & $8.74 \times 10^{-3}$ & $2.98 \times 10^{-2}$ & $3.46 \times 10^{-5}$ & 95.6 & 20.5 \\
\hline 1-octanol & 1.31 & $1.76 \times 10^{-2}$ & $9.76 \times 10^{-3}$ & $7.82 \times 10^{-4}$ & 56.6 & 76.7 \\
\hline 2-octanol & 2.30 & $1.33 \times 10^{-2}$ & $4.04 \times 10^{-3}$ & $2.24 \times 10^{-4}$ & 69.4 & 83.1 \\
\hline $\begin{array}{c}\text { 1:1 2-octanonel } \\
\text { Isopar }{ }^{\circledR} \mathrm{M}\end{array}$ & 3.42 & $1.65 \times 10^{-3}$ & $3.91 \times 10^{-4}$ & $1.64 \times 10^{-5}$ & 74.8 & 96.4 \\
\hline
\end{tabular}

a Na extraction conditions: $25^{\circ} \mathrm{C}, 1: 1$ phase ratio, one 1 h extraction contact. Matrix: $0.1 \mathrm{M} \mathrm{NaOH}, 5 \mathrm{M} \mathrm{NaNO},{ }^{22 \mathrm{Na}}$ spike.

bTc extraction and stripping data taken from Table 3.2. (Conditions: $25^{\circ} \mathrm{C}, 1: 1$ phase ratio, two $1 \mathrm{~h}$ extraction contacts, two 1 h extraction contacts. Matrix: $0.1 \mathrm{M} \mathrm{NaOH}, 5 \mathrm{M} \mathrm{NaNO}_{3}, 60 \mathrm{mM}^{99} \mathrm{TcO}_{4}^{-}$. 


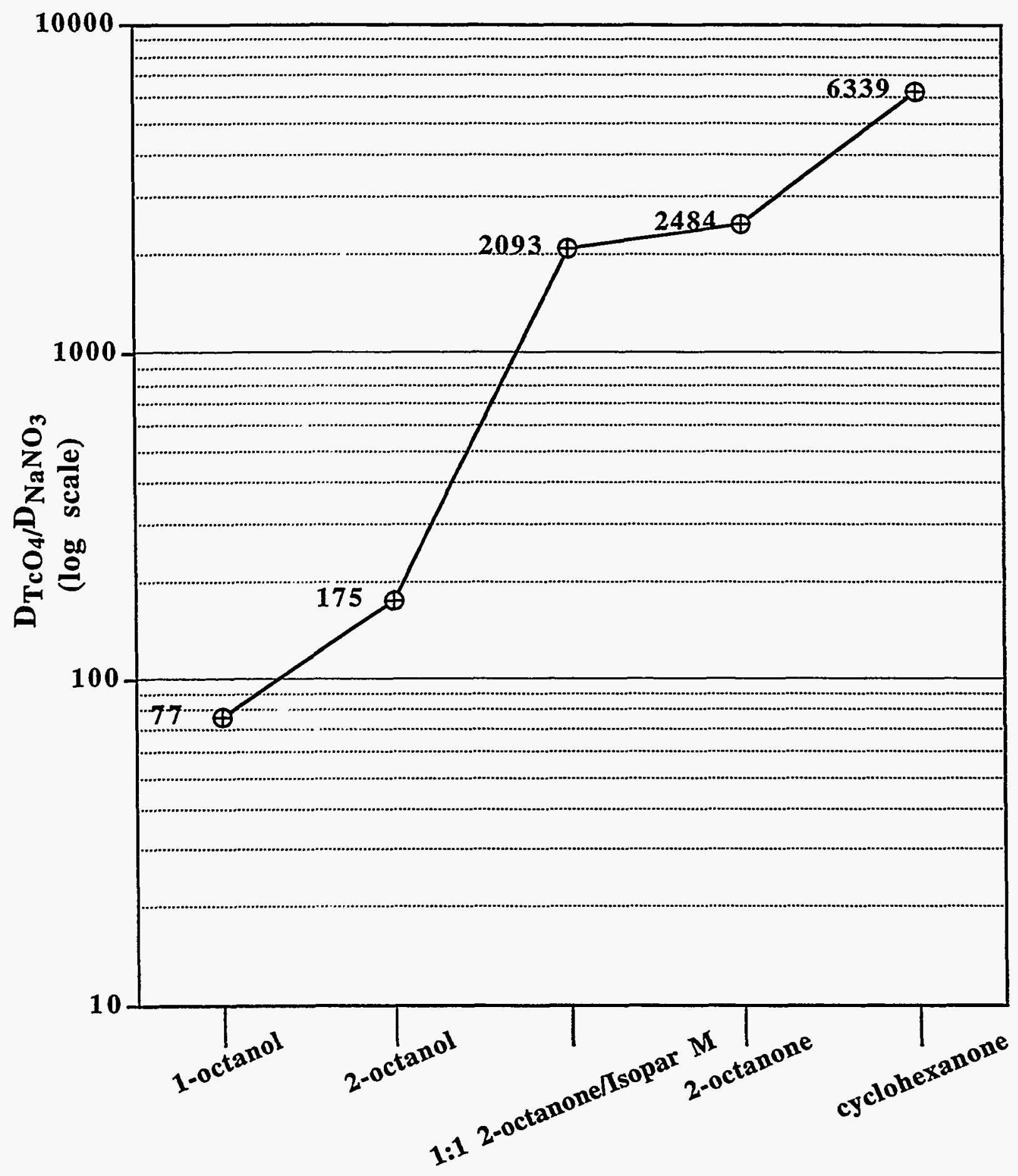

Diluent or Diluent Blend

Fig. 3.3. Pertechnetate/nitrate selectivity $\left(\mathrm{D}_{\mathrm{NaTcO}_{4}} / \mathrm{D}_{\mathrm{NaNO}_{3}}\right)$ for extraction by DCH18C6 (0.10 $\mathrm{M})$ in various diluents. 




Diluent or JDiluent Blend

Fig. 3.4. Extraction of sodium pertechnetate and nitrate by DCH18C6 $(0.10 \mathrm{M})$ in various diluents (corrected for diluent). 


\subsubsection{Performance of Selected Synthetic and Commercial Crown Ethers in}

\section{Various Waste Simulants (Simple, NCAW, and DSSF-7)}

Commercially Available Crown Ethers. As was seen in Fig. 2.3, the best three commercially available crown ethers with regard to technetium extraction efficiency from $5.0 \mathrm{M}$ $\mathrm{NaNO}_{3}, 0.10 \mathrm{M} \mathrm{NaOH}$ (the "Simple Simulant") were, in descending order, DCH18C6, 4-t$\mathrm{BuCH} 15 \mathrm{C} 5$, and DCH21C7. These crowns, along with a better lot of di-t-BuCH18C6 (see Sect. 2.2.1), were screened for extraction and stripping performance from the "simple simulant" as well as the two Hanford simulants (see Table 3.1). Since good extraction and stripping results were observed using DCH18C6 at $0.1 \mathrm{M}$ on a $1: 1 \mathrm{vol} / \mathrm{vol}$ blend of 2-octanone and Isopar ${ }^{\circledR} \mathrm{M}$, the crown ethers were all dissolved in a 2:1 vol/vol blend of of 2-octanone/Isopar ${ }^{\circledR} \mathrm{M}$ at a concentration of $0.04 \mathrm{M}$, to test whether good extraction performance could be achieved with lower crown ether concentration by increasing the amount of 2-octanone. The results are shown in Fig. 3.5. The extraction (distribution) ratio, as was stated above, is the average of is the average of duplicate runs of the first and second contacts. Generally, the agreement in the extraction ratios $E_{1}$ and $E_{2}$ between contacts was excellent, though some variability was observed for $\mathrm{DCH} 18 \mathrm{C} 6$, and to a lesser degree, for di-t-BuCH18C6, during extraction from the DSSF-7 simulant. As can be seen, the best extraction results were obtained using DCH18C6, followed by the better lot of di$\mathrm{t}$-BuCH18C6. The extraction of Tc from the simple simulant by DCH18C6 was 2.47 here, representing a small decrease relative to that shown in Table 3.2 for the crown was at $0.10 \mathrm{M}$ in 1:1 2-octanone//sopar ${ }^{\circledR} \mathrm{M}\left(\mathrm{D}_{\mathrm{Tc}}=3.42\right)$. Thus, good extraction performance could be achieved with lower crown ether concentration by increasing the amount of 2-octanone. The dramatic increase in the technetium extraction ratio observed for these two crown ethers on progressing from the "simple" to NCAW to DSSF-7 simulants can likely be attributed to the progressive increase in the concentration of potassium in these simulants and to the fact that the 18-crown- 6 family of crown ethers has a higher affinity for potassium than sodium. 5 In two contacts, it was possible to extract $98.4 \%$ and $97.6 \%$ of the pertechnetate present in the NCAW simulant with DCH18C6 and di-t-BuCH18C6, respectively. Similarly, $99.7 \%$ and $99.3 \%$, respectively, of the pertechnetate present in the DSSF-7 simulant could be removed. It is worth noting that these high efficiencies for Tc extraction occur despite nitrate/pertechnetate concentration ratios of 27,800 to 1 for the NCAW simulant, and 58,700 to 1 for the DSSF-7 simulant.

Contacting the pertechnetate-containing organic phases twice with deionized water in effect removes nearly all of the technetium and regenerates the extractant. Figure 3.6 shows the percent technetium remaining in the organic phase after just one contact with water and after the second contact with water. In general (but not always), it was noted by comparison with Fig. 3.5 that for a given crown ether stripping efficiency varied inversely with extraction efficiency. Nearly $64 \%$ of the technetium present in the organic solution containing DCH18C6 (after extraction from DSSF-7 
Technetium Distribution Ratio (uncorrected for diluent)
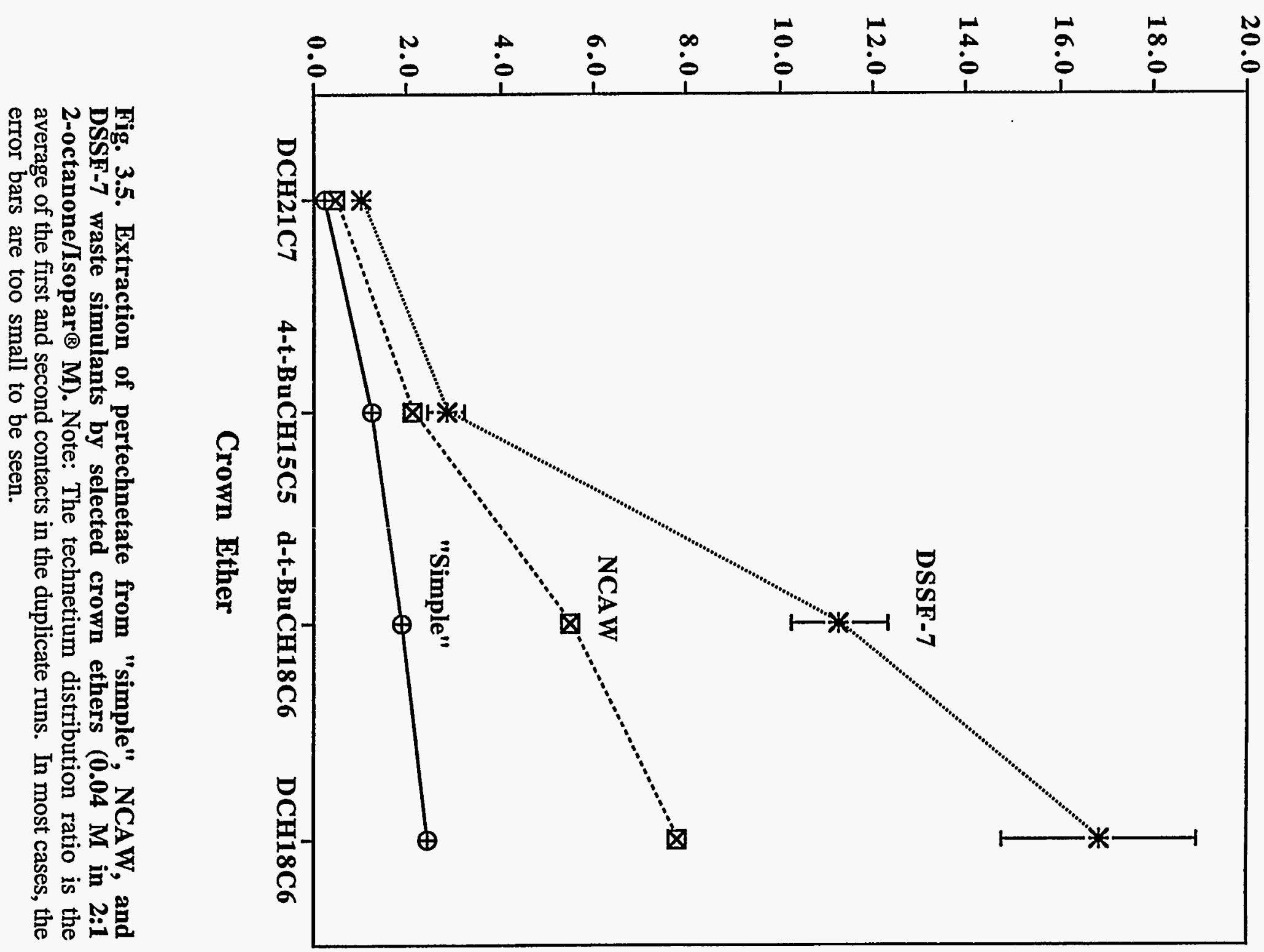

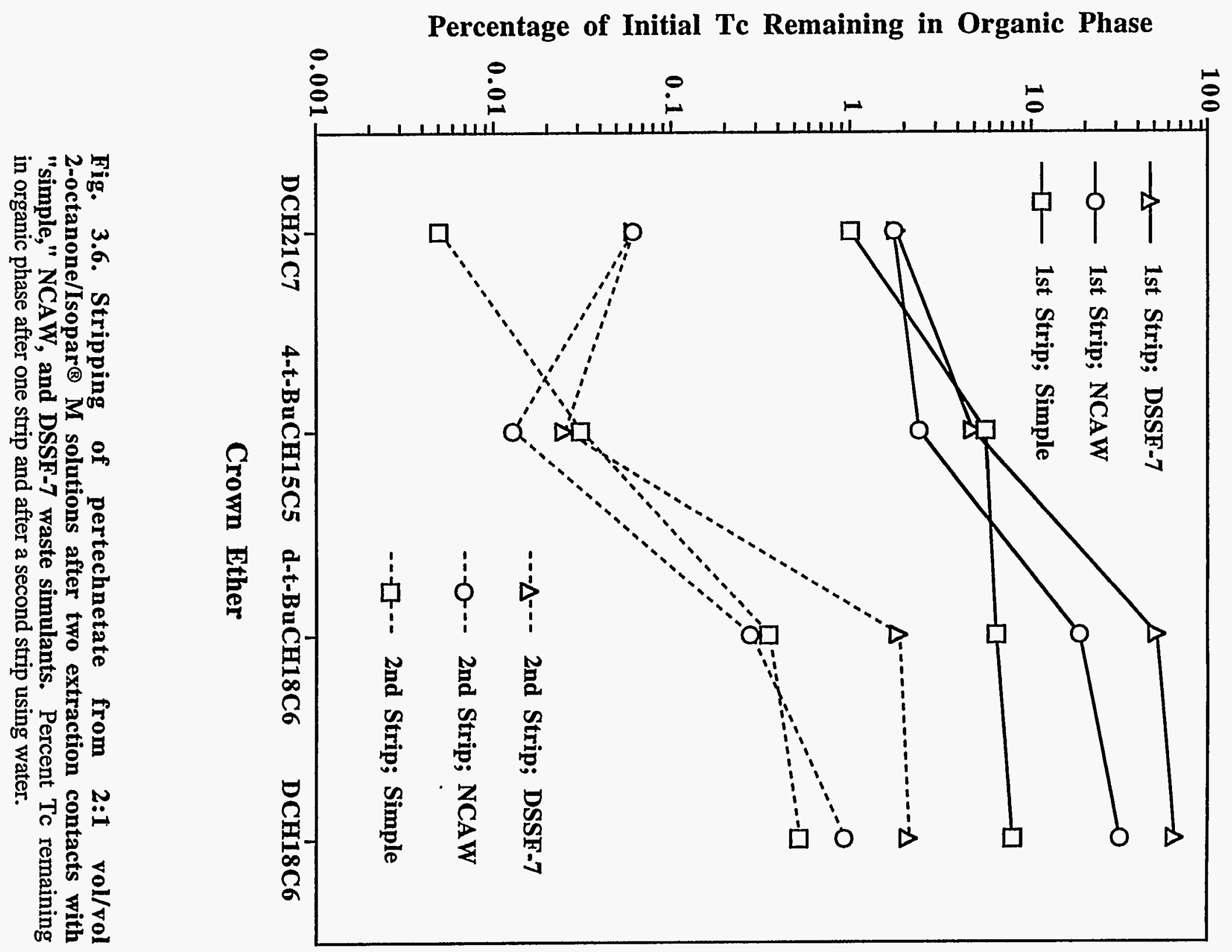
simulant) remained after the first stripping contact. However, technetium removal is more complete on the second stripping contact with deionized water (presumably due to the now lowered cationic content of the organic phase), resulting in only $2.1 \%$ technetium remaining in this organic phase after the second contact. In principle, $\geq 99 \%$ stripping efficiency is achievable by a third water contact, even for the strongly extracting systems. It should be noted that cross-current stripping with fresh water each time will likely result in more efficient stripping, but it will use more water than a counter-current stripping process in which the water is recycled. In a countercurrent process, the water could be recycled until the sodium and potassium concentrations become too large for efficient stripping to occur; portions of the stripping water would be discharged, and "reinfused" with water of low sodium and potassium concentations.

ORNL-Synthesized Crown Ethers. Three commercially unavailable dibenzo-14-crown-4 ethers (crowns 1-3 in Fig. 3.1) synthesized in these laboratories as a part of this work ${ }^{1}$ were also tested (all $0.04 \mathrm{M}$ in a 2:1 vol/vol blend of 2-octanone//sopar ${ }^{\circledR} \mathrm{M}$ ) for pertechnetate extraction and stripping efficiency. Because of limited supply, they were only tested on the "simple" and DSSF-7 waste simulants. The extraction and stripping results for three synthetic crown ethers are presented in Table 3.4, along with the comparable data for the four commercial crown ethers previously shown in Figs. 3.5 and 3.6. As was seen previously, BOB-14C4-diol was competitive with these four commercial crowns. However, the mono-methoxy and di-methoxy derivatives of BOB14C4-diol proved to be much weaker extractants.

The best overall performance (best balance of extraction and stripping) from DSSF-7 waste simulant was afforded by di-t-BuCH18C6, with DCH18C6 as a close second. The presence of potassium in the waste simulants allows a greater overall alkali metal loading to occur for the $18 \mathrm{C} 6 \mathrm{~s}$, as they are good sodium ion and excellent potassium ion complexants. 5 The former crown ether also has the advantage of being considerably more lipophilic than DCH18C6, thus reducing losses to the aqueous phase. However, di-t-BuCH18C6 has the disadvantage of being about ten times more expensive than $\mathrm{DCH} 18 \mathrm{C} 6$ (due to the greater number of isomers possible, it is more difficult to prepare material of good and uniform quality).

Interestingly, the pertechnetate/nitrate selectivity was found to be about the same (2000:1) for both (MeO) ${ }_{2} \mathrm{BOB}-14 \mathrm{C} 4$ and $\mathrm{DCH} 18 \mathrm{C} 6$ under high sodium loading conditions. BOB-14C4diol (crown 1 in Fig. 3.1) has the ability to form hydrogen bonds with nitrate and pertechnetate and is thus a stronger anion extractor, but it is less pertechnetate selective (pertechnetate/nitrate selectivity only 600:1 under high sodium-loading conditions). ${ }^{1}$ To improve extractive strength while maintaining high selectivity, it would be necessary to attach a substituent with a "larger reach" (and perhaps more electron donor atoms) to the BOB-14C4 platform, while avoiding the use of substituents containing hydrogen-bond donors (e.g., alcohols). 
Table 3.4. Solvent extraction of pertechnetate from "simple" and

DSSF-7 simulants, and stripping efficiency for selected synthetic and commercial crown ethers ${ }^{a}$

\% Extracted / \% Stripped

\begin{tabular}{|c|c|c|}
\hline Crown Ether & Simple Simulant & DSSF-7 Simulant \\
\hline $\begin{array}{c}\text { MeOBOB14C4 } \\
\text { (ORNL-Synthesized) }\end{array}$ & $11.76 / 99.35$ & $21.10 / \geq 99.99$ \\
\hline $\begin{array}{l}(\mathrm{MeO})_{2} \mathrm{BOB14C4} \\
\text { (ORNL-Synthesized) }\end{array}$ & $50.91 / 99.99$ & $68.48 / 99.98$ \\
\hline $\begin{array}{l}\text { DCH21C7 } \\
\text { (Commercial) }\end{array}$ & $33.04 / \geq 99.99$ & $75.60 / 99.94$ \\
\hline $\begin{array}{c}\text { BOB-14C4-diol } \\
\text { (ORNL-Synthesized) }\end{array}$ & $73.40 / \geq 99.99$ & $86.38 / 99.88$ \\
\hline $\begin{array}{c}\text { 4-t-BuCH15C5 } \\
\text { (Commercial) }\end{array}$ & $80.15 / 99.97$ & $93.17 / 99.98$ \\
\hline $\begin{array}{l}\text { DCH18C6 } \\
\text { (Commercial) }\end{array}$ & $91.67 / 99.48$ & $99.68 / 97.89$ \\
\hline $\begin{array}{c}\text { di-t-BuCH18C6 } \\
\text { (Commercial) }\end{array}$ & $87.95 / 99.65$ & $99.33 / 98.15$ \\
\hline
\end{tabular}

aConditions: crown ether concentration $=0.04 \mathrm{M}$; diluent blend $=2: 1 \mathrm{vol} / \mathrm{vol} \mathrm{2-}$ octanone/Isopar ${ }^{\circledR} \mathrm{M} ; 25^{\circ} \mathrm{C}, 1: 1$ phase ratio, $1 \mathrm{~h}$ contacts; two extraction steps, two stripping steps.

It was theorized that incorporating a ketone moiety into the BOB-14C4 platform might improve the extractive strength of the crown. Crown ether cis-BOB-14C4-bis(oxyacetone) (4) is a cousin of crown ether 2 , where acetone groups have replaced the methyl groups. The two additional donor atoms (carbonyl oxygens) appeared to significantly improve the extractive strength (and perhaps selectivity), as the Tc distribution coefficient (0.04 M CE in 2:1 2octanone/Isopar ${ }^{\circledR} \mathrm{M}$ ) increased from $11.28 \pm 1.05$ and $16.84 \pm 2.09$ for di-t-BuCH18C6 or DCH18C6, respectively, to $29.41 \pm 3.71$ for cis-BOB14C4-bis(oxyacetone). However, although this crown ether can be prepared by a number of different routes, we have not been able to avoid an undesirable column purification. Upon subsequent preparation of other lots by different routes, 
and upon improved purification, it was discovered that pure 4 performed less well than di-tBuCH18C6 (see Sect. 3.3.6 for a comparison of three lots of cis-BOB14C4-bis(oxyacetone) with di-t-BuCH18C6). Thus, the outstanding extraction and stripping performance afforded by the first lot of cis-BOB-14C4-bis(oxyacetone) may be due to an as yet undiscovered impurity, or derivative/intermediate, of 4 that formed during the synthesis or purification.

\subsubsection{Extraction/Stripping Cycling of Selected Systems}

The initial extraction and stripping studies employed two extraction steps followed by two stripping steps. It was of interest to examine extraction efficiency upon repeated cycles, and specifically to determine if the extraction efficiency of a stripped solution remained the same as it was on initial extraction. Thus, the two-extraction/two-strip experiment was conducted in the usual manner, but the stripped organic solution was then recovered and used in a second twoextraction/two-strip cycle (using fresh DSSF-7 simulant feed and fresh water for stripping). The cycle was repeated once more, for a total of three cycles. Whereas this solvent-recycle procedure does not mimic a continuous counter-current process, it would reveal whether the decontamination factors (DF) were stable during two solvent recycles. The tests were conducted with DCH18C6 and di-t-BuCH18C6 at $0.04 \mathrm{M}$ in 1:1 2-octanone/Isopar ${ }^{\circledR} \mathrm{M}$. The results (Table 3.5) show that although DCH18C6 initially performs better than di-t-BuCH18C6 (as expected), its performance drops upon solvent recycle, likely due to losses to the aqueous phase, most of which probably occurs during the stripping steps. In contrast, the decontamination factors for di-t-BuCH18C6 are quite stable, and the stripping factors are generally higher (a stripping factor of 1000 means $99.9 \%$ stripped, thus in every case there is $<0.1 \%$ carry-over of T'c into the following cycle). It follows that di-t-BuCH18C6 represents the more appropriate crown ether for an industrial process. Whereas the capital cost of the material would be higher than that of DCH18C6, the replacement cost during operation would likely be much lower, since the addition of eight carbons to DCH18C6 is expected to decrease the loss of the crown ether to the aqueous phase by approximately four orders of magnitude. The main mechanism for loss of di-t-BuCH18C6 would likely be due to entrainment of small droplets of solvent in the aqueous phase.

\subsubsection{Evaluation of Other Stripping Methods}

The ability to economically remove (strip) the pertechnetate from the extractant and thus regenerate the solvent represents a major advantage of crown ethers in tank-waste remediation. In our routine experiments, the loaded organic phase is stripped a first time by contact with deionized water and then a second time by recontact of the organic phase with a fresh supply of deionized 


\section{Table 3.5. Pertechnetate extraction from DSSF-7 simulant and stripping over three cycles using DCH18C6 and di-t-BuCH18C6}

\begin{tabular}{|c|c|c|c|c|}
\hline System & Cycle & $\mathbf{D F}\left(\right.$ each cycle) ${ }^{\mathbf{a}}$ & DF (each contact) $)^{\mathbf{b}}$ & Strip Ratioc \\
\hline DCH18C6 & 1 & $71.9 \pm 0.1$ & 8.47 & $1450 \pm 170$ \\
\hline $0.04 \mathrm{M}$ in $1: 1$ & 2 & $66.8 \pm 0.1$ & 8.18 & $2880 \pm 410$ \\
\hline 2-octanone / Isopar ${ }^{\circledR} \mathrm{M}$ & 3 & $50.8 \pm 0.3$ & 7.13 & $3180 \pm 380$ \\
\hline di-t-BuCH18C6 & 1 & $49.3 \pm 1.4$ & 7.02 & $2960 \pm 690$ \\
\hline $0.04 \mathrm{M}$ in $1: 1$ & 2 & $48.9 \pm 0.1$ & 6.99 & $5000 \pm 110$ \\
\hline 2-octanone / Isopar ${ }^{\circledR} \mathrm{M}$ & 3 & $50.7 \pm 0.1$ & 7.12 & $2220 \pm 510$ \\
\hline
\end{tabular}

aDecontamination factor after two contacts, calculated as the Tc activity per unit volume in the DSSF-7 feed divided by the Tc activity per unit volume in the aqueous raffinate after the second contact.

bDecontamination factor per contact $=$ square root of $\mathrm{DF}$ per two-contact cycle.

${ }^{c}$ After two contacts. Calculated as the Tc activity per unit volume in the organic phase prior to stripping divided by the Tc activity per unit volume in the organic phase after the second stripping contact.

water. As was mentioned above in Sect. 3.3.2, the first stripping ratio is generally lower than the second, since the concentration of dissolved salts (both complexed and uncomplexed by the crown ether) in the organic phase is higher prior to the first strip than the second. In a process, it will be desirable to recycle as much of the stripping water as possible. It was therefore of interest to determine how the overall stripping efficiency would be affected by using stripping phases that contained various dissolved ions. Table 3.6 illustrates the effect on stripping efficiency when the loaded organic solution (0.04 M DCH18C6 in 2:1 2-octanone/Isopar $® \mathrm{M}$; average $\mathrm{D}_{\mathrm{Tc}}=7.82 \pm$ 0.46 from NCAW) was stripped with aqueous solutions containing either potassium nitrate, sodium nitrate, sodium perchlorate, or magnesium sulfate (all at $0.10 \mathrm{M}$ ionic strength), along with ORNL process water and deionized water for comparison. For both deionized water and tap water the second stripping ratio is more than an order of magnitude greater than the first. As was discussed in Sect. 1.2, the stripping reaction (Eq. 2) is simply a reversal of the equilibrium forces driving the crown ether to complex the alkali metal ion. During extraction, the very high concentration of alkali metal ions drives the reaction toward formation of the CE-alkali metal complex. To dissociate this complex, the stripping phase needs to be as low in extractable cations as possible. As shown in Table 3.6, the presence of potassium or sodium nitrate in the stripping phase impairs stripping, much more so for potassium, since potassium is complexed more strongly than sodium by $\mathrm{DCH} 18 \mathrm{C} 6.5$ Stripping using sodium perchlorate appears to be effective, but it 
Table 3.6 Stripping efficiency as a function of dissolved salts in stripping phase: Comparison to deionized water. Ascending total \% Tc stripped

\begin{tabular}{ccccc}
\hline $\begin{array}{c}\text { Stripping } \\
\text { Phase }\end{array}$ & $\begin{array}{c}\text { Ionic } \\
\text { Strength }\end{array}$ & $\begin{array}{c}\text { 1st Strip } \\
\text { Ratio }\end{array}$ & $\begin{array}{c}\text { 2nd Strip } \\
\text { Ratio }\end{array}$ & $\begin{array}{c}\text { Total \% Tc } \\
\text { Strippeda }\end{array}$ \\
\hline $0.10 \mathrm{M} \mathrm{KNO}_{3}$ & 0.10 & 0.18 & 0.25 & 32.0 \\
$0.10 \mathrm{M} \mathrm{NaNO}_{3}$ & 0.10 & 1.98 & 3.63 & 92.8 \\
$0.10 \mathrm{M} \mathrm{NaClO}_{4}$ & 0.10 & 6.93 & 8.57 & 98.7 \\
Process Water & $<0.05$ & 1.87 & 18.6 & 98.2 \\
Deionized water & 0.00 & 2.56 & 39.6 & 99.3 \\
$0.025 \mathrm{M} \mathrm{MgSO}_{4}$ & 0.10 & 2.46 & 44.2 & 99.4 \\
\hline
\end{tabular}

a From the loaded organic phase following two cross-current stripping steps employing the stripping phase indicated. Strip ratios $\left([\mathrm{Tc}]_{\text {aq }} /[\mathrm{Tc}]_{\text {org }}\right.$ ) are recorded above for each stripping contact. The loaded organic phase was prepared by contacting the NCAW simulant twice crosscurrently with $0.04 \mathrm{M} \mathrm{DCH} 18 \mathrm{C} 6$ in $2: 1 \mathrm{vol} / \mathrm{vol} 2$-octanone / Isopar ${ }^{\circledR} \mathrm{M}$ (each contact $1 \mathrm{~h}, 25^{\circ} \mathrm{C}$, $1: 1$ phase ratios). The average $\mathrm{D}_{\mathrm{Tc}}$ for the extraction contacts was $7.82 \pm 0.46$.

should be noted that perchlorate is an extractable anion (almost as extractable as pertechnetate) and that here the pertechnetate is probably being exchanged by the perchlorate. Thus, little true stripping probably occurs, simply ion-exchange, and the organic solution would be largely ineffective for subsequent pertechnetate extraction.

The use of magnesium sulfate demonstrates how the presence of both non-extractable anions and non-complexable cations in the strip solution may be beneficial. Owing to its small size (ionic radius about half that of potassium), the magnesium dication is only very weakly complexed by DCH18C6. A strip solution containing $\mathrm{MgSO}_{4}(0.025 \mathrm{M}, \mu=0.10)$ gave stripping ratios on a par with deionized water (second strip slightly better). Using a strip solution containing $\mathrm{MgSO}_{4}$ has the additional benefit (over deionized water) of improving phase disengagement, due to the higher ionic strength. It is known that addition of an "inert" salt A to a sparingly soluble salt B (where the inert salt $A$ does not react with any of the components of the salt $B$ ) increases the solubility of salt $\mathrm{B}, 6$ and a similar mechanism may be operating here. The presence of $\mathrm{MgSO}_{4}$ does not interfere with the CE-alkali metal-pertechnetate equilibrium but rather increases the "ionic atmosphere", 6 leading to a decrease in the attraction between any particular cation and anion (lowers the ionic activity of the pertechnetate in the stripping phase). This may facilitate both the 
dissociation of the CE-alkali metal-pertechnetate complex and the transfer of alkali metalpertechnetate to the aqueous stripping phase.

\subsubsection{Effect of Diluent on Solvent Selection}

The nature of the diluent, briefly discussed in Sects. 2.3.3 and 3.3.1, has a profound effect on both the Tc extraction and stripping efficiencies. For a plant-scale process, there are certain requirements that an ideal diluent (or modified diluent) should meet: low volatility and flash point $\geq 60{ }^{\circ} \mathrm{C}$ (the threshold below which solvents are deemed ignitable and thus RCRA hazardous); low toxicity; low solubility in water; high chemical stability; high radiation stability; good phase-disengagement behavior with low emulsion tendency; and good capability to solvate and extract the desired species. The ideal diluent should also possess a high resistance to chemical and radiolytic degradation, but at the very least any breakdown products that do form should not interfere with the process nor impart any hazards. Aliphatic kerosenes such as the those comprising the Isopar ${ }^{\circledR}$ and Norpar ${ }^{\circledR}$ line (Exxon Chemical) are excellent and economical diluents. However, due to their extremely low polarity they are often incapable of solvating the crown etheralkali metal-pertechnetate complex, let alone the crown ether extractant itself. It is therefore necessary to add a modifier possessing some degree of polarity to improve extraction power and promote solubility; the challenge is to select one which will not impart undesirable properties to the system. Another possibility is to design and synthesize a crown ether extractant that is soluble in the kerosene diluents and that possesses the proper balance of properties to successfully extract alkali-metal pertechnetates.

The ketone 2-octanone was an early candidate, due to its acceptable flashpoint of $145^{\circ} \mathrm{F}$, low toxicity, low water solubility, and relatively low cost $(\$ 10-11 / \mathrm{kg}$ in bulk). It performed generally quite well; however, it was noted that upon aging, hydroperoxides ${ }^{7}$ formed, which, while not having any noticable detrimental effect on the extraction efficiency, appeared to retard phase disengagement. Phase coalescence times for 2-octanone which tested positive for hydroperoxides were slower than those for 2-octanone which tested negative ( 2 min vs. immediate), and the aqueous phase acquired a slightly cloudy yellow-brown appearance after extraction with the impure 2-octanone as compared with the clear and near colorless condition of the pure 2-octanone after extraction. Thus, the impurity or its breakdown product from contact with the strongly basic aqueous phase appeared to transfer to the aqueous phase with a resultant increase in phase-disengagement time.

There is literature precedent for using trialkyl phosphates ${ }^{4}$ and pyridines ${ }^{4,8}$ as extractants for pertechnetate, and this formed a starting point for the selection of other candidate modifiers to add to the base aliphatic kerosene diluent. Some of the modifiers that we examined included 
tributyl phosphate 9 (TBP) and 4-(1-butylpentyl)pyridine (4-BPP). ${ }^{10}$ These modifiers both possess the desirable properties mentioned above; however, long-term chemical and radiation stabilities have not yet been determined. TBP has enjoyed a long history in solvent extraction in the nuclear industry, ${ }^{11}$ and 4-(1-butylpentyl)pyridine, while a bit exotic, has been investigated fairly extensively in Pakistan as an extractant for a variety of metals, ${ }^{12}$ including technetium. ${ }^{10} \mathrm{We}$ also examined octyl(phenyl)-N,N-diisobutyl-carbamoylmethylphosphine oxide (CMPO) (used in the TRUEX process) ${ }^{11}$ and the pyridine 2-(2-propoxyethyl)pyridine.

Table 3.7 lists 10 candidate systems using the crown ether di-t-BuCH18C6. The first strip ratio (1st $\mathrm{S}_{\mathrm{Tc}}$ ) is a good indicator of the differences in the strippability of each system, since this is performed when the organic phase is most loaded with electrolyte. After the second strip with fresh water, all systems are essentially completely stripped; the second stripping ratio is usually higher than the first due to the reduction in salt content of the organic phase. In fact, with the exception of system $A$, all systems show $\geq 99.9 \%$ technetium removal from the organic solution. In systems $A$ and $B$, the crown ether concentration was $0.04 \mathrm{M}$, and in systems $\mathrm{C}-\mathrm{J}$ the crown ether concentration was $0.02 \mathrm{M}$. The ketone 2-octanone was used as a modifier in systems $\mathrm{A}, \mathrm{E}$, and F; 4-(1-butylpentyl)pyridine was used in systems B-D; and 2-(2-propoxyethyl)pyridine was used in systems $\mathrm{G}$ and $\mathrm{H}$. For these modifiers, distribution ratios appeared to increase in the order 4-(1-butylpentyl)pyridine < 2-octanone < 2-(2-propoxyethyl)-pyridine, though some of them are the same within the experimental uncertainty. The use of Norpar ${ }^{\circledR} 12$ (systems D, F, and H) in place of Isopar ${ }^{\circledR} \mathrm{M}$ (systems $\mathrm{C}, \mathrm{E}$, and $\mathrm{G}$ ) resulted in a slightly decreased technetium distribution ratio but a slightly improved stripping ratio. In principle, the crown ether concentration and diluent blend can thus be tuned to provide the desired balance of extraction and stripping efficiencies. The background distribution ratios provided by any of these diluent blends themselves (without the crown ether) is less than $5 \times 10^{-2}$.

System I utilizes both TBP and CMPO, and system J utilizes only TBP (at $\sim 27$ vol\%) to modify Isopar ${ }^{\circledR}$ M. System I looks particularly promising; however, CMPO is fairly expensive, though not as expensive as di-t-BuCH18C6 $(\sim 2,200 / \mathrm{kg}$ vs. $\sim \$ 30,000 / \mathrm{kg}$, bulk pricing respectively). CMPO and TBP have recently been examined for the extraction of pertechnetate from nitric acid solutions ${ }^{13}$; for 1.4 M TBP and 0.2 M CMPO in dodecane, Tc distribution coefficients approached 8 at $0.5 \mathrm{M}$ nitric acid (no stripping experiments performed). Our results (shown here as system $\mathrm{K}$, with no crown ether) on the alkaline side using $0.8 \mathrm{M}$ TBP and $0.2 \mathrm{M}$ CMPO in Isopar ${ }^{\circledR} \mathrm{M}$ gave a Tc distribution coefficient of $1.21 \pm 0.03$ and a 1st stripping ratio of 91.6. Interestingly, TBP alone in Isopar ${ }^{\circledR} \mathrm{M}$ did show some extraction of pertechnetate (system L). The results obtained using TBP formed the basis of more detailed studies which will be discussed in Sect. 4. 
Table 3.7. Extraction of pertechnetate from DSSF-7 waste simulant by di-tBuCH18C6 in selected diluents. Stripping by back-extraction with water.a Two diluents with no crown ether for comparison

\begin{tabular}{|c|c|c|c|c|c|c|}
\hline System & {$[\mathrm{CE}]$} & Diluent $^{\mathbf{b}}$ & $\mathbf{D}_{\mathbf{T c}}$ & $\begin{array}{l}1 \mathrm{st} \\
\mathrm{S}_{\mathrm{Tc}}\end{array}$ & $\begin{array}{c}\% \\
\text { Extrc }\end{array}$ & $\begin{array}{c}\% \\
\text { Strip }\end{array}$ \\
\hline A & 0.04 & 2:1 2-octanone / Isopar ${ }^{\circledR} \mathrm{M}$ & $11.3 \pm 1.0$ & 1.0 & 99.3 & 98.2 . \\
\hline B & 0.04 & 1:1 4-(1-butylpentyl)pyridine//sopar ${ }^{\circledR} \mathrm{M}$ & $4.52 \pm 0.10$ & 20.1 & 96.7 & $\gg 99.9$ \\
\hline $\mathrm{C}$ & 0.02 & 1:1 4-(1-butylpentyl)pyridine/Isopar ${ }^{\circledR} \mathrm{M}$ & $2.04 \pm 0.02$ & 73.1 & 89.2 & $>99.9$ \\
\hline $\mathrm{D}$ & 0.02 & 1:1 4-(1-butylpentyl)pyridine/Norpar ${ }^{\circledR} 12$ & $1.57 \pm 0.03$ & 129 & 84.9 & $\gg 99.9$ \\
\hline $\mathrm{E}$ & 0.02 & 1:1 2-octanone//sopar ${ }^{\circledR} \mathrm{M}$ & $2.33 \pm 0.23$ & 28.3 & 91.0 & $\gg 99.9$ \\
\hline F & 0.02 & 1:1 2-octanone/Norpar ${ }^{\circledR} 12$ & $2.15 \pm 0.14$ & 32.9 & 89.9 & $\gg 99.9$ \\
\hline G & 0.02 & 1:1 2-(2-propoxyethyl)pyridine/Isopar ${ }^{\circledR} \mathrm{M}$ & $2.54 \pm 0.10$ & 7.6 & 92.0 & $>99.9$ \\
\hline $\mathrm{H}$ & 0.02 & 1:1 2-(2-propoxyethyl)pyridine/Norpar ${ }^{\circledR} 12$ & $2.15 \pm 0.09$ & 14.1 & 89.9 & $\gg>99.9$ \\
\hline I & 0.02 & $0.8 \mathrm{M} \mathrm{TBP}, 0.2 \mathrm{M}$ CMPO in Isopar ${ }^{\circledR} \mathrm{M}$ & $3.85 \pm 0.10$ & 27.2 & 95.7 & $>99.9$ \\
\hline $\mathrm{J}$ & 0.02 & $1.0 \mathrm{M} \mathrm{TBP}$ in Isopar ${ }^{\circledR} \mathrm{M}$ & $1.55 \pm 0.03$ & 66.6 & 84.6 & $>99.9$ \\
\hline $\mathrm{K}$ & None & $0.8 \mathrm{M}$ TBP, $0.2 \mathrm{M}$ CMPO in Isopar ${ }^{\circledR} \mathrm{M}$ & $1.21 \pm 0.03$ & 91.6 & 79.5 & $>99.9$ \\
\hline $\mathrm{L}$ & None & 1.0 M TBP in Isopar ${ }^{\circledR} \mathrm{M}$ & $0.14 \pm 0.00$ & 82.3 & 23.6 & 99.7 \\
\hline
\end{tabular}

a2 $25^{\circ} \mathrm{C}, 1: 1$ phase ratio, $1 \mathrm{~h}$ contacts.

bRatios are by volume.

'Two extraction steps, two stripping steps.

\subsubsection{Comparison of di-t-BuCH18C6 with cis-BOB14C4-bis(oxyacetone)}

As was discussed in Sect. 3.3.2, one synthetic crown ether, cis-BOB-14C4bis(oxyacetone), appeared to perform remarkably well, better than any other crown ether tested. The potential benefits of being able to use more powerful "designer" crown ethers include lowered crown ether concentrations and diminished losses to the aqueous phase (both leading to lower cost) as well as lowered modifier concentrations (leading to potentially higher selectivities and improved process performance due to improved phase disengagement and chemical and radiation stabilities). Efforts directed toward finding synthetically less demanding ways to prepare this material (and suitable analogs), so that it could be competitive with the best commercial crown ether di-t- 
BuCH18C6, led to the discovery that subsequent lots of material prepared by slightly different routes performed less well. The purity of the earlier lots was not as high as the purity of the later lot, suggesting the outstanding results first observed might be due to a an effective impurity. Table 3.8 shows extraction and stripping results for cis-BOB-14C4-bis(oxyacetone) (0.04 $\mathrm{M}$ in $1: 1$ $\mathrm{vol} / \mathrm{vol}$ 4-(1-butylpentyl)pyridine/Isopar ${ }^{\circledR} \mathrm{M}$ ) from DSSF-7 waste simulant, along with results for the trans isomer of BOB-14C4-bis(oxyacetone), di-t-BuCH18C6, and Aliquat ${ }^{\circledR} 336$ Nitrate for comparison.

Table 3.8. Extraction ${ }^{a}$ of pertechnetate from DSSF-7 waste simulant by various lots of BOB-14C4-Bis(oxyacetone) (di-t-BuCH18C6 and Aliquat ${ }^{\circledR} 336$ Nitrate also shown for comparison), and stripping by back-extraction with water.

\begin{tabular}{|c|c|c|c|c|}
\hline Extractanta & Lot & $\mathbf{D}_{\mathbf{T c}}$ & \% Extractedb & $\%$ Stripped \\
\hline cis-BOB14C4-bis(oxyacetone) & $\mathbf{1}$ (first synthesis) & $24.96 \pm 0.63$ & 99.8 & $>99.9$ \\
\hline cis-BOB14C4-bis(oxyacetone) & 2 (higher purity) & $9.74 \pm 0.28$ & 99.1 & 99.9 \\
\hline cis-BOB14C4-bis(oxyacetone) & 3 (highest purity) & $3.25 \pm 0.09$ & 94.5 & 99.5 \\
\hline trans-BOB14C4-bis(oxyacetone) & highest purity & $0.08 \pm 0.00$ & 13.6 & 99.8 \\
\hline di-t-BuCH18C6 & LBM & $4.52 \pm 0.10$ & 96.7 & $>>99.9$ \\
\hline Aliquat $^{\circledR} 336$ Nitrate & Aldrich as received & $58.0 \pm 2.4$ & $>99.9$ & 0.06 \\
\hline
\end{tabular}

aAll extractants were at $0.04 \mathrm{M}$ in 1:1 vol/vol 4-(1-butylpentyl)pyridine/Isopar ${ }^{\circledR} \mathrm{M}$.

bAfter two contacts.

As can be seen in Table 3.8, lot 3, which is the most pure, did not perform as well as di-tBuCH18C6. It would be of interest to reveal the nature of the remarkably effective impurity in lots 1 and 2. (This might be investigated under a basic research program). The trans isomer of BOB14C4-bis(oxyacetone), in which one of the oxyacetone arms is pointing away from the cavity (and thus would be unable to coordinate to the metal ion) did not perform as well as the cis isomer, as expected. The quaternary ammonium compound tricaprylmethyl-ammonium nitrate (Aliquat ${ }^{\circledR}$ $336 \mathrm{~N}$ ) exhibited outstanding extraction behavior (as was observed previously in Sect. 2.3.5). However, stripping using water was not possible, but instead would require the use of chemical reagents such as concentrated nitric acid. 14 


\subsubsection{The Effect of Temperature, Contact Time, and Tc Concentration}

All of our standard experiments were conducted in a temperature-controlled air box set to $25 \pm 1{ }^{\circ} \mathrm{C}$. However, as it is unlikely that the temperature would be a stable $25^{\circ} \mathrm{C}$ under "real world" process conditions, it was of interest to determine how the technetium distribution coefficient varied with temperature. A temperature study $\left(25,30\right.$, and $35^{\circ} \mathrm{C} ; 1$ hour contact time) performed using $0.04 \mathrm{M}$ di-t-BuCH18C6 in 1:1 4-(1-butylpentyl)pyridine/Isopar ${ }^{\circledR} \mathrm{M}$ and NCAW simulant, revealed that the $\mathrm{D}_{\mathrm{Tc}}$ varied inversely with temperature, decreasing from $2.22 \pm 0.02$ at $25^{\circ} \mathrm{C}$, to $1.02 \pm 0.01$ at $35^{\circ} \mathrm{C}$ (a $54 \%$ reduction). Figure 3.7 is a van't Hoff-type plot of the natural $\log (\mathrm{ln}) \mathrm{D}_{\mathrm{Tc}}$ vs. $1000 / \mathrm{T}$, where $\mathrm{D}_{\mathrm{Tc}}$ is related to $\mathrm{K}_{\mathrm{eq}}$ by a constant factor (and thus does not change the slope), and $\mathrm{T}$ is in Kelvins. The $\Delta H$ of the reaction calculated from the slope is -14.2 $\mathrm{kcal} / \mathrm{mol}$. This thermodynamic parameter is not unusual and is in fact quite similar to that observed for pertechnetate extraction by other processes, such as the extraction of pertechnetate from nitric acid by dihexyl-N,N-diethylcarbamoylphosphate ${ }^{15}(\Delta H=-13 \mathrm{kcal} / \mathrm{mol})$. However, this experiment does illustrate that the extraction process behaves as an exothermic reaction favoring the products and that higher temperatures will have a detrimental effect on the extraction efficiency for a given system. To achieve a set level of decontamination for a set number of contacts, either the temperature will need to be controlled, or the crown ether concentration would need to be varied depending on the temperature of the feed. In view of the expense of the solvent, some gain in process economics might be achieved by maintaining as low a temperature as mass-transfer, solubility, and energy considerations will allow.

A kinetics study was also performed using NCAW simulant and $0.04 \mathrm{M}$ di-t-BuCH18C6 in 1:1 4-(1-butylpentyl)pyridine/Isopar ${ }^{\circledR} \mathrm{M}$, and it was revealed that the extraction was $\geq 95 \%$ complete within 5 minutes (the shortest time interval that could be easily measured using our contacting procedures). Fast equilibrium is an important criterion for a process, and it appears that equilibrium for this pertechnetate extraction is reached quickly.

Finally, an experiment designed to investigate how and if the Tc distribution coefficient varies with $\mathrm{Tc}$ concentration was performed using $0.04 \mathrm{M}$ di-t-BuCH18C6 in 1:1 2octanone/Isopar ${ }^{\circledR} \mathrm{M}$ and DSSF-7 waste simulant (same system used in the cycling experiment shown in Table 3.5). A slight decrease in $\mathrm{D}_{\mathrm{Tc}}$ was observed as the pertechnetate concentration was increased from $6 \times 10^{-6} \mathrm{M}\left(\mathrm{D}_{\mathrm{Tc}}=7.13 \pm 0.11\right)$ to $6 \times 10^{-4} \mathrm{M}\left(\mathrm{D}_{\mathrm{Tc}}=5.87 \pm 0.16\right)$, while the crown ether concentration was held constant. Interestingly, the $D_{\mathrm{Tc}}$ was fairly stable for intermediate concentrations $\left(6.61 \pm 0.16\right.$ for $1.9 \times 10^{-5} \mathrm{M}, 6.40 \pm 0.13$ for $6 \times 10^{-5} \mathrm{M}$, and $6.53 \pm$ 0.13 for $1.9 \times 10^{-4} \mathrm{M}$, see Fig. 3.8). This concentration range is representative of the Tc concentrations believed to be present in most of the Hanford waste tanks. 


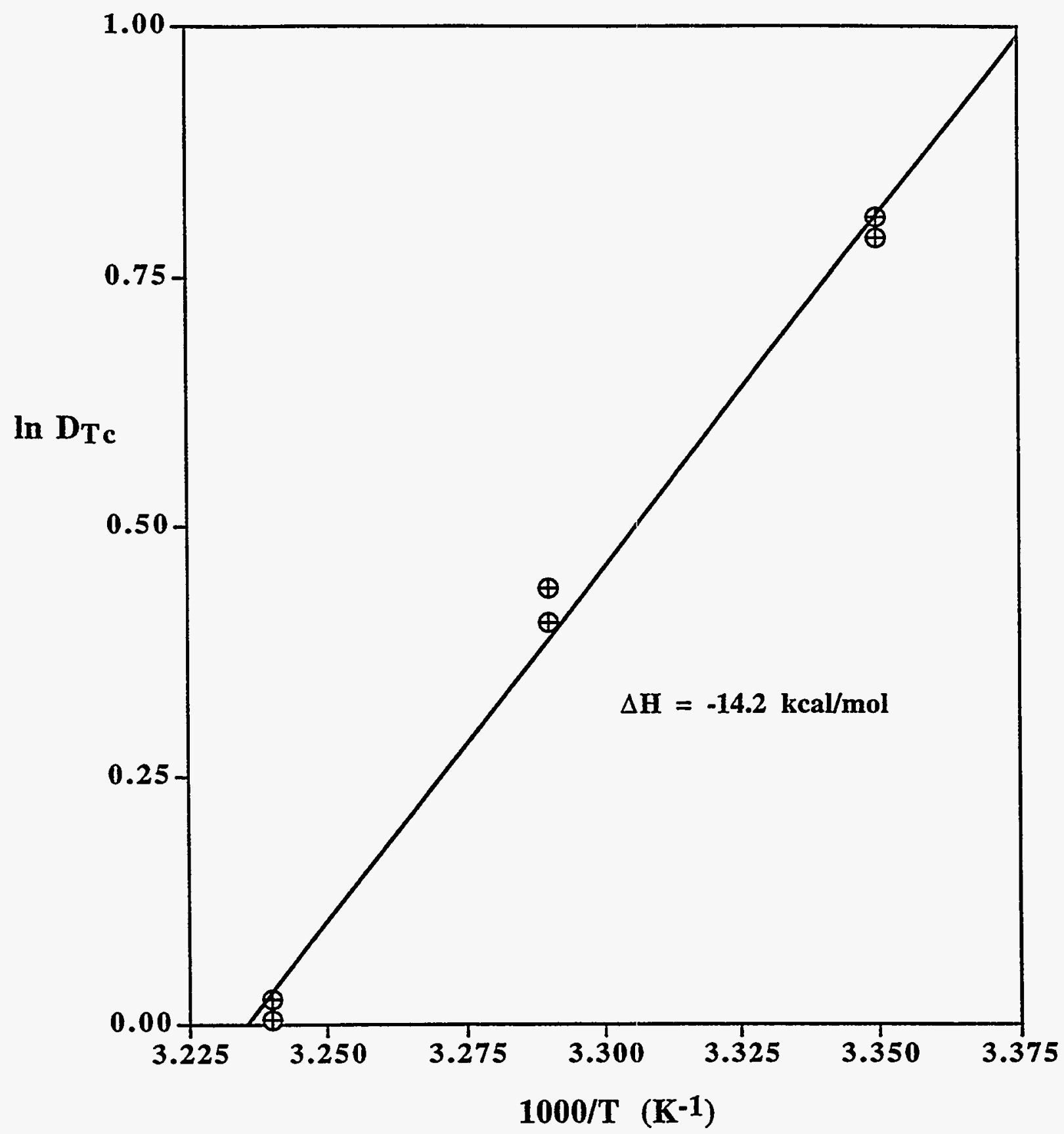

Fig. 3.7. Technetium distribution ratio as a function of temperature. Di-t-BuCH18C6 (0.04 M in 1:1 4-BPP/Isopar $\left.{ }^{\circledR} \mathrm{M}\right)$ from NCAW simulant. 




Fig. 3.8. Technetium distribution ratio as a function of Tc concentration. Di-t-BuCH18C6 (0.04 M in 1:1 2-octanone/Isopar $\left.{ }^{\circledR} M\right)$ from DSSF-7 simulant. 


\subsection{CONCLUSIONS}

From the work performed in FY 1994, we find that good extraction and stripping efficiency can be achieved using either DCH18C6 or di-t-BuCH18C6 in 2-octanone or 4-(1butylpentyl)pyridine modified isoparaffinic kerosene (Isopar ${ }^{\circledR} \mathrm{M}$ ). However, DCH18C6 partitions sufficiently to the aqueous phase for decreases in performance due to aqueous losses to be observed during recycle of the solvent. Hence, di-t-BuCH18C6, which is expected to partition four orders of magnitude less well to the aqueous phase than DCH18C6, is the more appropriate crown ether for the process. Several diluent/modifier systems using di-t-BuCH18C6 were identified which allow $\geq 95 \%$ of the Tc contained in a double-shell slurry feed waste simulant to be removed upon just two contacts and for $\geq 98 \%$ of the Tc contained in the solvent to be recovered upon two back-extractions (stripping) with water at relatively low crown ether concentrations (0.02-0.04 M).

Synthetic crown ether cis-sym-bis(tert-octylbenzo)-14-crown-4-bis(oxyacetone) (cisBOB14C4-bis(oxyacetone)) initially looked especially promising, but upon further refinement of the synthesis and purification, it was found to perform less well than di-t-BuCH18C6. The impurity which gave rise to the outstanding extraction and stripping behavior remains unknown.

Thermodynamics, concentration dependence, and kinetics studies revealed Tc extraction efficiency to vary inversely with temperature, to be approximately independent of the Tc concentration between 6 and $600 \mu \mathrm{M}( \pm 18 \%$ over entire range), and to reach equilibrium quickly (within 5 minutes using gentle agitation).

The following section describes work performed in FY 1995, which focused on exploring TBP as a modifier, narrowing the solvent candidates to a select few, and testing the candidates using waste simulants under more process-oriented conditions, as well as testing actual tank waste supernate.

\subsection{REFERENCES AND NOTES}

1. Armstrong, V.S.; Bonnesen, P.V.; Haverlock, T.J.; Moyer, B.A.; Sachleben, R.A. Unpublished results.

2. Kuruth, D.E.; Bray, L.A.; Brooks, K.P.; Brown, G.N.; Bryan, S.A.; Carlson, C.D.; Carson, K.J.; DesChane, J.R.; Elovich, R.J.; Kim, A.Y. "Experimental Data and Analysis to Support the Design of an Ion-Exchange Process for the Treatment of Hanford Tank Waste Supernatant Liquids", Pacific Northwest Laboratory report \#PNL-10187 (1994).

3. Schulz, W. W. In International Solvent Extraction Conference (ISEC '80); Liege, Belgium, 1980; paper \#108.

4. Boyd, G.E.; Larson, Q.V. J. Phys. Chem. 1960, 6, 988. 
5. Izatt, R.M.; Bradshaw, J.S.; Nielsen, S.A.; Lamb, J.D.; Christensen, J.J., Sen, D. Chem. Rev. 1985, 85, 271.

6. Harris, D.C. Quantitative Chemical Analysis, 2nd Ed., W.H. Freeman and Company: New York, 1987, pp 87-90.

7. It is not known for certain what the reducible impurity is, but older bottles of 2-octanone gave positive iodide and dichromate tests for hydroperoxides; newer bottles did not. Newer samples of 2-octanone behaved well.

8. Zaitsev, A.A.; Lebedev, I.A.; Pirozhkov, S.V.; Yakovlev, G.N. Sov. Radiochem. 1964, $6,428$.

9. Pruett, D.J.; McTaggart, D.R. Radiochim. Acta 1983, 34, 203.

10. Iqbal, M.; Ejaz, M. J. Radioanal. Chem. 1974, 23, 51.

11. See for example : Horwitz, E.P.; Kalina, D.G.; Diamond, H.; Vandegrift, G.F.; Schulz, W.W. Solvent Extr. Ion Exch. 1985, 3, 75.

12. See for example (a) Mohammad, D.; Mahmood, T.; Qureshi, M.A.; Ejaz, M. J. Radioanal. Chem. 1978, 42, 45, and references cited; (b) Bhatti, M.S.; Zuha, S.; Qureshi, M.A. J. Radioanal. Chem. 1984, 82, 45, and references cited therein.

13. Takeuchi, M.; Tanaka, S.; Yamawaki, M. Radiochimica Acta 1993, 63, 97-100.

14. Dyrkacz, G.R.; Vandegrift, G.F.; Thomsen, M.W.; Horwitz, E.P. J. Phys. Chem. 1979, 83,670 .

15. McIsaac, L.D. Separation Science and Technology. 1982, 17, 387-405. 


\section{DEVELOPMENT OF A PROCESS FLOWSHEET}

\subsection{INTRODUCTION}

In FY 1995, we sought to outline a basic process flowsheet for the extraction and stripping process. To this end, we narrowed the field of process-suitable solvents to a select few, we conducted extensive tests on both the extraction and stripping cycles using a realistic simulant for Melton Valley Storage Tank (MVST) W-29 supernate, we tested authentic MVST W-29 supernate, and we outlined a new "tandem" process cycle for Tc removal and concentration from tank waste. We considered many criteria, including the cost and availability of the crown ethers, diluents, and modifiers. Ultimately, it was the intention to supply the basis for a flowsheet that defined both the solvent cycle and the subsequent strip cycle. Options for the strip cycle include 1) simple evaporation of the strip solution and recycle of the condensed water or 2) anion exchange of the Tc from the strip solution and recycle of part or all of the resulting column effluent. TBP-modified kerosene was shown to perform well as a solvent for the preferred crown ether bis- $4,4^{\prime}\left(5^{\prime}\right)[($ tertbutyl)cyclohexano]-18-crown-6, and tests with actual MVST waste supernate support the more extensive tests with simulants of MVST and Hanford tank supernates. Realistic batch tests mimicking process solvent and stripping cycles prove the viability of a crown ether-based solvent extraction process for Tc removal from alkaline HLW tank supernate solutions. Engineering-scale testing is now needed.

\subsection{EXPERIMENTAL}

\subsubsection{Materials and Instrumentation}

Reagents. The crown ether bis-4,4'(5')[(tert-butyl)cyclohexano]-18-crown-6 was received from Eichrom Industries, Inc. (lot \#TT210; stated $\mathrm{D}_{\mathrm{Sr}}=3.9$ ) and was used without further purification. This material performed on average about $10 \%$ better than Parrish lots \#LBM and \#4VNH. As stated previously (c.f. Sect. 2.2.1) the performance varies with the isomer ratio. Bis-4,4' $\left(5^{\prime}\right)$ [(tert-butyl)cyclohexano]-18-crown-6 is the preferred crown ether for the SREX process, ${ }^{1}$ and thus the isomer ratio of material prepared by Eichrom is optimized to give the highest $\mathrm{D}_{\mathrm{Sr}}$ achievable. (An isomer ratio which leads to a higher $\mathrm{D}_{\mathrm{Sr}}$ would also likely lead to a higher distribution ratio for potassium and sodium). As mentioned previously, it is important to use the same batch, or batches of equivalent performance, when making comparisons; all experiments in this section employed crown from this lot. Tributyl phosphate (TBP) and 4-(1-butylpentyl)pyridine were used as received from Aldrich Chemical Company (97\% or better purity). Amberlite ${ }^{\circledR}$ IRA-904 anion exchange resin was obtained from Aldrich and was successively 
washed with $1 \mathrm{~N} \mathrm{NaOH}$, water, $1 \mathrm{~N} \mathrm{HCl}$, water, and then filtered to a moist solid, prior to use. All other diluents, modifiers and reagents were used as received without further purification or are described previously in Sects. 2.2.1 and 3.2.1 of this report. All diluent blends were prepared on a volume basis, unless otherwise noted.

Radionuclides. Technetium-99 as described in Sect. 2.2.1 was employed. Strontium-85 (strontium chloride in $0.1 \mathrm{M} \mathrm{HCl}$ ) was obtained from Isotope Products Laboratories, Burbank, CA.

Instrumentation. Beta-liquid scintillation counting of ${ }^{99} \mathrm{Tc}$ was performed using either a Packard Tricarb ${ }^{\circledR}$ Model 4530 or Tricarb ${ }^{\circledR}$ Model 2700TR counter and Packard Ultima Gold ${ }^{\mathrm{MM}}$ XR scintillation cocktail. Gamma counting of ${ }^{85} \mathrm{Sr}(514 \mathrm{keV})$ was performed using a 3-inch sodium iodide well-type detector connected to an Oxford Tennelec multichannel analyzer controlled by a Macintosh Quadra 700 computer. Analyses for sodium and potassium were performed using a Thermo Jarrell Ash IRIS/CID Inductively Coupled Argon Plasma (ICAP) spectrometer.

\subsubsection{Actual and Simulated Waste}

Waste and Waste Simulants. The Hanford waste simulant DSSF-7 was prepared as described in Sect. 3.2.2 and Table 3.1. Melton Valley Storage Tank W-29 (MVST W-29) simulant was prepared in our laboratories on the basis of an analysis obtained on actual MVST W29 supernatant solution (analytical reference \#IPA 7252). Table 4.1 compares the composition of the simulant with the actual waste. (A recipe for the preparation of our MVST W-29 simulant is given in Appendix A). Technetium-99 was added to the waste simulants during the last stage of preparation by spiking the simulant with the appropriate amount of $3.0 \mathrm{mM} \mathrm{NH}_{4}{ }^{99} \mathrm{TcO}_{4}$ to give the desired concentration of $6 \times 10^{-5} \mathrm{M}$. This Tc concentration was selected as a representative concentration for $\mathrm{Tc}$ in most Hanford tanks, though Melton Valley supernatant waste contains much lower concentrations. Strontium-85 was also added in tracer amounts where appropriate (usually 0.7 to $0.8 \mu \mathrm{Ci} / \mathrm{mL}$ ).

A sample of actual MVST W-29 filtered supernate was obtained from Jack Collins of the Chemical Technology Division at Oak Ridge. The waste was treated twice with Savannah River Rescorcinol-Formaldehyde Resin (SRR) to reduce the cesium-137 activity from $2.2 \times 10^{8} \mathrm{~Bq} / \mathrm{L}$ to $4.0 \times 10^{5} \mathrm{~Bq} / \mathrm{L}$. Although the SRR was washed five times with the cold simulant solution (matrix) to equilibrate the resin and to remove colored impurities, the resin was still brown in color and imparted a dark amber tint to the actual waste after treatment. 
Table 4.1. Composition of simulated MVST W-29 waste supernate, and comparison with actual waste

\begin{tabular}{|c|c|c|}
\hline \multirow[b]{2}{*}{ Species } & \multicolumn{2}{|c|}{ Concentration (M) } \\
\hline & Simulant & Actuala \\
\hline \multicolumn{3}{|l|}{ Metals } \\
\hline $\mathrm{Al}$ & $1.65 \times 10^{-5}$ & $1.65 \times 10^{-5}$ \\
\hline $\mathrm{Ba}$ & not added & $2.6 \times 10^{-6}$ \\
\hline $\mathrm{Ca}$ & $8.7 \times 10^{-5}$ & $8.7 \times 10^{-5}$ \\
\hline Cs (total) & $4.3 \times 10^{-6}$ & $4.3 \times 10^{-6}$ \\
\hline $\mathrm{Cr}^{\mathrm{b}}$ & $4.2 \times 10^{-5}$ & $4.2 \times 10^{-5}$ \\
\hline $\mathrm{Cu}$ & not added & $3.1 \times 10^{-6}$ \\
\hline $\mathrm{K}$ & $2.90 \times 10^{-1}$ & $2.90 \times 10^{-1}$ \\
\hline $\mathrm{Na}$ & 4.69 & 4.44 \\
\hline $\mathrm{Pb}$ & not added & $3.4 \times 10^{-5}$ \\
\hline Sr (total) & $1.1 \times 10^{-5}$ & $1.1 \times 10^{-5}$ \\
\hline Th & not added & $4.3 \times 10^{-7}$ \\
\hline $\mathrm{U}$ & not added & $5.5 \times 10^{-6}$ \\
\hline $\mathrm{Zn}$ & not added & $9.3 \times 10^{-4}$ \\
\hline \multicolumn{3}{|l|}{ Anions } \\
\hline $\mathrm{Br}^{-}$ & $6.3 \times 10^{-4}$ & $6.3 \times 10^{-4}$ \\
\hline $\mathrm{Cl}^{-}$ & $8.5 \times 10^{-2}$ & $8.5 \times 10^{-2}$ \\
\hline $\mathrm{F}^{-}$ & not added & $2.6 \times 10^{-4}$ \\
\hline $\mathrm{OH}^{-}$ & $1.58 \times 10^{-1}$ & $\mathrm{pH}=13.2$ \\
\hline $\mathrm{NO}_{2}^{-}$ & not added & not reported \\
\hline $\mathrm{NO}_{3}^{-}$ & 4.52 & 4.52 \\
\hline $\mathrm{CO}_{3}^{2-}$ & $1.00 \times 10^{-1}$ & See footnote c \\
\hline $\begin{array}{l}\mathrm{SO}_{4}^{2-} \\
\mathrm{PO}_{4}^{3-}\end{array}$ & $7.0 \times 10^{-3}$ & $\begin{array}{l}7.0 \times 10^{-3} \\
53 \times 10^{-4}\end{array}$ \\
\hline \multirow{2}{*}{\multicolumn{3}{|c|}{ Radionuclides }} \\
\hline & & \\
\hline $\begin{array}{l}\mathrm{Cs}^{134} \\
\mathrm{Cs}_{137}\end{array}$ & not added & $5.3 \times 10^{-10}$ \\
\hline $\mathrm{Cs}^{137}$ & not added & $5.1 \times 10^{-7}$ \\
\hline $\mathrm{Co}^{60}$ & not added & $1.6 \times 10^{-10}$ \\
\hline $\mathrm{Eu}^{154}$ & not added & $\mathrm{BDL}^{\mathrm{d}}$ \\
\hline $\mathrm{Sr}^{90}$ & not added & $5.3 \times 10^{-9}$ \\
\hline $\mathrm{Tc}^{99}$ & $6.0 \times 10^{-5}$ & $3.2 \times 10^{-7}$ \\
\hline
\end{tabular}

aAnalytical data for supernatant liquid of MVST W-29 (analysis \#IPA 7252) provided by Zane Egan and Jack Collins (Chemical Technology Division, ORNL).

bAdded in simulant as $\mathrm{CrO}_{4}^{2-}$.

${ }^{c} A$ carbonate concentration of $10 \mathrm{ppm}\left(2 \times 10^{-4} \mathrm{M}\right)$ was determined by titration. The simulant was prepared before this value was available.

dBelow detection limit. 


\subsubsection{Batch-Equilibrium Three-Stage Counter-Current Contacting Procedure}

To mimic a three-stage counter-current contacting procedure, the two-extraction, two-strip batch-equilibrium experiment described in Sect. 3.2.3 was modified. The procedures used for extraction and stripping are diagrammed in Figs. 4.1, and 4.2, respectively. Aliquots of both phases were removed at each contact (six contacts for extraction and six contacts for stripping) to determine the ${ }^{99} \mathrm{Tc}$ activity by LSC. The experiment was performed at $25^{\circ} \mathrm{C}$ using equal volumes of aqueous and organic phases as shown. The decontamination factor over the course of the three stages $\left(1,2\right.$, and 3 in Figure 4.1) was calculated as the ratio of ${ }^{99} \mathrm{Tc}$ in the feed entering stage 1 $\left(\mathrm{A}^{\prime \prime}{ }_{0}\right.$, where $\mathrm{A}_{0}=\mathrm{A}_{0}{ }_{0}=\mathrm{A}^{\prime \prime}{ }_{0}$ ) divided by the ${ }^{99} \mathrm{Tc}$ activity in the raffinate after stage $3\left(\mathrm{~A}_{3}\right)$. The stripping factor was calculated in the analogous manner by dividing the ${ }^{99} \mathrm{Tc}$ activity in the loaded organic entering stage $1\left(\mathrm{O}_{\mathrm{o}}^{\prime}\right)$ by the ${ }^{99} \mathrm{Tc}$ activity in the stripped organic exiting from stage 3 $\left(\mathrm{O}_{3}^{\prime}\right)$.

\subsubsection{Extraction/Stripping Cycling of Candidate Systems}

The final group of solvent candidates were subjected to a one-extraction, three-strip procedure in a manner similar to that described in Sect. 3.2.3, with the following additions and modifications. Following the single extraction contact, the organic phase was carried through three cross-current stripping stages (aliquots were analyzed for Tc content after each contact), and then saved. Aliquots of the aqueous phases for each strip following each stripping contact were additionally treated with Amberlite ${ }^{\circledR}$ IRA-904 anion exchange resin to remove pertechnetate (to < $10^{-10} \mathrm{M}$ ) and were then analyzed by ICAP spectrometry for sodium and potassium. The remaining aqueous stripping phases from the three strips were combined, analyzed for $\mathrm{Tc}$, and then passed through a $1.6 \mathrm{~cm}^{3}$ bed of resin (contained in a Kontes Economy Flex-Column of dimensions 1.0 $\mathrm{cm}$ I.D. by $10.0 \mathrm{~cm}$ long) at a flowrate of $1 \mathrm{~mL} / \mathrm{min}$ to remove Tc (to $<4 \times 10^{-9} \mathrm{M}$ ). Aliquots of the eluate were analyzed for Tc (LSC), and $\mathrm{Na}$ and $\mathrm{K}$ (ICAP). This procedure would complete one "cycle", which would include a set of Tc extraction and stripping ratios, together with $\mathrm{Na}$ and $\mathrm{K}$ concentration data for the stripping contacts. A second cycle using fresh aqueous feed (simulant) was then initiated, utilizing the stripped organic solvent from the previous cycle, along with the Tc depleted stripping solution as the stripping phase for the three cross-current strips. The general procedure is shown diagramatically in Fig. 4.3 below. This procedure was repeated for a total of four cycles, with the same resin column being employed throughout. At the end of the four cycles, the resin was treated with a solution containing stannous chloride (0.01 M), ethylenediamine $(0.10 \mathrm{M})$, and $\mathrm{NaOH}(1.0 \mathrm{M})$ to reduce, complex, and elute $\mathrm{Tc}$ from the resin in a manner described by N. C. Schroeder ${ }^{2}$ and coworkers at Los Alamos National Laboratory. 




Fig. 4.1. Contacting procedure for batch-equilibrium extraction to approach three-stage counter-current. Volumes $(\mathrm{mL})$ of each phase are listed as they enter each stage. The asterisk $\left(^{*}\right)$ denotes when samples were taken for analysis for $\mathrm{Tc}$ content.

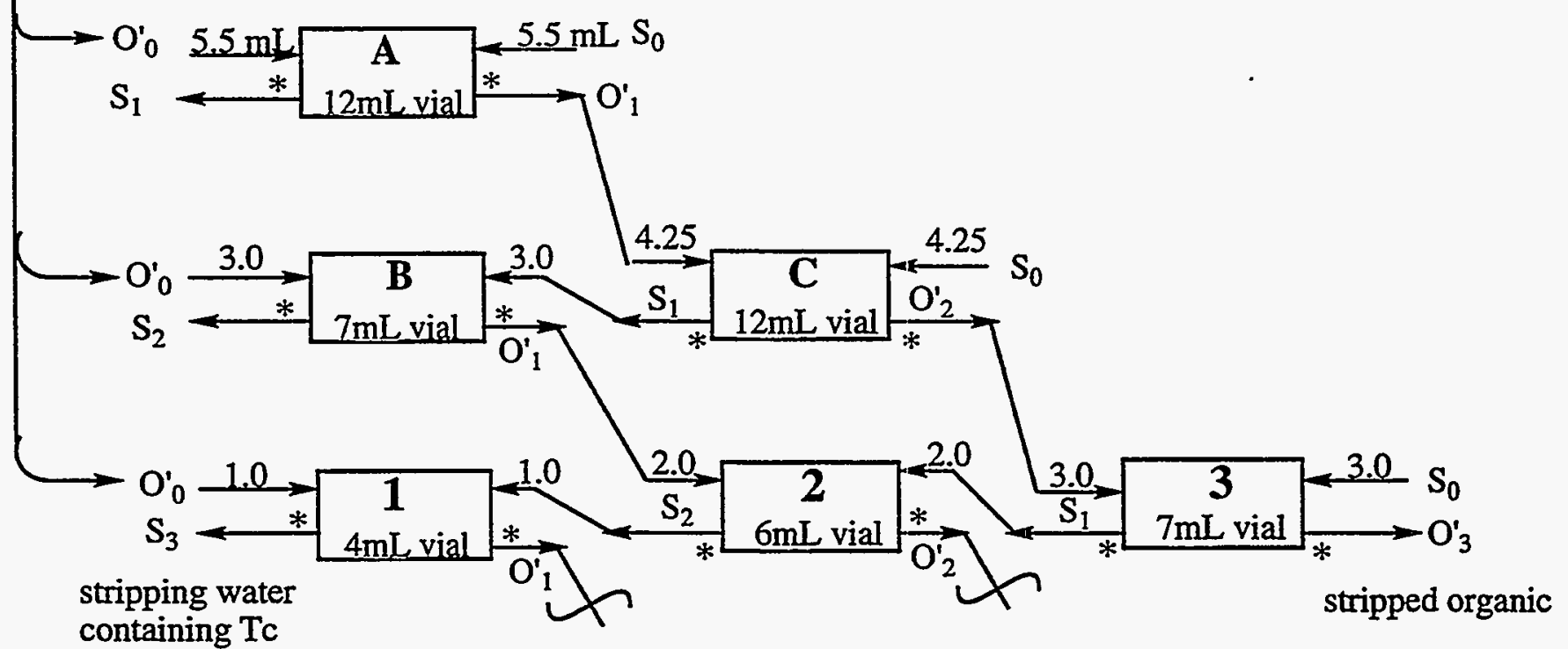

Fig. 4.2. Contacting procedure for batch-equilibrium stripping to approach three-stage counter-current. 
However, the regenerated resin was not used in these experiments, but instead a fresh bed of resin was used for each four-cycle experiment with a particular solvent.

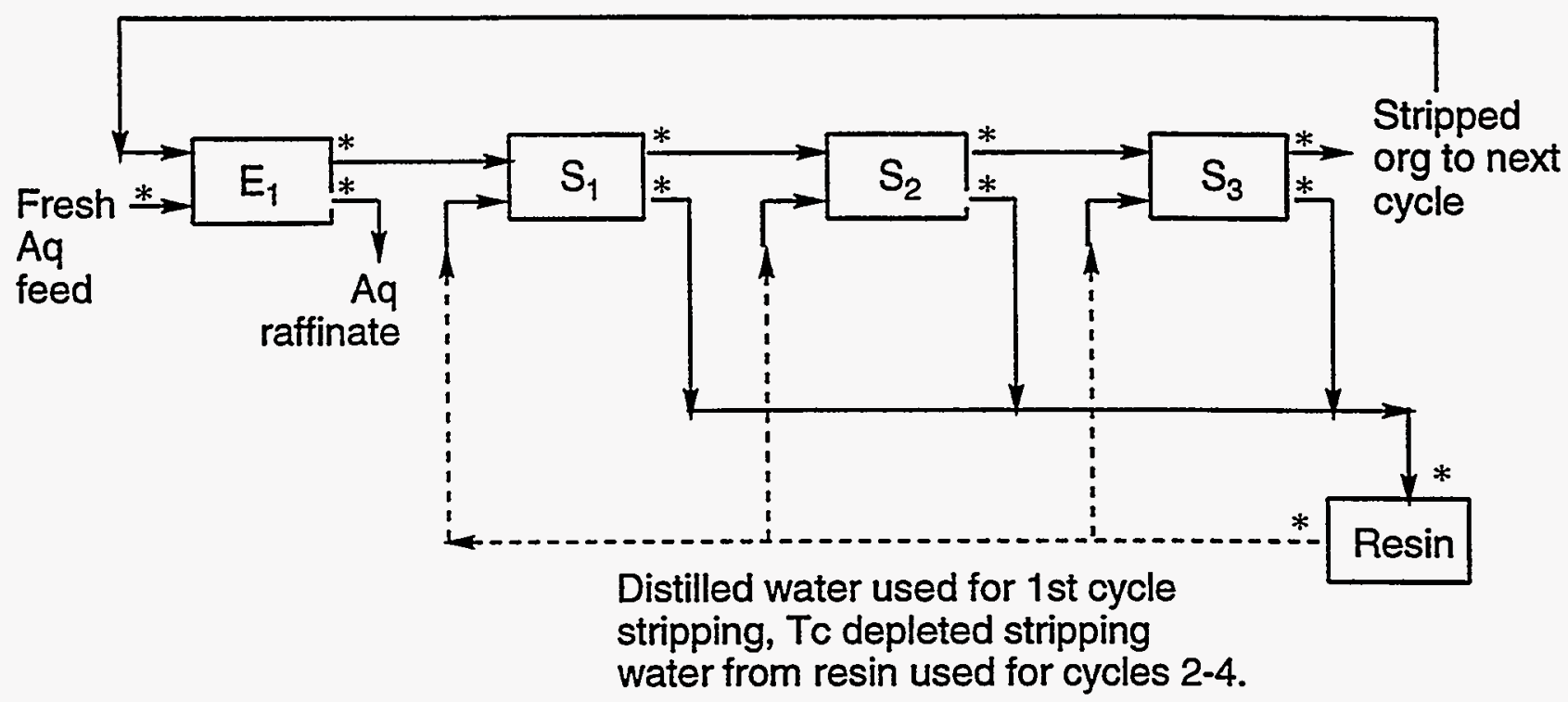

Fig. 4.3. Diagram of one-extraction, three-strip contacting procedure with solvent and stripping water recycle used to test the efficiency of the strip cycle. The first cycle employed pristine solvent and deionized water. The subsequent cycles (three additional) all employed solvent and stripping water recycled from the previous cycle. The asterisk $\left(^{*}\right)$ denotes where samples were taken for analysis for Tc content. This diagram forms a basis for a process flowsheet, which will be further described later in Sect. 4.3.5.

\subsection{RESULTS AND DISCUSSION}

\subsubsection{Selection of Final Candidate Solvents}

Continuing with work initiated in FY 1994, we screened for diluents and modified diluents that would provide the best extraction and stripping efficiency, while still being suitable for a process cycle. The requirements of an ideal diluent (or modified diluent) were described previously in Sect. 3.3.5. The two-extraction, two-strip cross-current contacting procedure described in Sect. 3.2.3 was employed. Since tributyl phosphate ${ }^{3}$ (TBP) looked especially promising as a modifier, we focused our investigation on it as well as on 4-(1-butylpentyl)pyridine (4-BPP). ${ }^{4}$ The ketone 2-octanone was not considered further due to its expense and its questionable long-term stability to radiation and base. (Concerns regarding 2-octanone's stability were initiated by the hydroperoxide problem encountered in earlier work - see Sect. 3.3.5). 
Extraction and stripping results for solvents containing Isopar ${ }^{\circledR} M$ and varying amounts of crown ether and either TBP or 4-BPP are shown in Table 4.2. Excellent coalescence on both extraction and stripping was observed for all systems and was particularly characteristic of the TBP/Isopar ${ }^{\circledR} \mathrm{M}$ systems. The first four entries demonstrate that TBP is a stronger modifier than 4-BPP, with the distribution ratios for Tc from DSSF-7 simulant using TBP as modifier being roughly twice that obtained using 4-BPP as modifier for a given crown ether concentration. (The molar concentrations of TBP and 4-BPP at $1: 1 \mathrm{vol} / \mathrm{vol}$ are respectively $1.84 \mathrm{M}$ and $2.15 \mathrm{M}$ ). Stripping in all cases was excellent, but only slightly better using 4-BPP.

Table 4.2. Extraction of pertechnetate from DSSF-7 and MVST W-29 waste simulants by di-t-BuCH18C6 in selected diluents, and stripping by back-extraction with water ${ }^{a}$

\begin{tabular}{|c|c|c|c|c|c|}
\hline$[\mathbf{C E}], \mathbf{M}$ & Simulant & Diluent & $\mathbf{D}_{\mathrm{Tc}} \mathrm{b}^{\mathbf{b}}$ & $\%$ Extr.c & \% Stripc \\
\hline 0.02 & DSSF-7 & 1:1 TBP / Isopar ${ }^{\circledR} \mathrm{M}$ & $4.77 \pm 0.25$ & 97.0 & 99.8 \\
\hline 0.02 & DSSF-7 & 1:1 4-BPP / Isopar ${ }^{\circledR} \mathrm{M}$ & $2.04 \pm 0.02$ & 89.2 & $>99.9$ \\
\hline 0.04 & DSSF-7 & 1:1 TBP / Isopar ${ }^{\circledR} \mathrm{M}$ & $8.46 \pm 0.21$ & 98.9 & 99.6 \\
\hline 0.04 & DSSF-7 & 1:1 4-BPP / Isopar ${ }^{\circledR} \mathrm{M}$ & $4.52 \pm 0.10$ & 96.7 & $\gg 99.9$ \\
\hline 0.04 & MVST W-29 & 1:1 TBP / Isopar ${ }^{\circledR} \mathrm{M}$ & $3.49 \pm 0.21$ & 95.0 & 99.5 \\
\hline 0.02 & MVST W-29 & 2:1 TBP / Isopar ${ }^{\circledR} \mathrm{M}$ & $3.90 \pm 0.06$ & 95.8 & 98.6 \\
\hline 0.02 & DSSF-7 & 2:1 TBP / Isopar ${ }^{\circledR} \mathrm{M}$ & $8.67 \pm 0.27$ & 98.9 & 99.1 \\
\hline 0.01 & DSSF-7 & $100 \%$ 4-BPP & $6.56 \pm 0.20$ & 98.2 & 91.7 \\
\hline 0.02 & DSSF-7 & $100 \%$ 4-BPP & $11.6 \pm 0.8$ & 99.4 & 91.0 \\
\hline none & MVST W-29 & $100 \%$ TBP & $4.34 \pm 0.04$ & 96.5 & 97.1 \\
\hline none & DSSF-7 & $100 \%$ TBP & $7.87 \pm 0.04$ & 98.7 & 97.1 \\
\hline
\end{tabular}

a25 ${ }^{\circ} \mathrm{C}, 1: 1$ phase ratio, $1 \mathrm{~h}$ contacts.

${ }^{b} D_{\mathrm{Tc}}$ is the average of the technetium extraction ratios ([Tc] $]_{\mathrm{org}} /[\mathrm{Tc}]_{\mathrm{aq}}$ ) obtained in the two stages $\mathrm{E}_{1}$ and $\mathrm{E}_{2}$.

'Total \% extracted, and total \% stripped, respectively, after two extraction steps and two stripping steps.

The next three entries in Table 4.2 illustrate the differences in extraction and stripping performance between the DSSF-7 and MVST W-29 sirnulants; also shown are the effects of increasing the TBP concentration and lowering the CE concentration. There is considerably less 
sodium and potassium in the MVST W-29 simulant than in the DSSF-7 simulant (0.290 M vs. $0.945 \mathrm{M}$ ), and thus it is expected that the degree of loading of the crown ether, and hence the Tc extraction ratio, would be lower for the MVST simulant. It can also be seen that increasing the TBP vol fraction from $50 \%$ to $67 \%$ allows essentially equivalent extraction and stripping performance to be achieved using only half the $\mathrm{CE}$ concentration.

The final four entries examined the use of 4-BPP or TBP alone with no added Isopar ${ }^{\circledR} \mathrm{M}$. Intriguingly, TBP alone, with no crown ether, performs quite well with regard to Tc extraction and stripping performance. This seems to be somewhat unique to TBP, as other trialkyl phosphates do not perform as well. In addition, some of the longer alkyl chain phosphates exhibit entrainment and emulsification problems. It can be seen that pure TBP outperforms 4-BPP containing $0.01 \mathrm{M}$ crown with regard to both extraction and stripping efficiency. Further comparisons of TBP with 4-BPP show TBP to have additional advantages: TBP is available in bulk at about $\$ 2 / \mathrm{lb}$ (4-BPP is available in very limited amounts at around $\$ 50 / \mathrm{lb}$ ), and TBP has been used in the nuclear industry longer and more widely than 4-BPP, and thus the behavior of TBP in nuclear processing applications is much better understood. On account of TBP's advantages, further testing of 4-BPP modified systems was abandoned, and more attention was paid to the TBP-modified systems.

A clear inverse relationship between the Tc extraction (distribution) ratio and the first stripping ratio may be seen in Figs. 4.4 and 4.5. For purposes of solvent formulation, one may achieve a balance between extraction and stripping ratios by appropriate choice of crown or modifier concentrations. A change in aqueous composition apparently leads to a new line, but the inverse relationship persists. On the basis of such information, a solvent having desired characteristics may be readily identified for a given waste composition.

\subsubsection{Batch-Equilibrium Three-Stage Counter-Current Test}

We were interested in learning how well extraction and stripping results obtained using cross-current contacting (two-extraction, two-strip experiment) would compare with results obtained using a counter-current contacting procedure. In particular, we wanted to know if the distribution ratios remained stable for each contact, and if the stripping efficiency would be as effective when using a stripping phase that contained back-extracted salt instead of deionized water. We designed a three-stage batch-equilibrium counter-current extraction procedure as outlined in Sect. 4.2.3 and illustrated in Fig. 4.1. The first three contacts (stages "X", "Y", and "Z") were used to prime the system, with the actual extraction stages shown in the boxes marked "1", "2", and "3" in Fig. 4.1. Two extraction runs were performed using DSSF-7 simulant as the feed: one run employed di-t-BuCH18C6 at $0.0223 \mathrm{M}$ in 1:1 TBP/Isopar ${ }^{\circledR} \mathrm{M}$ (run "A"), and the other run ("B") employed the crown ether at $0.0247 \mathrm{M}$ (essentially a duplicate run). The 


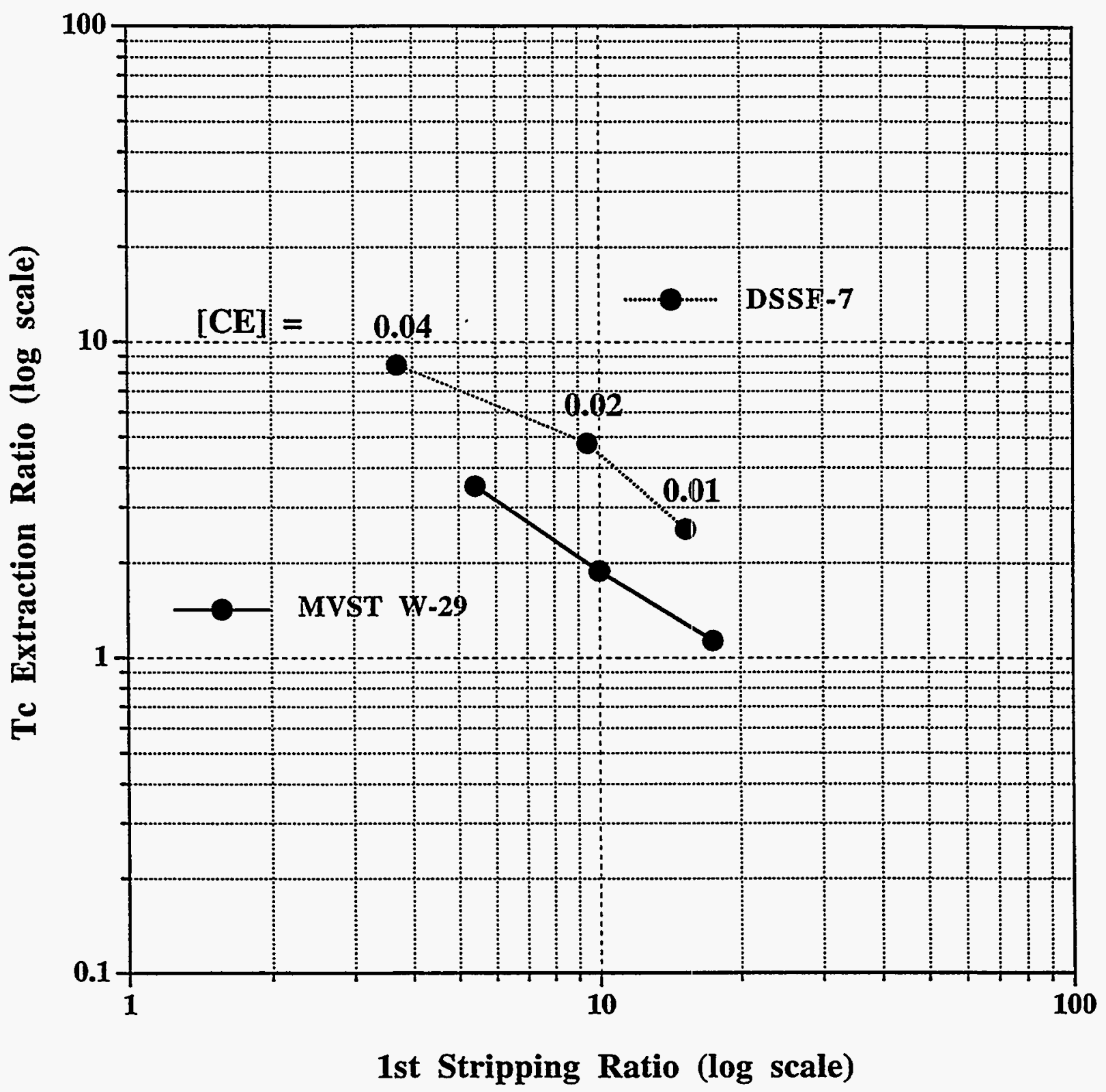

Fig. 4.4. Tc extraction and stripping ratios for $1: 1 \mathrm{vol} / \mathrm{vol}$ TBP/Isopar ${ }^{\circledR} M$ as a function of di-t-BuCH18C6 concentration $(0.04,0.02$, and $0.01 \mathrm{M})$. 




Fig. 4.5. Tc extraction and stripping ratios for $0.02 \mathrm{M}$ di-t-BuCH18C6 in TBP/Isopar® $M$ blends as a function of vol\% TBP (67, 50, and 25 vol\%). 
decontamination factor ([Tc $]_{\text {feed }} /[\mathrm{Tc}]_{\text {raffinate }}$ ) obtained over the stages 1 through 3 was 284 for the " $\mathrm{A}$ " run and 320 for the " $\mathrm{B}$ " run. The average distribution ratio per extraction contact (all six contacts as per Fig. 4.1) was $5.49 \pm 0.40$ for the " $\mathrm{A}$ " run and $5.90 \pm 0.38$ for the " $\mathrm{B}$ " run; these correlate well with the $D_{T c}$ 's obtained using $0.010,0.020$, and $0.040 \mathrm{M}$ crown ether in $1: 1$ TBP/Isopar ${ }^{\circledR} \mathrm{M}$ for extraction of Tc from DSSF-7 using the two-extraction, two-strip crosscurrent procedure (see data plotted in Fig. 4.4), as illustrated in Fig. 4.6. The loaded organic $\left(" \mathrm{O}_{3}\right.$ ") exiting from stage 1 for runs " $\mathrm{A}$ " and " $\mathrm{B}$ " were each subjected to an analogous three-stage batch-equilibrium counter-current stripping procedure (see Fig. 4.2). The stripping factor ([Tc $]_{\text {loaded organic }} /[\mathrm{Tc}]_{\text {stripped organic }}$ ) over the course of the stripping stages 1 through 3 was 3900 for the "A" run and 61,000 for the "B" run (the amount of activity remaining was close to background in both cases). For both runs, the amount of Tc stripped from the organic exceeded 99.9\%. The organic phase [Tc] and the aqueous phase [Tc] for the three extraction stages (for both runs) are linearly related within the concentration ranges of this experiment as shown in Fig. 4.7 .

\subsubsection{Technetium Extraction and Stripping Experiments with Actual MVST W-29 Supernate}

It was necessary to determine how well suitable solvents would perform on actual waste, since simulants can serve only as convenient approximations for screening purposes. A sample of actual MVST W-29 supernatant liquid was provided by the Chemical Technology Division and was treated to remove most of the cesium-137 as described above in Sect. 4.2.2. The Tc content of MVST W-29 was extremely low to begin with $\left(3.2 \times 10^{-7} \mathrm{M}\right)$, and it was necessary for detection purposes to run some samples of SRR-treated waste with various concentrations of added pertechnetate. Three levels of added Tc were tested: none, $6.0 \mu \mathrm{M}$ and $60 \mu \mathrm{M}$. For comparison, a simulant of MVST W-29 was also run at $60 \mu \mathrm{M}$ Tc. The solvent used was $0.02 \mathrm{M}$ crown in 1:1 vol/vol TBP/Isopar ${ }^{\circledR} \mathrm{M}$. In a second series of experiments, pure TBP was tested on the simulant and SRR-treated supernate spiked to $60 \mu \mathrm{M}$ in Tc. The contacting method was our standard two-extraction, two-strip procedure.

As summarized in Table 4.3, the results confirm efficient removal of Tc from actual MVST supernatant waste. Unfortunately, the residual background due to the remaining cesium-137 present in the SRR-treated waste interfered with the accurate determination of the low level of Tc present. However, the results obtained using the real waste to which $\mathrm{Tc}$ had been added agreed quite well with that obtained using the simulant. Moreover, the rate at which the phases separated using the real waste was actually faster for this system than with the simulant. (Phase separation was immediate with a sharply-defined interface.) As may be seen in Table 4.3, the crown ether 


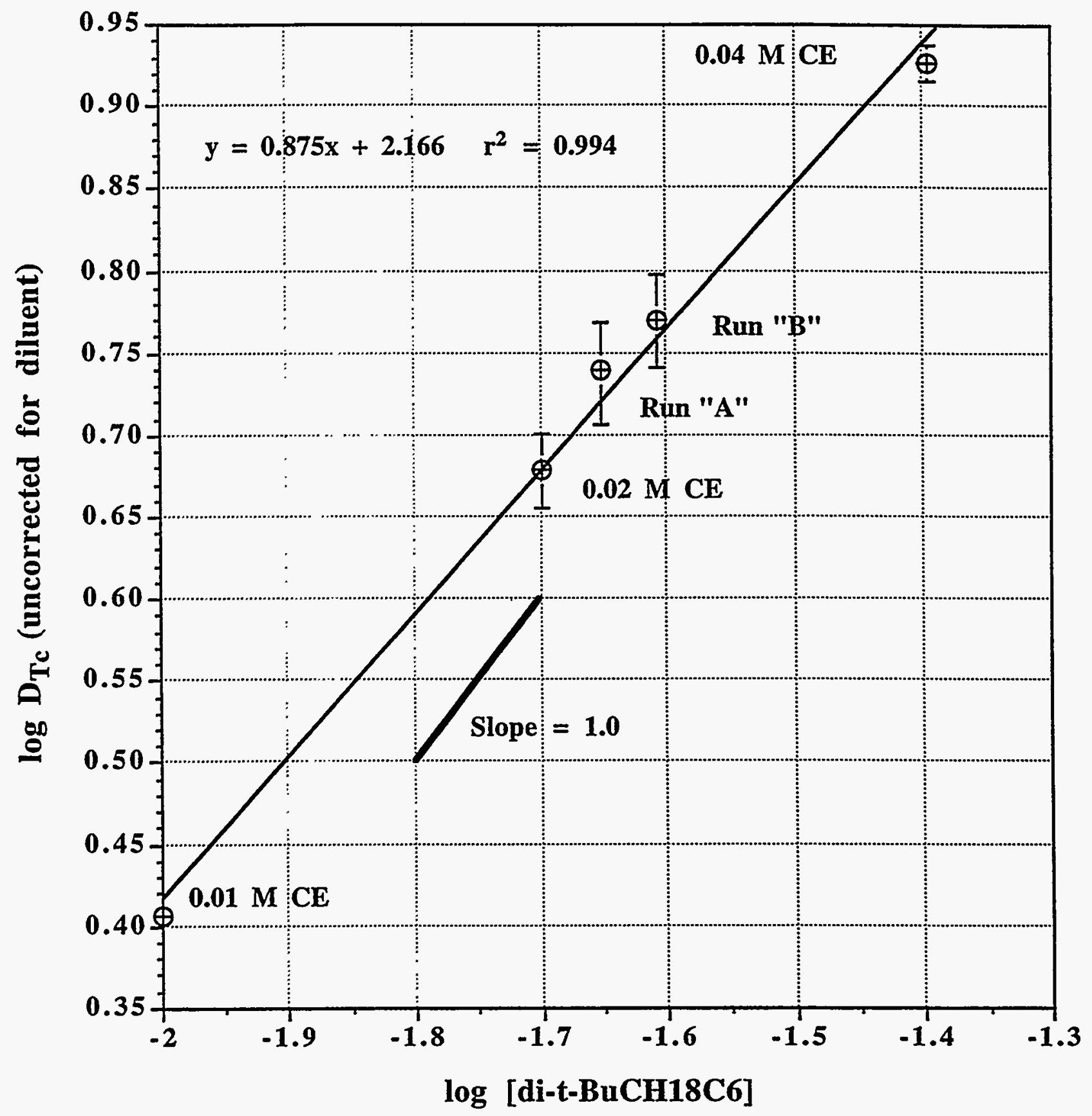

Fig. 4.6. Technetium distribution ratio as a function of crown ether concentration for extraction from DSSF-7 simulant using di-t-BuCH18C6 in 1:1 vol/vol TBP/Isopar ${ }^{\circledR} \mathrm{M}$. Tc distribution data for $0.01,0.02$, and $0.04 \mathrm{M}$ crown ether concentrations is the same as in Fig. 4.4. Runs " $\mathrm{A}$ " and " $\mathrm{B}$ " are from three-stage batch counter-current test. 


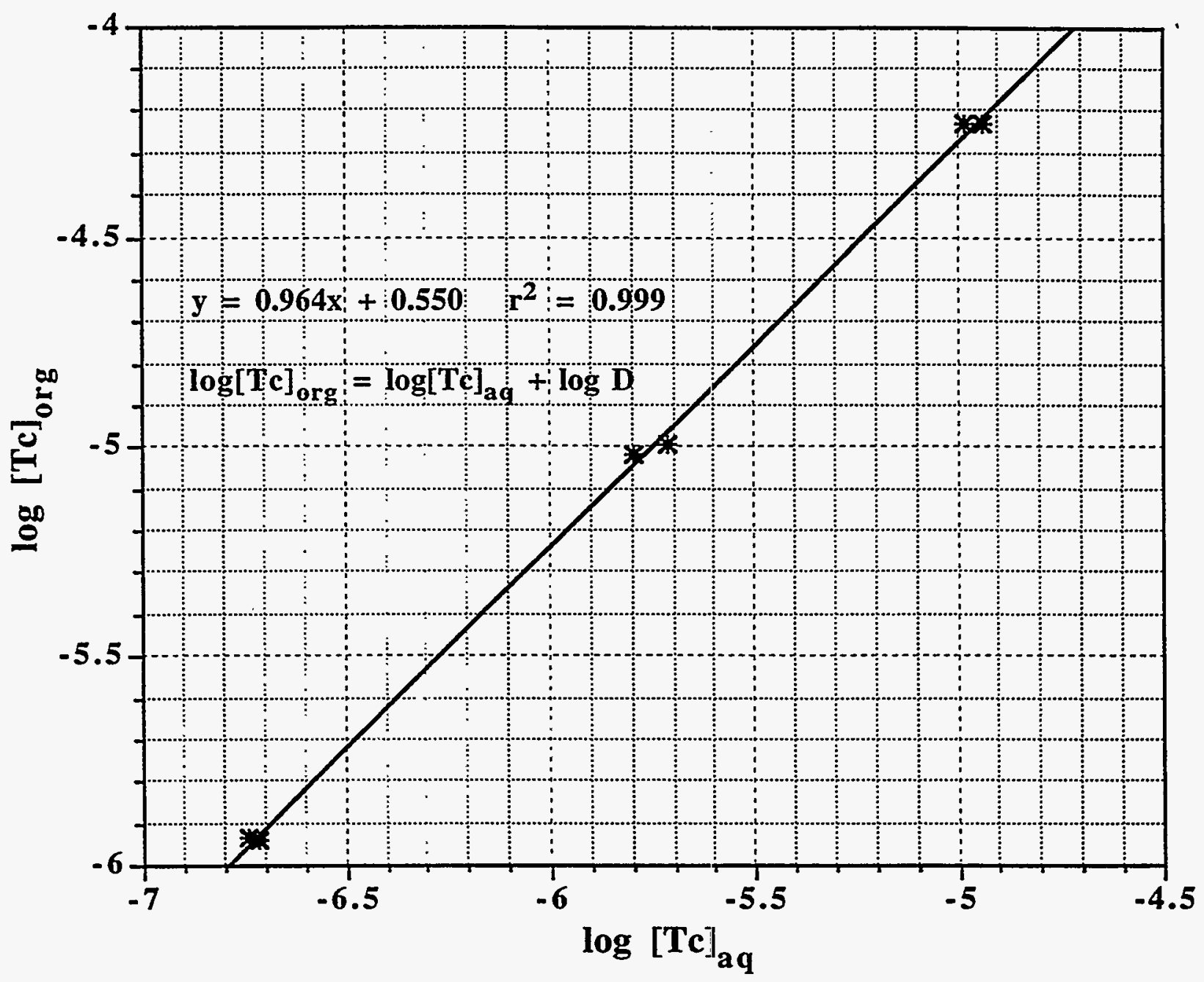

Fig. 4.7. Equilibrium data for three stage extraction of Tc using $0.02 \mathrm{M}$ di-t-BuCH18C6 in 1:1 $\mathrm{TBP}^{-} \operatorname{ssopar}^{\circledR} \mathrm{M}$ 
Table 4.3. Tc extraction from actual and simulated Melton Valley Storage Tank W-29 Supernate using $0.02 \mathrm{M}$ di-t-BuCH18C6 in 1:1 TBP/Isopar ${ }^{\circledR} \mathrm{M}$ (experiments \#1-4) and pure TBP (experiments \#5-6) ${ }^{\mathrm{a}}$

\begin{tabular}{|c|c|c|c|c|}
\hline $\begin{array}{c}\text { Exp. } \\
\#\end{array}$ & Aqueous Feed & $\mathrm{D}_{\mathrm{Tc}}{ }^{\mathrm{b}}$ & \%Extracted & \%Strippedc \\
\hline 1 & $\begin{array}{c}\text { MVST W-29 Simulant } \\
60 \mu \mathrm{M} \text { Tc }\end{array}$ & $1.66 \pm 0.02$ & 85.9 & 99.2 \\
\hline 2 & $\begin{array}{c}\text { SRR-treated actual } \\
\text { W-29 supernate } \\
\text { No Tc spike }\end{array}$ & $0.55 \pm 0.40 *$ & $58.5 * *$ & 96.0 \\
\hline \multirow[t]{2}{*}{3} & $\begin{array}{l}\text { SRR-treated actual } \\
\text { W-29 supernate }\end{array}$ & $1.53 \pm 0.20$ & $84.3 * *$ & 99.3 \\
\hline & $6 \mu \mathrm{M} \mathrm{Tc}$ & & & \\
\hline \multirow[t]{2}{*}{4} & $\begin{array}{l}\text { SRR-treated actual } \\
\text { W-29 supernate }\end{array}$ & $1.61 \pm 0.06$ & $85.3 * *$ & 99.6 \\
\hline & $60 \mu \mathrm{M} \mathrm{Tc}$ & & & \\
\hline 5 & $\begin{array}{c}\text { MVST W-29 Simulant } \\
60 \mu \mathrm{M} \text { Tc }\end{array}$ & $4.02 \pm 0.02$ & 96.0 & 97.4 \\
\hline 6 & $\begin{array}{l}\text { SRR-treated actual } \\
\text { W-29 supernate }\end{array}$ & $3.39 \pm 0.29$ & $94.8 * *$ & 97.8 \\
\hline & $60 \mu \mathrm{M} \mathrm{Tc}$ & & & \\
\hline
\end{tabular}

a25 ${ }^{\circ} \mathrm{C}, 1: 1$ phase ratio, $1 \mathrm{~h}$ contacts.

${ }^{b} D_{T c}$ is the average of the technetium extraction ratios ([Tc $]_{\text {org }} /[\mathrm{Tc}]_{\text {aq }}$ ) obtained in the two stages $\mathrm{E}_{1}$ and $\mathrm{E}_{2}$; these ratios are usually the same within experimental errors.

cTotal \% extracted and total \% stripped, respectively, after two extraction steps and two stripping steps.

*The beta-background due to residual Cs-137 and Sr-90 was estimated and subtracted to obtain the Tc-99 activity. The uncertainty decreases when more Tc-99 is present, making the true uncertainty for that sample quite large.

**For the SRR-treated systems, the percent extracted was calculated from the average $D_{T c}$ value. As no detectable Cs was extracted, the stripping phases contained essentially only Tc-99 (with perhaps trace Sr-90); thus the \% stripped is based on raw counting data (like the simulant) - no Cs background adjustment was necessary. 
solvent showed little or no dependence of $D_{\mathrm{Tc}}$ on the level of Tc present up to $60 \mu \mathrm{M}$. With no crown ether present, TBP used undiluted performed well, in accordance with simulant results (Table 4.2). Despite the disadvantages of its high viscosity and density near that of water, TBP can therefore optionally serve as a solvent for Tc removal from alkaline tank supernate.

\subsubsection{Effect of Sodium and Potassium Concentration on Stripping Efficiency}

The ability to economically remove (strip) the pertechnetate from the extractant and thus regenerate the solvent represents a major advantage of crown ethers in tank-waste remediation. Since some carryover of $\mathrm{KNO}_{3}$ and $\mathrm{NaNO}_{3}$ into the strip solution is expected, the question arises concerning the relationship between stripping efficiency and the concentrations of these salts in the strip solution. Ultimately, the strength of this effect determines our ability to recycle the stripping water. As shown later, the fraction of water recycled plays an economic role.

In our routine experiments, we used a "once-through" cross-current stripping procedure in which the loaded organic phase was stripped a first time by contact with deionized water and then a second time by recontact of the organic phase with a fresh supply of deionized water. We observed that the first stripping ratio is generally lower than the second, in large part because the concentration of dissolved salts (both complexed and uncomplexed by the crown ether) in the organic phase was higher prior to the first strip than the second. As was discussed in Sect. 1.2, the stripping reaction is simply a reversal of the equilibrium forces driving the crown ether to complex the alkali metal ion. During extraction, the very high concentration of alkali metal ions drives the reaction toward formation of the crown ether-alkali metal complex. To dissociate this complex, the stripping phase needs to be as low in concentration of extractable cations as possible.

We performed an experiment to determine how the overall stripping efficiency would be affected by using stripping phases that contained sodium and potassium at various concentrations. A solvent consisting of $0.02 \mathrm{M}$ di-t-BuCH18C6 in 1:1 vol/vol TBP/Isopar ${ }^{\circledR} \mathrm{M}$ was contacted in the usual manner with DSSF-7 simulant so that the solvent contained a nominal concentration of technetium $\left(5.3 \times 10^{-5} \mathrm{M}\right)$. Aliquots of the Tc-laden solvent were then stripped once with equal volumes of either deionized water (control), sodium nitrate solutions of $1.1 \times 10^{-4}$ to $5.55 \mathrm{M}$, or potassium nitrate solutions of $1.0 \times 10^{-5}$ to $1.0 \mathrm{M}$. The effect on the stripping efficiency is shown in Fig. 4.8, in which the percent Tc stripped from the organic is plotted against either the sodium or potassium concentration in the stripping phase. Not surprisingly, the stripping efficiency is less tolerant of the potassium ion concentration than the sodium ion concentration, since potassium is complexed more strongly than sodium by di-t-BuCH18C6. From the plots shown in Fig. 4.8, it appears that for this solvent and aqueous feed solution (DSSF-7), stripping performance does not begin to seriously erode (from the $88 \%$ Tc removal value obtained using deionized water) until the 


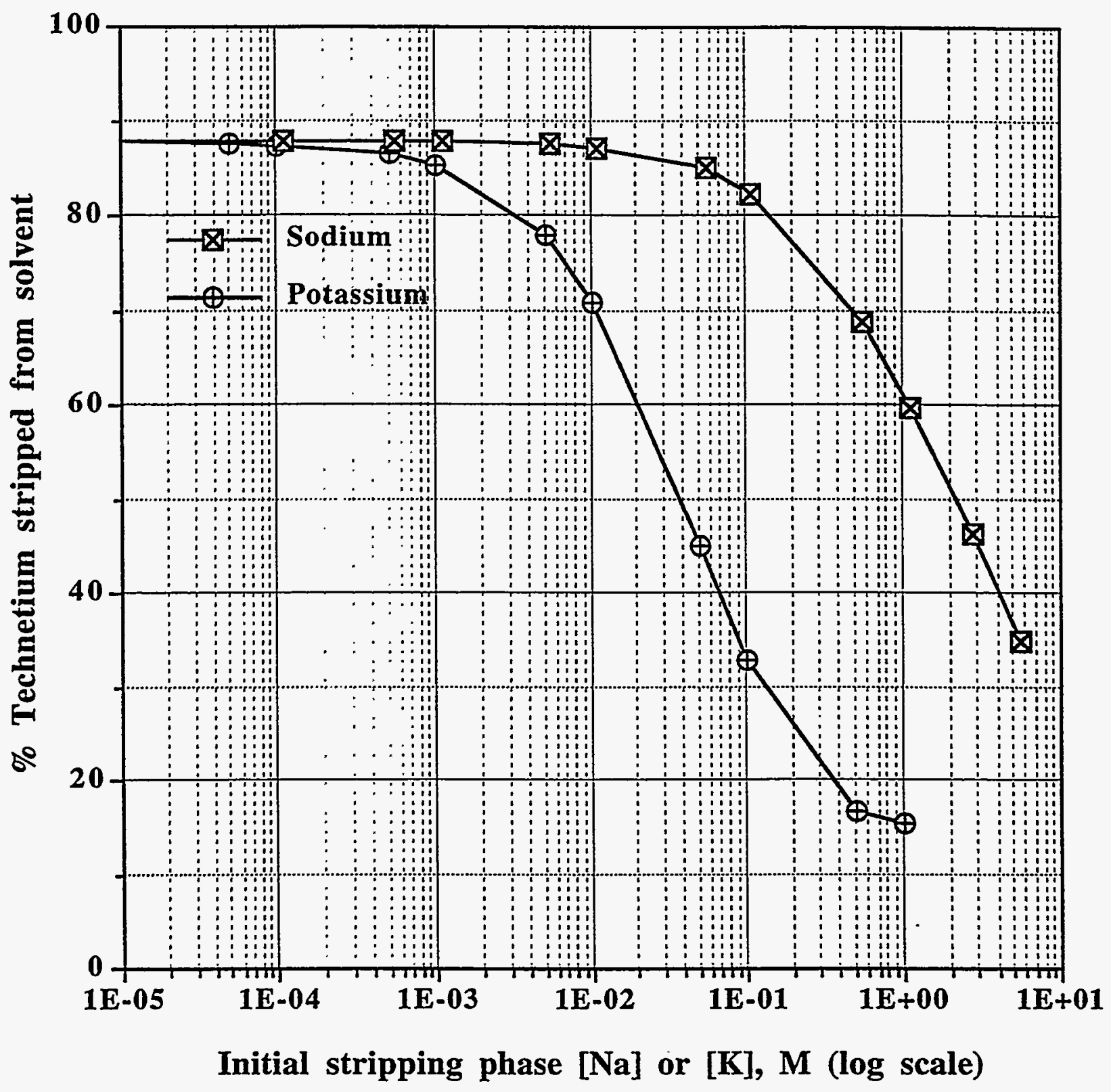

Fig. 4.8. Technetium stripping efficiency from Tc-laden solvent as a function of the initial stripping-phase sodium or potassium nitrate concentration. Solvent is $0.02 \mathrm{M}$ di-t-BuCH $18 \mathrm{C} 6$ in $1: 1 \mathrm{vol} / \mathrm{vol}$ TBP/Isopar ${ }^{\circledR} \mathrm{M}$. Stripping efficiency is for one equal-volume contact at $25^{\circ} \mathrm{C}$ for 1 hour. 
sodium concentration in the stripping solution exceeds $0.1 \mathrm{M}$, or the potassium concentration in the stripping phase exceeds $0.005 \mathrm{M}$.

It is important to note that the stripping equilibrium is ultimately dependent on the total $\mathrm{Na}$ and $\mathrm{K}$ concentration in the combined organic and aqueous phases during the contact, and that this includes the $\mathrm{Na}$ and $\mathrm{K}$ dissolved in the solvent, as well as the $\mathrm{Na}$ and $\mathrm{K}$ in the aqueous stripping phase. In order to ascertain the organic phase $\mathrm{Na}$ and $\mathrm{K}$ concentrations, an extraction was performed as above using similarly extracting perrhenate $\left(\mathrm{ReO}_{4}{ }^{-}\right)$as a stand-in for $\mathrm{TcO}_{4}^{-}$, and the solvent phase was subjected to three cross-current stripping contacts with deionized water. Analysis of the aqueous strips by ICAP spectrometry revealed the organic-phase sodium and potassium concentrations prior to stripping to be $8.4 \mathrm{mM}$ and $3.6 \mathrm{mM}$, respectively, which is a good indication of the organic-phase sodium and potassium concentrations in the analogous Tcladen solvent prior to stripping. The organic phase $\mathrm{Na}$ and $\mathrm{K}$ would need to be taken into account for any detailed investigation of stripping performance as a function of $\mathrm{Na}$ and $\mathrm{K}$ concentrations, and additional experiments to probe the relationship between the stripping ratios and the total [Na] and $[\mathrm{K}]$ concentration in the contact $(\mathrm{Na}$ and $\mathrm{K}$ contained in both the solvent and the stripping solution) are described below in Sect. 4.3.5.

\subsubsection{Extraction/Stripping Cycling of Candidate Systems.}

Having examined many of the parameters influencing the extraction and stripping of $\mathrm{Tc}$ we turned to the question of evaluating and comparing the characteristics and economics of candidate process flowsheets. Since the question hinges on later steps in processing the strip solution, one may consider two basic options entailing either simple evaporation of the strip solution with recycle of the condensed water or concentration of $\mathrm{Tc}$ on an anion-exchange column with recycle (full or partial) of the aqueous column effluent. Since the fate of the Tc after its removal from the tank waste has not yet been determined, all of the criteria for choosing among these and perhaps other options are not available. Nevertheless, a small batch demonstration of candidate flowsheets was judged to be a useful step toward evaluation. Spreadsheet simulations were employed as a tool to generate preliminary cost estimates.

Since TBP appeared to be an excellent modifier, detailed extraction and stripping tests were conducted to determine its optimum concentration in Isopar ${ }^{\circledR} \mathrm{M}$ (see Figs. 4.4 and 4.5). At the same time, this question relates also to the optimum concentration of crown ether. From the previous tests shown in Figs. 4.4, 4.5, and 4.6, some initial predictions may be made. However, the impact on the stripping cycle cannot be addressed, particularly if the stripping water from the anion-exchange resin is recycled. Three final candidate formulations were selected for further study: $0.04 \mathrm{M} \mathrm{d}-\mathrm{t}-\mathrm{BuCH} 18 \mathrm{C} 6$ in 1:1 vol/vol TBP/sopar ${ }^{\circledR} \mathrm{M}$ (Solvent A); $0.02 \mathrm{M} \mathrm{d-t-BuCH18C6}$ 
in 2:1 vol/vol TBP/Isopar ${ }^{\circledR} \mathrm{M}$ (Solvent B); and pure TBP (Solvent C) (see also Table 4.2). These were subjected to an extraction/stripping experiment in which both the solvent and stripping water were recycled; this provided information on the extraction and stripping efficiency of these particular solvent systems as the sodium and potassium concentrations built up in the strip water, leading to a set of data for flowsheet analysis. The experiment described above in Sect. 4.3.4 was a prelude to this experiment, in which the effect of sodium or potassium on stripping performance was examined individually. Here, the combined effect will be examined under more realistic contacting conditions. The evaluation consisted of a single extraction contact (MVST W29 simulant containing 60 micromolar Tc) followed by three cross-current stripping contacts with water (deionized for the first cycle). Technetium, sodium, and potassium concentrations were assayed at various points in the cycle, as described above in Sect. 4.2.4 and Fig. 4.3. Following the three stripping contacts, the stripped solvent was reused in a subsequent cycle on fresh aqueous feed. The combined aqueous stripping phases, after passage through the resin to remove pertechnetate, were also reused in the three cross-current stripping contacts of the subsequent cycle. This procedure was repeated for a total of four cycles. For each cycle, one Tc distribution ratio was obtained, and three Tc stripping ratios were obtained. To assess the impact of the salt into the stripping solution, the total $[\mathrm{Na}]$ and $[\mathrm{K}]$ in each extraction and stripping contact were also obtained for each cycle.

For the sake of brevity, the relevant data have been condensed and are shown in Table 4.4. The extraction performance of Solvents A and B were similar; Solvent $\mathrm{C}$ gave a slightly higher distribution ratio. The distribution ratio remained quite stable over the course of cycles 2-4 for all the solvents (a very slight drop in the distribution ratio was observed after the first cycle for all the solvents, but this was expected, as pristine solvent not pre-equilibrated with the feed matrix solution was used for the first cycle). The main difference among the three solvents, other than their cost and density, is the amount of sodium and potassium co-extracted, which affects the efficiency of the strip cycle. A comparison of the organic phase Tc concentrations ([Tc $]_{\text {org }}$ ) after the extraction contact and after each stripping contact (for cycles 2-4, cycle 1 omitted for clarity) for each of the three solvents is provided in Fig. 4.9, which shows how the residual Tc in the solvent builds up after each cycle. While the degree of the buildup is higher for Solvents $A$ and $B$ than for Solvent $\mathrm{C}$, it can be seen that the [Tc] org is still into the sub-micromolar range for the solvent following strip \#3 of cycle \#4, but that the [Tc $]_{\text {org }}$ for Solvent $C$ was in the sub- $10^{-5} \mathrm{M}$ range even after cycle \#2. There is thus a residual amount of Tc in the solvent that is carried back into the following extraction cycle, and thus the amount of $\mathrm{Tc}$ in the organic phase during the extraction contact, and in the extraction contact itself, increases with each successive cycle for Solvent $\mathrm{C}$. Fig. 4.10 illustrates how the [Tc] org following the extraction contact increases for Solvent $C$ with successive cycles, but remains fairly stable for Solvents A and B. 
Table 4.4. Extraction, stripping, and processing data for extraction of Tc from MVST W-29 simulant (59.1 micromolar Tc) using candidate solvents ${ }^{\mathrm{a}}$

\begin{tabular}{|c|c|c|c|}
\hline Item & $\begin{array}{c}\text { Solvent } A \\
(0.04 \mathrm{M} \mathrm{CE} \text { in } 1: 1 \\
\left.\text { TBP/Isopar }{ }^{\circledR} \mathrm{M}\right)\end{array}$ & $\begin{array}{c}\text { Solvent } B \\
(0.02 \mathrm{M} \mathrm{CE} \text { in } 2: 1 \\
\left.\text { TBP/Isopar }{ }^{\circledR} \mathrm{M}\right)\end{array}$ & $\begin{array}{l}\text { Solvent } C \\
\text { (Pure TBP) }\end{array}$ \\
\hline Avg. DTc (four cycles) & $3.09 \pm 0.10$ & $3.27 \pm 0.05$ & $3.77 \pm 0.15$ \\
\hline \multirow{3}{*}{$\begin{array}{l}\text { Stripping Factors for Strip } \\
\# 1 \text {, cycles 2, 3, and } 4\end{array}$} & (2) $5.30 \pm 0.01$ & (2) $3.68 \pm 0.01$ & (2) $1.08 \pm 0.00$ \\
\hline & (3) $4.50 \pm 0.01$ & (3) $3.04 \pm 0.01$ & (3) $1.09 \pm 0.00$ \\
\hline & (4) $3.79 \pm 0.01$ & (4) $2.65 \pm 0.01$ & (4) $1.03 \pm 0.00$ \\
\hline \multirow{3}{*}{$\begin{array}{l}\text { Stripping Factors for Strip } \\
\# 2 \text {, cycles } 2,3 \text {, and } 4\end{array}$} & (2) $10.62 \pm 0.07$ & (2) $6.60 \pm 0.04$ & (2) $1.39 \pm 0.00$ \\
\hline & (3) $7.47 \pm 0.05$ & (3) $3.85 \pm 0.02$ & (3) $1.10 \pm 0.00$ \\
\hline & (4) $5.06 \pm 0.03$ & (4) $3.10 \pm 0.01$ & (4) $1.00 \pm 0.00$ \\
\hline \multirow{3}{*}{$\begin{array}{l}\text { Stripping Factors for Strip } \\
\# 3 \text {, cycles } 2,3 \text {, and } 4\end{array}$} & (2) $7.92 \pm 0.17$ & (2) $5.38 \pm 0.08$ & (2) $0.90 \pm 0.00$ \\
\hline & (3) $5.97 \pm 0.10$ & (3) $2.97 \pm 0.03$ & (3) $0.81 \pm 0.00$ \\
\hline & (4) $4.54 \pm 0.06$ & (4) $2.46 \pm 0.02$ & (4) $0.83 \pm 0.00$ \\
\hline $\begin{array}{l}\text { Solvent Densityb } \\
\left(\mathrm{gm} / \mathrm{mL} \text { at } 25^{\circ} \mathrm{C}\right)\end{array}$ & $0.873 \pm 0.008$ & $0.904 \pm 0.002$ & 0.976 \\
\hline Est. Solv. Cost $\$ / \mathrm{kg}^{*}$ & $\$ 585$ & $\$ 295$ & $\$ 4.20$ \\
\hline $\begin{array}{l}{[\text { Tc] }]_{\text {org after } 3 \text { 3rd stripping }}} \\
\text { contact after cycle } 1\end{array}$ & $0.86 \mathrm{nM}$ & $3.11 \mathrm{nM}$ & $366 \mathrm{nM}$ \\
\hline 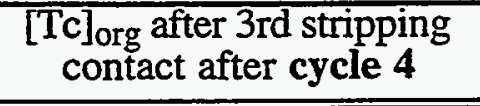 & $279 \mathrm{nM}$ & $882 \mathrm{nM}$ & $6900 \mathrm{nM}$ \\
\hline $\begin{array}{l}{[\mathrm{Tc}]_{\text {org after extraction }}} \\
\text { contact for cycle } 1\end{array}$ & $45.1 \mu \mathrm{M}$ & $45.5 \mu \mathrm{M}$ & $46.9 \mu \mathrm{M}$ \\
\hline $\begin{array}{l}{[\text { Tc] }]_{\text {org after extraction }}} \\
\text { contact for cycle } 4\end{array}$ & $44.8 \mu \mathrm{M}$ & $45.6 \mu \mathrm{M}$ & $\dot{51.1 \mu \mathrm{M}}$ \\
\hline $\begin{array}{l}\text { Avg. }[\mathrm{Tc}]_{\text {aq }} \text { in strip before } \\
\text { resin treatment (4 cycles) }\end{array}$ & $19.3 \pm 2.9 \mu \mathrm{M}$ & $17.8 \pm 1.9 \mu \mathrm{M}$ & $17.4 \pm 2.9 \mu \mathrm{M}$ \\
\hline $\begin{array}{l}\text { Avg. }[\mathrm{Tc}]_{\mathrm{aq}} \text { in strip after } \\
\text { resin treatment (4 cycles) }\end{array}$ & $<2 \mathrm{nM}\left(\mathrm{K}_{\mathrm{d}}>10^{5}\right)$ & $2.5 \mathrm{nM}\left(\mathrm{K}_{\mathrm{d}}>10^{5}\right)$ & $<2 \mathrm{nM}\left(\mathrm{K}_{\mathrm{d}}>10^{5}\right)$ \\
\hline $\begin{array}{c}\text { Avg. }[\mathrm{Na}]_{\mathrm{aq}},[\mathrm{K}] \mathrm{aq} \text { in strip } \\
\text { after resin treatment after } \\
4 \text { cycles }\end{array}$ & $\begin{array}{l}17.3 \mathrm{mM} \mathrm{Na} \\
7.0 \mathrm{mM} \mathrm{K}\end{array}$ & $\begin{array}{c}21.2 \mathrm{mM} \mathrm{Na} \\
6.0 \mathrm{mM} \mathrm{K}\end{array}$ & $\begin{array}{c}49.5 \mathrm{mM} \mathrm{Na} \\
0.9 \mathrm{mM} \mathrm{K}\end{array}$ \\
\hline$\%$ Tc desorbed from resin & $85.8 \%$ & $86.2 \%$ & $95.6 \%$ \\
\hline
\end{tabular}
cycles.

a25 ${ }^{\circ} \mathrm{C}, 1: 1$ phase ratio, $1 \mathrm{~h}$ contacts, one extraction steps, three stripping steps per cycle; four

bDensities for Solvents A and B were obtained by weighing $2.00 \mathrm{~mL}$ aliquots. The density value for TBP is from the 11th Edition of the Merck Index (entry number 9531).

*Using the best prices available as of $1 / 1 / 95$ for bulk quantities: $\$ 30 / \mathrm{g}$ for di-t-BuCH $18 \mathrm{C} 6$, $\$ 1.87 / \mathrm{lb}$ for TBP, and $\$ 0.34 / \mathrm{lb}$ for Isopar ${ }^{\circledR} \mathrm{M}$. 


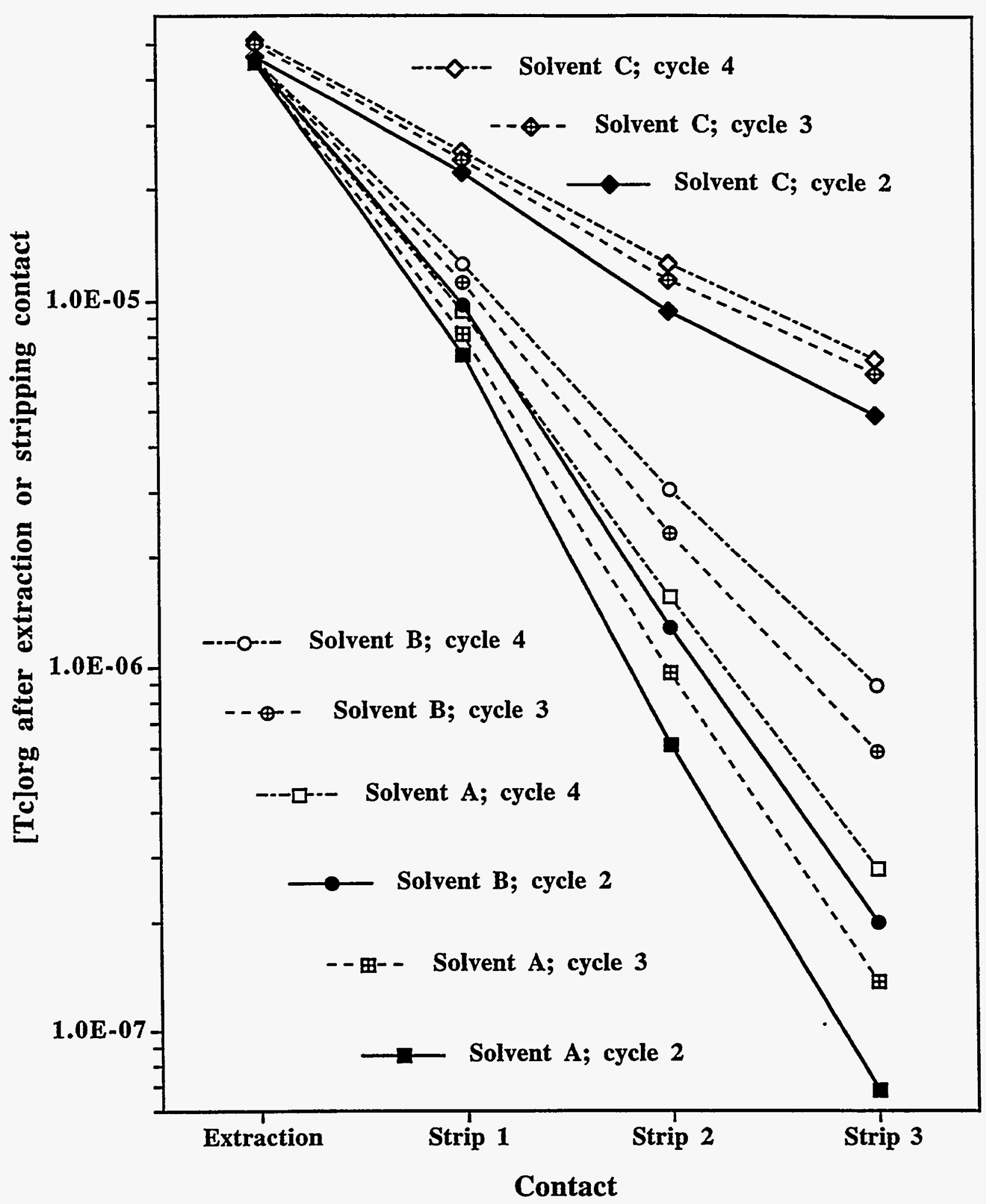

Fig. 4.9. $[\mathrm{Tc}]_{\text {org }}$ following extraction and stripping for each solvent as a function of cycle\# (cycle \#1 omitted). 


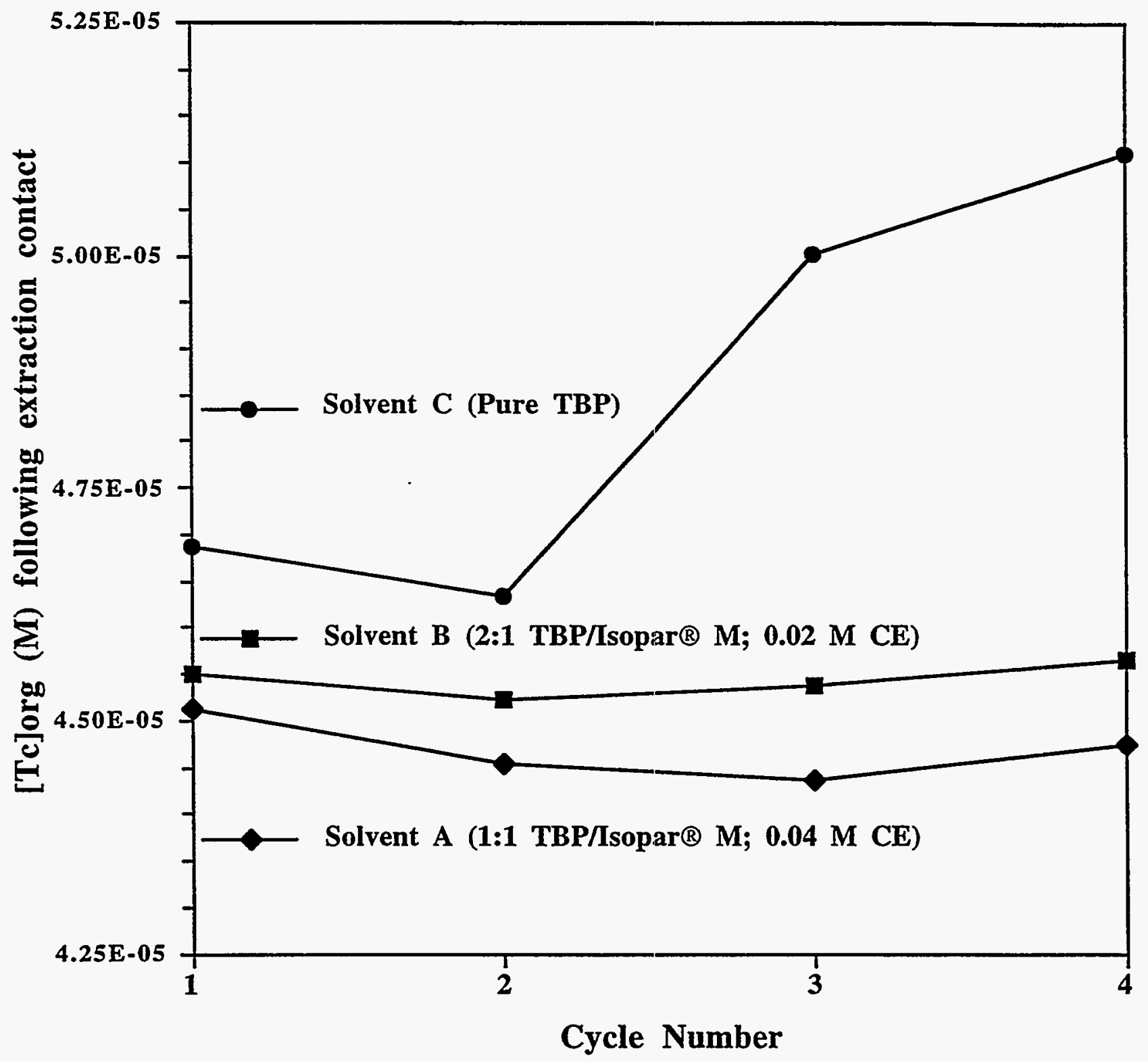

Fig. 4.10. $[\mathrm{Tc}]_{\text {org }}$ following extraction contact for each solvent as a function of cycle number. 
shows how the residual Tc in the solvent builds up after each cycle. While the degree of the buildup is higher for Solvents A and B than for Solvent C, it can be seen that the [Tc] org is still into the sub-micromolar range for the solvent following strip \#3 of cycle \#4, but that the [Tc] org for Solvent $\mathrm{C}$ was in the sub-10-5 $\mathrm{M}$ range even after cycle \#2. There is thus a residual amount of Tc in the solvent that is carried back into the following extraction cycle, and thus the amount of Tc in the organic phase during the extraction contact, and in the extraction contact itself, increases with each successive cycle for Solvent C. Figure 4.10 illustrates how the [Tc] org following the extraction contact increases for Solvent $\mathrm{C}$ with successive cycles, but remains fairly stable for Solvents A and B.

It can also be seen that the stripping factors are much lower (residual [Tc] higher) for Solvent $\mathrm{C}$ than for Solvents A or B. TBP is a weak Lewis base and will accordingly extract some sodium: the higher the TBP component of the solvent, the more sodium is co-extracted, and consequently the lower is the stripping factor. (The crown ether favors the extraction of potassium 5 over sodium: the amount of potassium extracted decreases as the crown ether concentration decreases). The stripping factors drop upon successive cycles as the sodium and potassium concentrations in the stripping phases build up, but it is interesting to note that for all three solvents, the stripping factors follow the general trend of being higher for the second stripping contact than either the first or third stripping contacts. Figures $4.11,4.12$, and 4.13 show the $[\mathrm{Tc}]_{\mathrm{aq}} /[\mathrm{Tc}]_{\text {org }}$ (Stripping Ratio) for Solvents A, B, and C, respectively, as a function of the total sodium or potassium concentration in the extraction contact, or stripping contact. The fit is roughly linear, but the scatter increases as the TBP concentration increases (and the crown ether concentration decreases). The scatter is greatest for the very low sodium and potassium concentrations found in the second and third stripping contact of the first cycle. The fit for Solvent $\mathrm{C}$ is not that good, and most of the stripping ratios are clustered in a "shotgun" pattern around unity. Interestingly, the ratio of total sodium to total potassium in all the stripping contacts remains fairly uniform for each solvent. While Solvent A may be much more expensive than Solvent $\mathrm{C}$ (or B), it appears to provide the better overall performance.

Figures $4.14,4.15$, and 4.16 are respectively plots of the total sodium versus the total potassium concentration in the stripping contacts for Solvents $A, B$, and $C$. It can be seen that the slope of the line (the $[\mathrm{Na}] /[\mathrm{K}]$ ratio) increases upon progressing from Solvents $A$ to $C$ (in which the crown ether concentration decreases and the TBP concentration increases). As noted above, TBP prefers to extract sodium, while the crown ether prefers to extract potassium.

Balancing the desirability of recycling the stripping water is the necessity to effectively remove the pertechnetate. Passing the combined stripping phases for the cycle through an anionexchange resin reduces the Tc concentration in the strip solution from $10^{-5} \mathrm{M}$ to $10^{-9} \mathrm{M}$. However, the sodium and potassium remain in the strip solution after the resin treatment, and after 


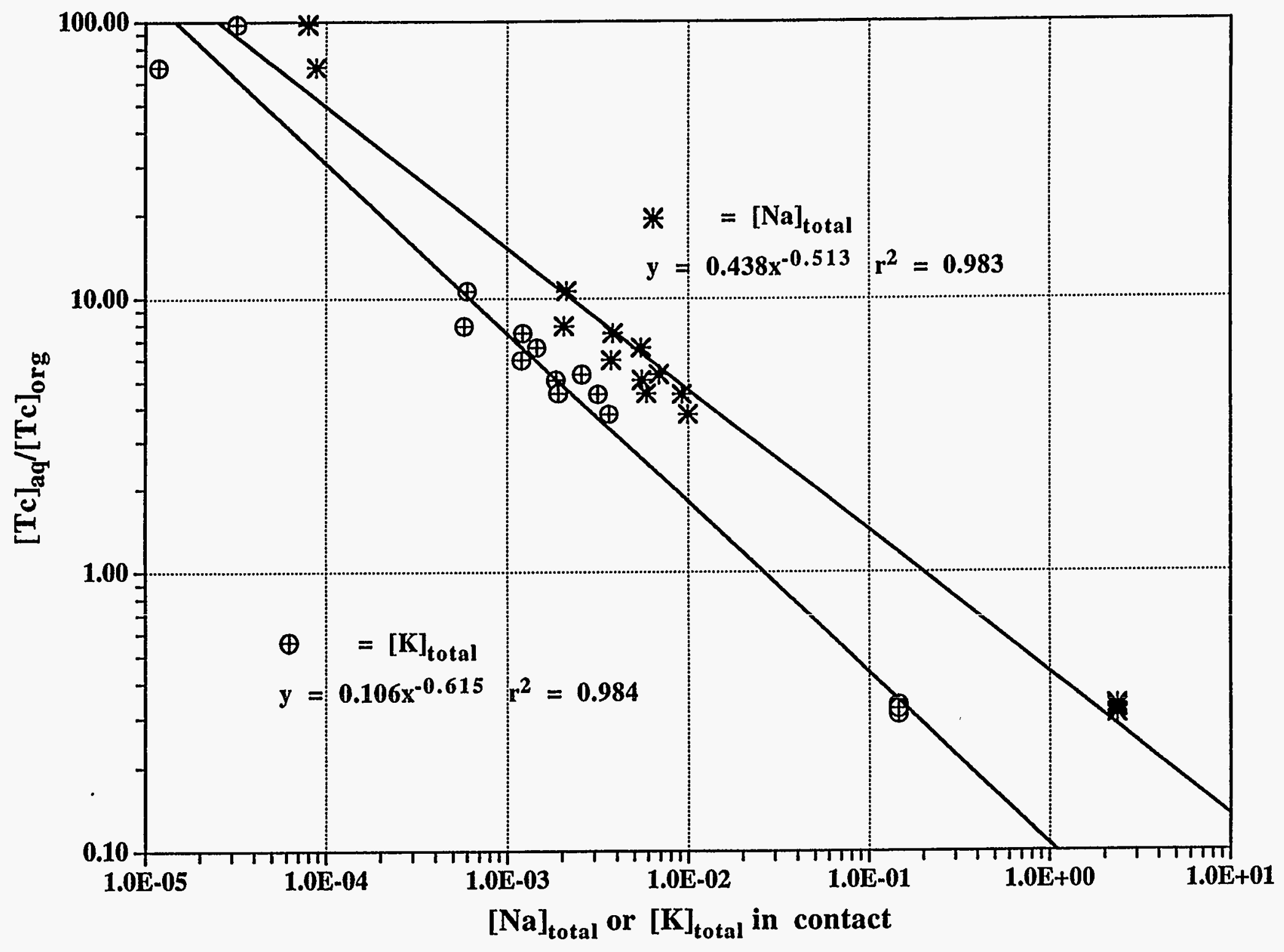

Fig. 4.11. $[\mathrm{Tc}]_{\mathrm{aq}} /[\mathrm{Tc}]_{\text {org }}$ vs. $[\mathrm{M}]_{\text {total }}(\mathrm{M}=\mathrm{Na}$ or $\mathrm{K})$ in stripping or extraction contact for solvent $A\left(0.04 \mathrm{M}\right.$ di-t-BuCH18C6 in 1:1 TBP/Isopar $\left.{ }^{\circledR} \mathrm{M}\right)$. 


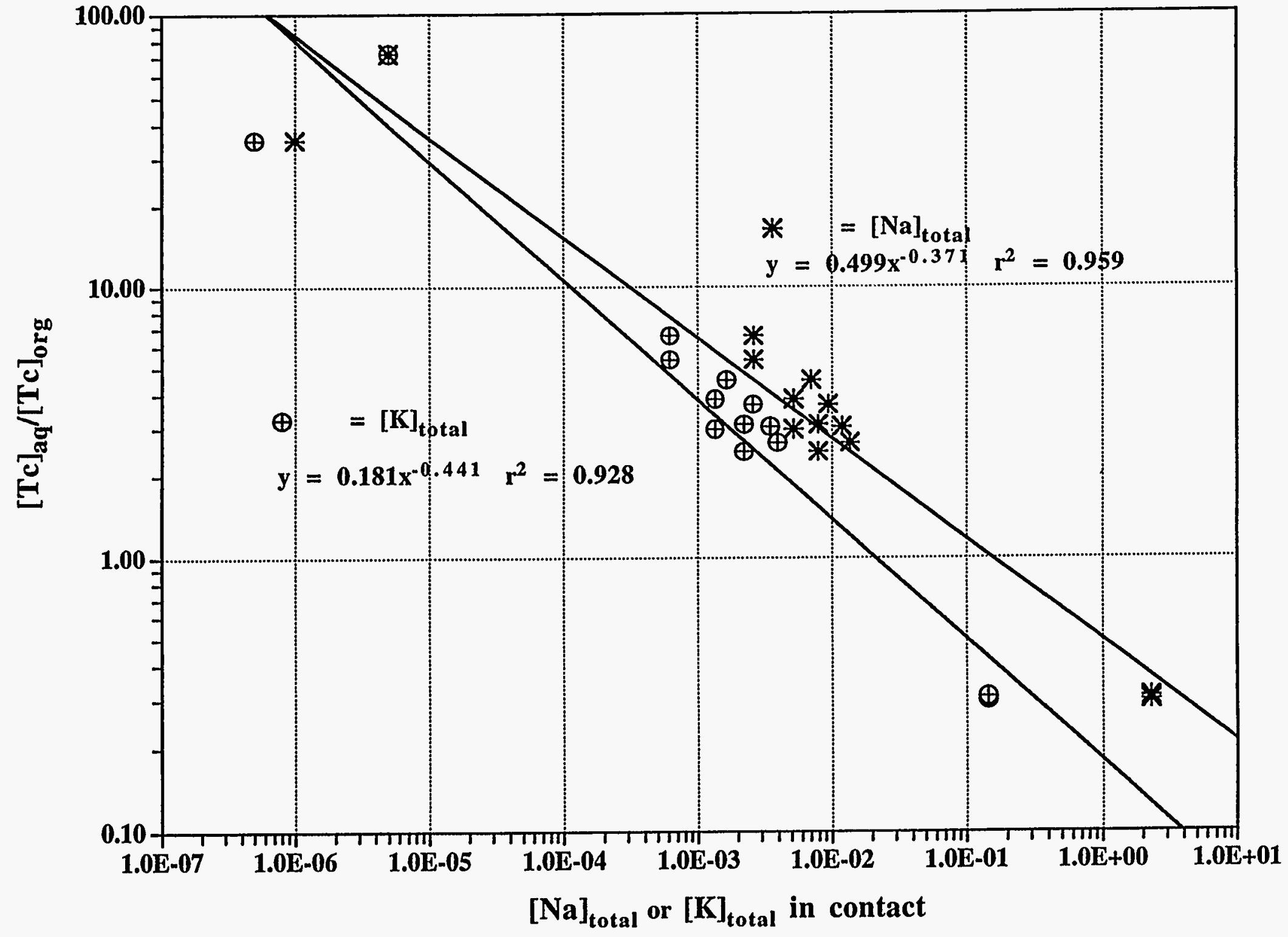

Fig. 4.12. $[\mathrm{Tc}]_{\mathrm{aq}} /[\mathrm{Tc}]_{\text {org }}$ vs. $[M]_{\text {total }}(\mathrm{M}=\mathrm{Na}$ or $\mathrm{K})$ in stripping or extraction contact for solvent $B\left(0.02 \mathrm{M}\right.$ di-t-BuCH18C6 in 2:1 $\left.\mathrm{TBP}^{\mathrm{I}} \mathrm{Isopar}{ }^{\circledR} \mathrm{M}\right)$. 


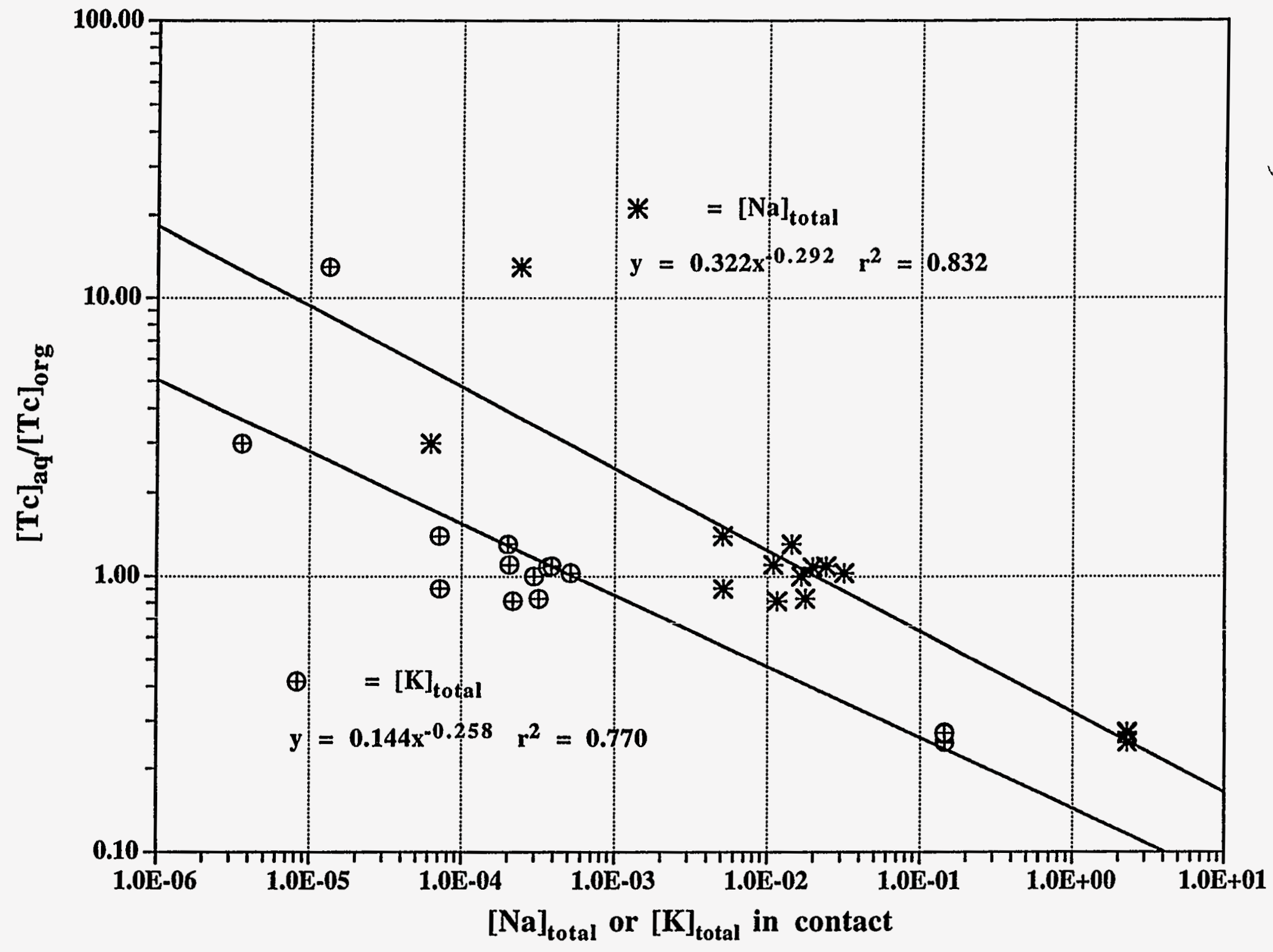

Fig. 4.13. $[\mathrm{Tc}]_{\mathrm{aq}} /[\mathrm{Tc}]_{\text {org }}$ vs. $[\mathrm{M}]_{\text {total }}(\mathrm{M}=\mathrm{Na}$ or $\mathrm{K})$ in stripping or extraction contact for solvent $C$ (Pure TBP). 


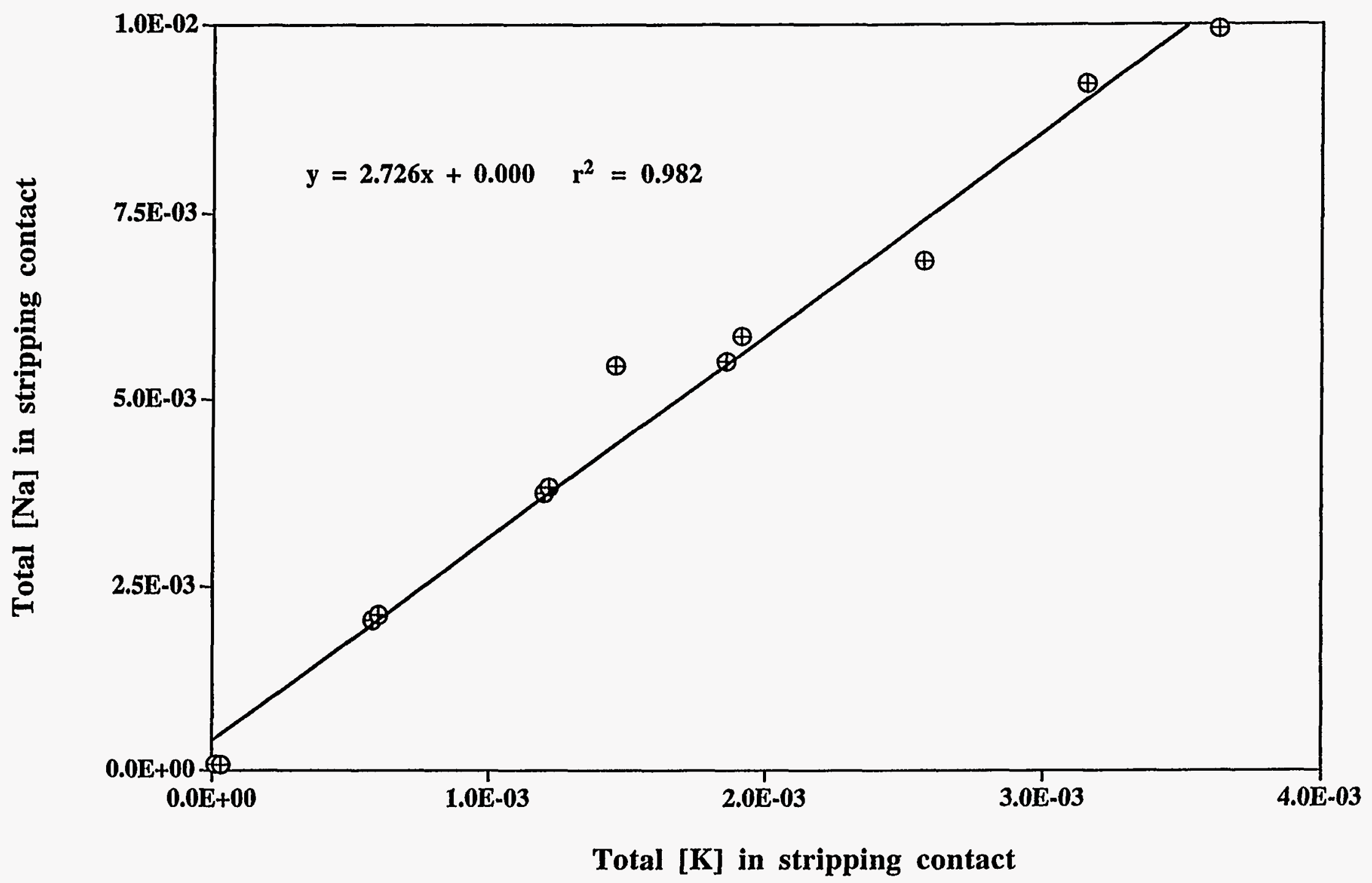

Fig. 4.14. Ratio of total $[\mathrm{Na}]$ to total $[\mathrm{K}]$ in stripping contact for Solvent $A$

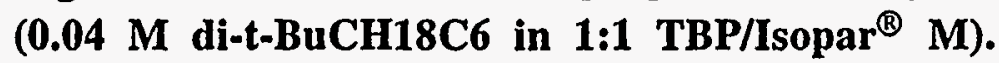




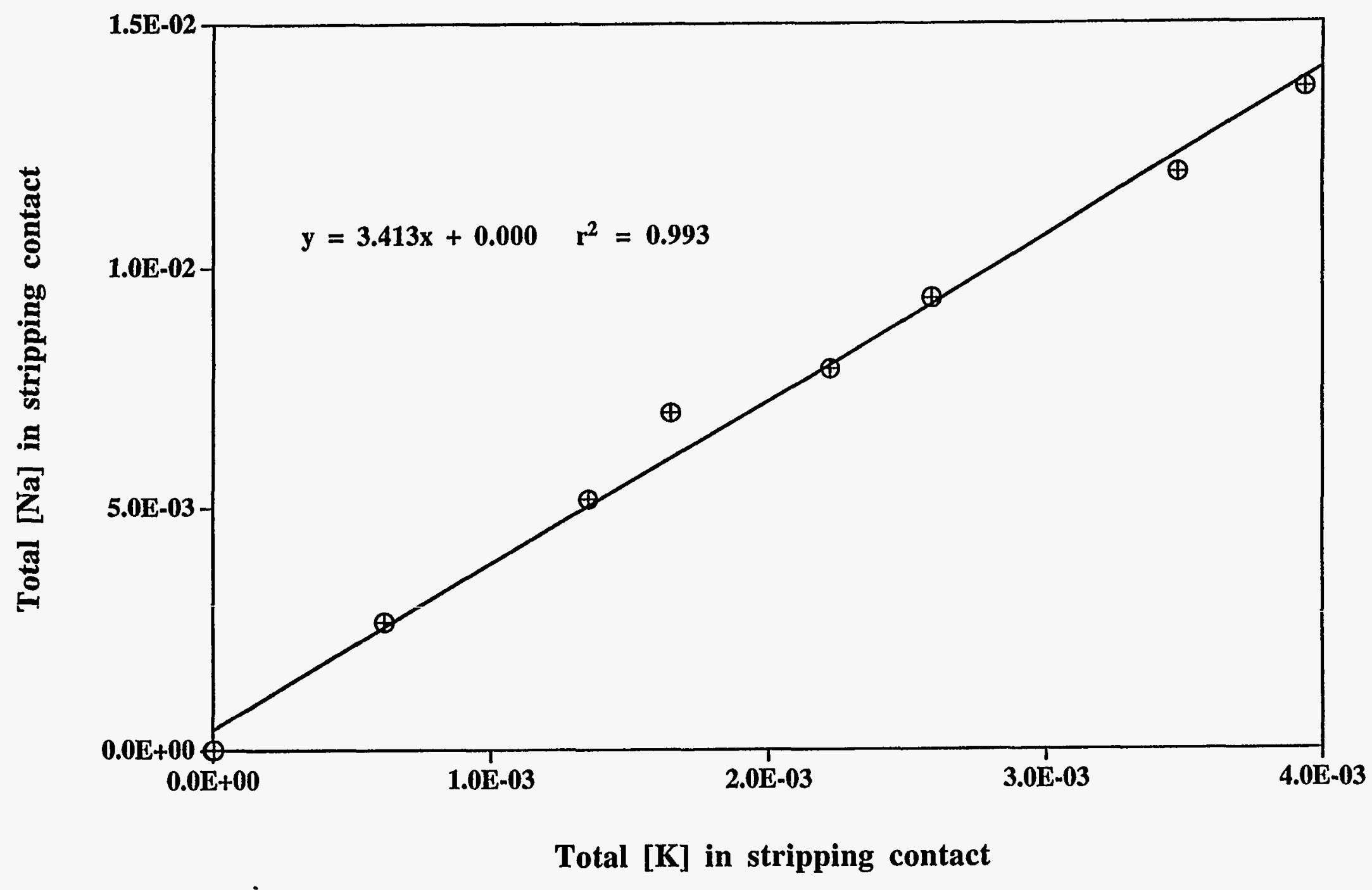

Fig. 4.15. Ratio of total $[\mathrm{Na}]$ to total $[\mathrm{K}]$ in stripping contact for Solvent $B$ (0.02 $\mathrm{M}$ di-t-BuCH18C6 in 2:1 $\mathrm{TBP}^{\mathrm{Isopar}}{ }^{\circledR} \mathrm{M}$ ). 


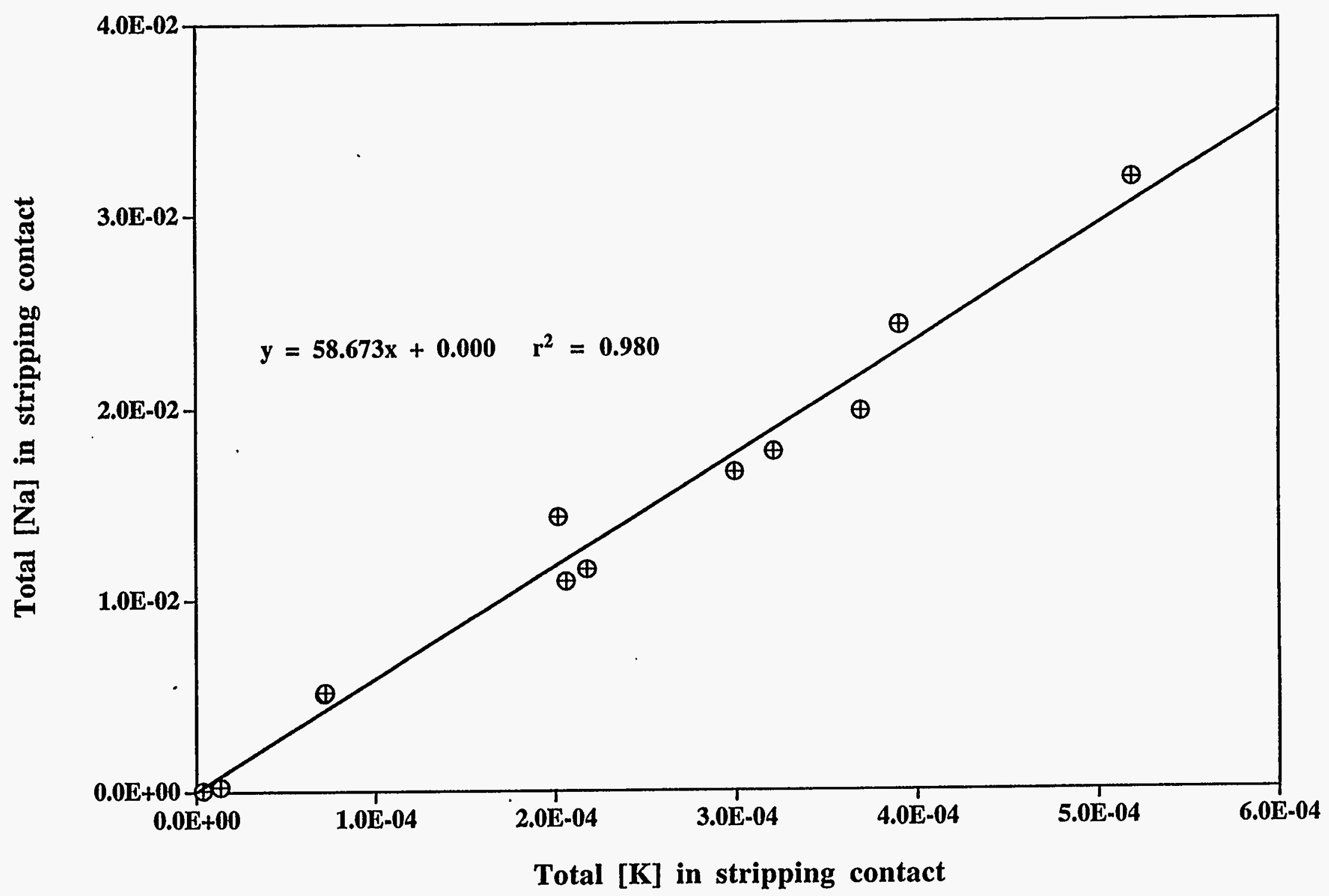

Fig. 4.16. Ratio of total [Na] to total [K] in stripping contact for Solvent C (TBP). 
four cycles, their concentrations build up; this is particularly true for Solvent $\mathbf{C}$ (where the sodium and potassium concentrations increase to respectively 49.5 and 0.9 millimolar). As shown in Fig. 4.8 , the increasing concentration of sodium and potassium in the stripping water again suppresses the stripping efficiency. This suppression can be moderated to the extent desired by partial replacement of the recycled strip solution with fresh water. Some estimates of the economic consequences are discussed further below.

The resin can be regenerated by treatment with a solution containing stannous chloride $(0.01 \mathrm{M})$, ethylenediamine $(0.10 \mathrm{M})$, and $\mathrm{NaOH}(1.0 \mathrm{M})$, as described by Schroeder ${ }^{2}$ and coworkers. Passage of $8 \mathrm{~mL}$ of this solution through the resin bed generally results in the immediate elution of $\geq 85 \%$ of the resin-bound technetium. In these experiments, we elected not to reuse a regenerated resin; however, in an actual process it is expected that the regenerated resins would be reused.

The data obtained for all three solvent candidates (extraction and stripping ratios together with concentrations of $\mathrm{Tc}, \mathrm{Na}$, and $\mathrm{K}$ in the contact phases) were used as input for performance evaluation in a spreadsheet simulation of a process flowsheet. The simulation produced preliminary cost estimates of Tc removal according to the simplified conceptual flowsheet shown in Fig. 4.17. This study-level representation provided an estimation of the relevant material and energy balances, the required capital investment, and the annual operating costs. This estimation is based on an input of the flowrate and composition of the stream to be treated and other operational parameters. This conceptual process consists of counter-current extraction, counter-current or cross-current stripping, and removal of technetium from the strip solution, with the recycle of water used for stripping treated as a variable. There are two options for treating the stripping water: passage through an anion-exchange column, or evaporation. We employ the key assumption that solvent losses are negligible. Of course, this assumption cannot be justified in the absence of engineering scale tests with actual equipment and actual feed solutions. Although data exist to support the expectation of low entrainment losses (see below), the reader should assume that the cost estimates represent minimum values.

The results are shown in Table 4.5, where it can be seen that although the cost of Solvents $A$ and $B$ are much greater than that of Solvent C (TBP), the extractant investment cost is small in comparison to cost of the contacting equipment and the yearly operating expenditures. The differences in the costs for each solvent are due to differences in flowrates, energy costs, and the size of the equipment required for each solvent system, based on its performance. For the anionexchange option, discharging all (100\%) of the water results in smaller equipment, and a reduction of the overall equipment and operating costs (the cost of the make-up water is included in the estimate). (Discharging $50 \%$ of the water results in a slight increase in the costs relative to $100 \%$ discharge). For the evaporator/condenser option, the equipment and operating costs run 


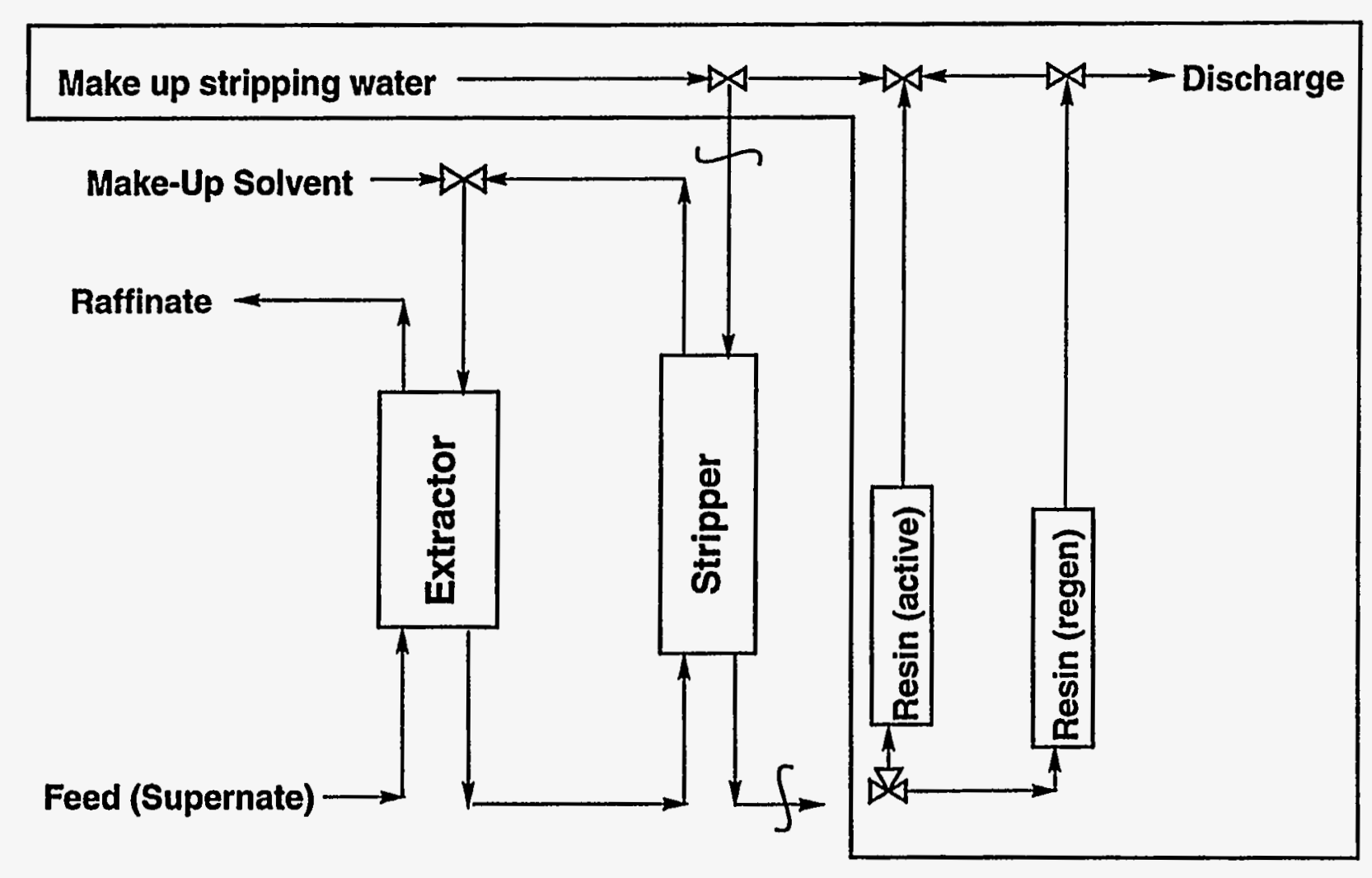

Anion-exchange option for treating strip water

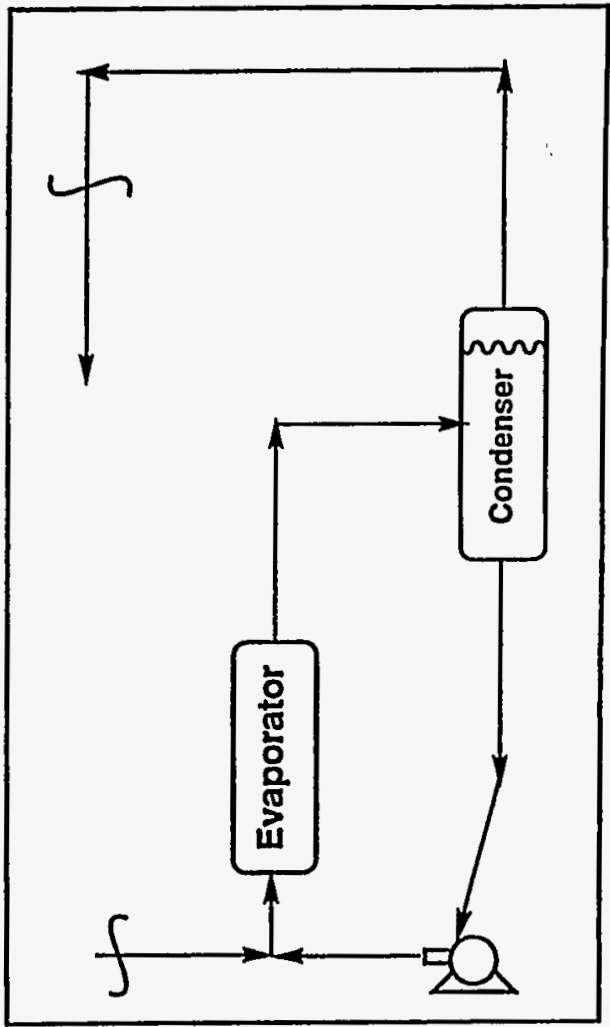

Evaporator/condenser option for treating strip water

Fig. 4.17. Technetium removal step: simplified conceptual process flowsheet. 
Table 4.5. Estimated yearly expenses for the three solvent candidates for a Tc extraction process with a decontamination factor for extraction and stripping of $99 \%$ from MVST W-29 simulant (59.1 micromolar Tc) ${ }^{a}$

\begin{tabular}{|c|c|c|c|}
\hline Item & $\begin{array}{c}\text { Solvent } A \\
(0.04 \mathrm{M} \text { CE in } 1: 1 \\
\left.\text { TBP/Isopar }{ }^{\circledR} \mathrm{M}\right)\end{array}$ & $\begin{array}{c}\text { Solvent } B \\
(0.02 \mathrm{M} \mathrm{CE} \text { in } 2: 1 \\
\left.\text { TBP/Isopar }{ }^{\circledR} \mathrm{M}\right)\end{array}$ & $\begin{array}{l}\text { Solvent C } \\
\text { (Pure TBP) }\end{array}$ \\
\hline Avg. DT (four cycles) & $3.09 \pm 0.10$ & $3.27 \pm 0.05$ & $3.77 \pm 0.15$ \\
\hline Est. Solv. Cost $\$ / \mathrm{kg}$ & $\$ 585$ & $\$ 295$ & $\$ 4.20$ \\
\hline Number of extraction stages & 14 & 14 & 14 \\
\hline Number of stripping stages & 10 & 10 & 10 \\
\hline Extractant Investment Cost ${ }^{b}$ & $\$ 68,000$ & $\$ 35,000$ & $\$ 440$ \\
\hline \multicolumn{4}{|c|}{ Anion-exchange Optionc } \\
\hline $\begin{array}{l}\text { Equipment investment } \\
-50 \% \text { water discharge }\end{array}$ & $\$ 31,000,000$ & $\$ 34,500,000$ & $\$ 33,000,000$ \\
\hline $\begin{array}{c}\text { Operating cost/yr } \\
-50 \% \text { water discharge }\end{array}$ & $\$ 6,500,000$ & $\$ 7,200,000$ & $\$ 7,000,000$ \\
\hline $\begin{array}{l}\text { Equipment investment } \\
-100 \% \text { water discharge }\end{array}$ & $\$ 29,500,000$ & $\$ 32,500,000$ & $\$ 30,500,000$ \\
\hline $\begin{array}{c}\text { Operating cost/yr } \\
-100 \% \text { water discharge }\end{array}$ & $\$ 6,200,000$ & $\$ 6,800,000$ & $\$ 6,600,000$ \\
\hline \multicolumn{4}{|c|}{ Evaporator / Condenser Option ${ }^{d}$} \\
\hline Equipment investment & $\$ 34,500,000$ & $\$ 38,500,000$ & $\$ 37,500,000$ \\
\hline Operating cost/yr & $\$ 7,100,000$ & $\$ 7,800,000$ & $\$ 7,700,000$ \\
\hline
\end{tabular}

aAssumptions for model: Cost of buildings/shielding not included. Plant operation is 8760 $\mathrm{h} / \mathrm{yr}$ at $90 \%$ availability. Extraction/stripping stage efficiency is $50 \%$.

bTwice minimum inventory, where minimum inventory is the extractor/stripper organic fraction.

cWater discharge is waste stream produced in Tc stripping operations - reducing water discharged from this step involves recycle/reuse of water. Solvent losses neglected due to use of centrifugal contactors. Aqueous flowrate for extractor set at $100 \mathrm{~L} / \mathrm{min}$.

dTotal evaporation of the strip solution is assumed. 
respectively $10-22 \%$ and $8-16 \%$ higher (degree depending on the solvent and how much water is discharged). It should be noted that this is only a model, and these costs are useful for rough comparisons only. Nevertheless, it is interesting that the lowest-cost process (by a narrow margin) for both options is the one using Solvent $\mathrm{A}$, which contains the most crown ether. As mentioned above, this solvent appears to be the most efficient, as it co-extracts the least amount of net sodium and potassium and so has the best stripping factors, allowing the stripping water to be recycled longer before requiring discharge and re-infusion of make-up water. It was also interesting to note that the most expensive operation was not the one using TBP, but instead was the one using Solvent B! (Again, by a narrow margin.; the three systems are almost equivalent according to this model.) However, we feel that the most efficient system is likely to be the one employing Solvent A. Factors owing to mass-transfer and phase disengagement are also likely to be better with Solvent $\mathrm{A}$, but data concerning these factors remain to be determined.

The annular-mixed centrifugal contactor, developed at $\mathrm{ORNL}^{6}$ and Argonne National Laboratory ${ }^{7}$ appears to be the likely contactor of choice for this process, owing to the fast contact times (less than three seconds) between the aqueous and organic phases, the low entrainment, high through-put, and low space requirements. The fast contacting times will minimize exposure of the solvent to radiation, and thus will minimize the radiolytic degradation of the solvent and the frequency with which the solvent inventory would need to be replaced. The very low entrainment of the solvent in the aqueous phase due to the high g-forces produced in the contactor will also minimize loss of the solvent. In fact, organic losses approaching the saturation level (aqueous solubility, which for di-t-BuCH18C6 is $<1 \mathrm{ppm}$ ) are achievable. Intimate mixing of the aqueous and organic phases will enable maximum use of the solvent. The high through-put and low space requirements will contribute to lowering the overall costs. Taken together, the features of the centrifugal contactors will also help lower the initial inventory of solvent required.

\subsubsection{Strontium and Technetium Extraction and Stripping Experiments.}

Although we have focused almost exclusively on Tc extraction in this report, the major criterion in solvent formulation could well be whether or not the user wishes to co-extract strontium. The three solvent candidates A, B, and C for the Tc extraction and stripping process were also evaluated with regard to strontium extraction and stripping from MVST W-29 simulant; as shown in Table 4.1, the simulant contains strontium at $1.1 \times 10^{-5} \mathrm{M}$, which is the same amount of total strontium that was found in the actual waste. Strontium extraction and stripping were followed using Sr-85 tracer. All three solvents were tested using MVST W-29 simulant to which no Tc had been added, since the actual MVST W-29 supernate contains very little Tc. Solvent B was additionally tested with Sr-85 spiked MVST W-29 simulant, to which Tc had been added to 
the usual 60 micromolar level, to determine what effect the presence of Tc would have on the strontium extraction and stripping efficiency. The results are shown in Table 4.6.

It can be seen that strontium can be practically extracted using Solvents A and B (which contain crown ether) but not by pure TBP. The distribution ratio (using Solvent B) was slightly lower when Tc was present (at 60 micromolar) than when it was absent. Stripping was essentially complete $(>95 \%)$ after the first stripping contact, with the second contact bringing the percent stripped to $>99.9 \%$. Solvent $\mathrm{C}$ may be of interest in cases where Tc removal is desired but $\mathrm{Sr}$ removal is not (e.g. when separation of $\mathrm{Tc}$ from $\mathrm{Sr}$ is desirable). All things being equal, the presence of pertechnetate (relative to nitrate) should increase the extractability of a cation; thus, it is interesting that the presence of Tc has a slight antagonistic effect on Sr extraction efficiency. Again, the actual MVST W-29 supernate contains very little Tc $\left(3.2 \times 10^{-7} \mathrm{M}\right)$, and therefore the extractability of strontium from actual MVST W-29 would be expected to more closely follow that obtained from the simulant without added Tc.

Table 4.6. Extraction and stripping performance for strontium (Sr-85 tracer) from simulated Melton Valley Storage Tank W-29 supernate using Solvents $A, B$, and $C_{\text {. }}{ }^{a}$

\begin{tabular}{|c|c|c|c|c|}
\hline Solvent & Aqueous Feed & $\mathbf{D}_{\mathbf{S r}} \mathbf{b}^{\mathbf{b}}$ & \%Extractedc & \% Strippedc \\
\hline $\mathbf{A}$ & $\begin{array}{l}\text { MVST W-29 Simulant } \\
\text { No Tc spike }\end{array}$ & $0.511 \pm 0.004$ & 56.2 & $>99.9$ \\
\hline $\mathbf{B}$ & $\begin{array}{l}\text { MVST W-29 Simulant } \\
\text { No Tc spike }\end{array}$ & $0.627 \pm 0.011$ & 62.2 & $>99.9$ \\
\hline $\mathbf{B}$ & $\begin{array}{c}\text { MVST W-29 Simulant } \\
60 \mu \mathrm{M} \text { Tc }\end{array}$ & $0.505 \pm 0.010$ & 55.9 & $>99.9$ \\
\hline C & $\begin{array}{l}\text { MVST W-29 Simulant } \\
\text { No Tc spike }\end{array}$ & $0.029 \pm 0.002$ & 5.56 & $>99.9$ \\
\hline
\end{tabular}

a25 ${ }^{\circ} \mathrm{C}, 1: 1$ phase ratio, $1 \mathrm{~h}$ contacts, standard two-extraction, two-strip experimental conditions. Total [Sr] is $1.1 \times 10^{-5} \mathrm{M}$. Solvents $\mathrm{A}, \mathrm{B}$, and $\mathrm{C}$ are the same as identified previously (c.f. Table 4.4)

${ }^{b} D_{S r}$ is the average of the strontium extraction ratios ( $[\mathrm{Sr}]_{\text {org }} /[\mathrm{Sr}]_{\mathrm{aq}}$ ) obtained in the two stages $\mathrm{E}_{1}$ and $\mathrm{E}_{2}$; these ratios are usually the same within experimental errors.

c'Total \% extracted and total \% stripped, respectively, after two extraction steps and two stripping steps. 


\subsection{CONCLUSIONS AND RECOMMENDATIONS}

Toward developing an effective solvent system for the separation of pertechnetate from alkaline tank supernate, an effective process can be designed employing di-t-BuCH18C6 dissolved in TBP-modified Isopar ${ }^{\circledR} \mathrm{M}$. With regard to process efficiency and overall economics, "Solvent $\mathrm{A}^{\prime \prime}$ (di-t-BuCH18C6 dissolved in 1:1 vol/vol TBP/Isopar ${ }^{\circledR} \mathrm{M}$ at $0.04 \mathrm{M}$ ) performs well in tests with MVST and Hanford waste simulants. However, a user may wish to modify the concentration of crown ether or TBP according to the nature of the waste feed or desirability of Sr co-extraction (see below). Using Solvent A, phase-disengagement and stripping efficiency from one cycle to another are excellent. Passage of the stripping water through an anion exchange resin effectively removes the pertechnetate, allowing the water to be recycled. The Tc can be reductively stripped from the resin as a concentrated solution. Thus, a process cycle can be constructed which allows for a closed-loop extraction and stripping procedure and concentration of Tc. The diluents are inexpensive and readily available, and the expense of the crown ether may be minimized to acceptable levels owing to the use of centrifugal contactors. The stripping water can be recycled many times, after which portions can be discharged to an evaporator and the collected water recirculated into the system; the residue can be disposed of as LLW.

We demonstrated Tc removal from actual MVST W-29 supernate and found the extraction and stripping behavior to be similar to that of the simulant. We also investigated the final solvent candidates for strontium removal and found solvents $\mathrm{A}$ and $\mathrm{B}$ to provide moderate $\mathrm{Sr}$ extraction with excellent stripping, demonstrating that $\mathrm{Sr}$ and $\mathrm{Tc}$ can be co-extracted and co-stripped.

It is as yet uncertain whether Tc removal from the Hanford waste tanks will be required, but given the mobility and persistence of pertechnetate in the environment, a safe, long-term storage facility for pertechnetate would be desirable. A solvent-extraction process such as the one described here could be employed to safely remove pertechnetate from tank waste. As a single unit operation, the process would likely follow the cesium removal step, and it would be possible to simultaneously remove strontium and technetium using this process, as has been demonstrated.

At this stage of development, the process described is ready for counter-current tests. Important questions regarding mass-transfer, phase-disengagement rate, entrainment losses, reagent stability, effects of impurities, etc. cannot be evaluated at the scale of a few milliliters. In addition, it must be considered that the final disposition of the separated $\mathrm{Tc}$ remains unresolved and that requirements for solidification will have an impact on the design and cost of the Tc separation process. We anticipate that the stripping cycle will be most affected. Two options offer flexibility, including evaporation to a concentrated solution or anion-exchange. The former offers the greatest simplicity, requires no addition of chemicals, generates no secondary waste, and only consumes energy; it also produces a stream of water that can be recycled for stripping. The latter has the potential to highly concentrate the Tc waste stream but raises the issue of stripping the column. 
Although a method to do this has been identified, reagents will be consumed, which could lead to secondary-waste generation.

Finally, the present results are providing input for further development of a process designed specifically to remove both $\mathrm{Tc}$ and $\mathrm{Sr}$ from alkaline nitrate waste solutions. Such a process essentially doubles the value of the Tc extraction process with relatively minor changes in the solvent system. Data being obtained indicate that higher values of $\mathrm{D}_{\mathrm{Sr}}$ well exceeding unity, even in the presence of $1 \mathrm{M}$ potassium ions, can be achieved. A separate report on this process will be issued at a later date.

\subsection{REFERENCES}

1. Horwitz, E.P.; Dietz, M.L.; Fisher, D.E. Solvent Extr. Ion Exch. 1991, 9, 1-25.

2. a) Schroeder, N. C., Efficient Separations and Integrated Program's 1995 Annual Technical Exchange Meeting, Gaithersburg, Maryland, January 24-26, 1995. b) Schroeder, N. C., Radzinski, S., Ashley, K.R., Ball, J., Stanmore, F., Whitener, G. "Technetium Partitioning for the Hanford Tank Waste Remediation System: Sorption of Technetium from DSS and DSSF-7 Waste Simulants Using Reillex ${ }^{\mathrm{TM}}$-HPQ Resin", Los Alamos National Laboratory Report LA-UR95-40 (1995).

3. Pruett, D.J.; McTaggart, D.R. Radiochim. Acta 1983, 34, 203.

4. Iqbal, M.; Ejaz, M. J. Radioanal. Chem. 1974, 23, 51.

5. Izatt, R.M.; Bradshaw, J.S.; Nielsen, S.A.; Lamb, J.D.; Christensen, J.J., Sen, D. Chem. Rev. 1985, 85, 271.

6. Jubin, R.T.; DeMuth, S.F.; Singh, S.P. "Developments in Centrifugal Contactor Technology", Oak Ridge National Laboratory Report ORNL/TM-10768 (1988).

7. Law, J.D.; Herbst, R.S.; Todd, T.A.; Brewer, K.N.; Romanovskiy, V.M.; Esimantovskiy, V.M.; Smirnov, I.V.; Babain, V.A.; Zaitsev, B.N.; Dzekun, E.G. "Flowsheet Development Studies Using Cobait Dicabollide and Phosphine Oxide Solvent Extraction Technologies for the Partitioning of Radionuclides from ICPP Sodium-Bearing Waste with Centrifugal Contactors", Idaho National Engineering Laboratory Report INEL95/0500 (1995). The contactors used were manufactured at Argonne National Laboratory. 


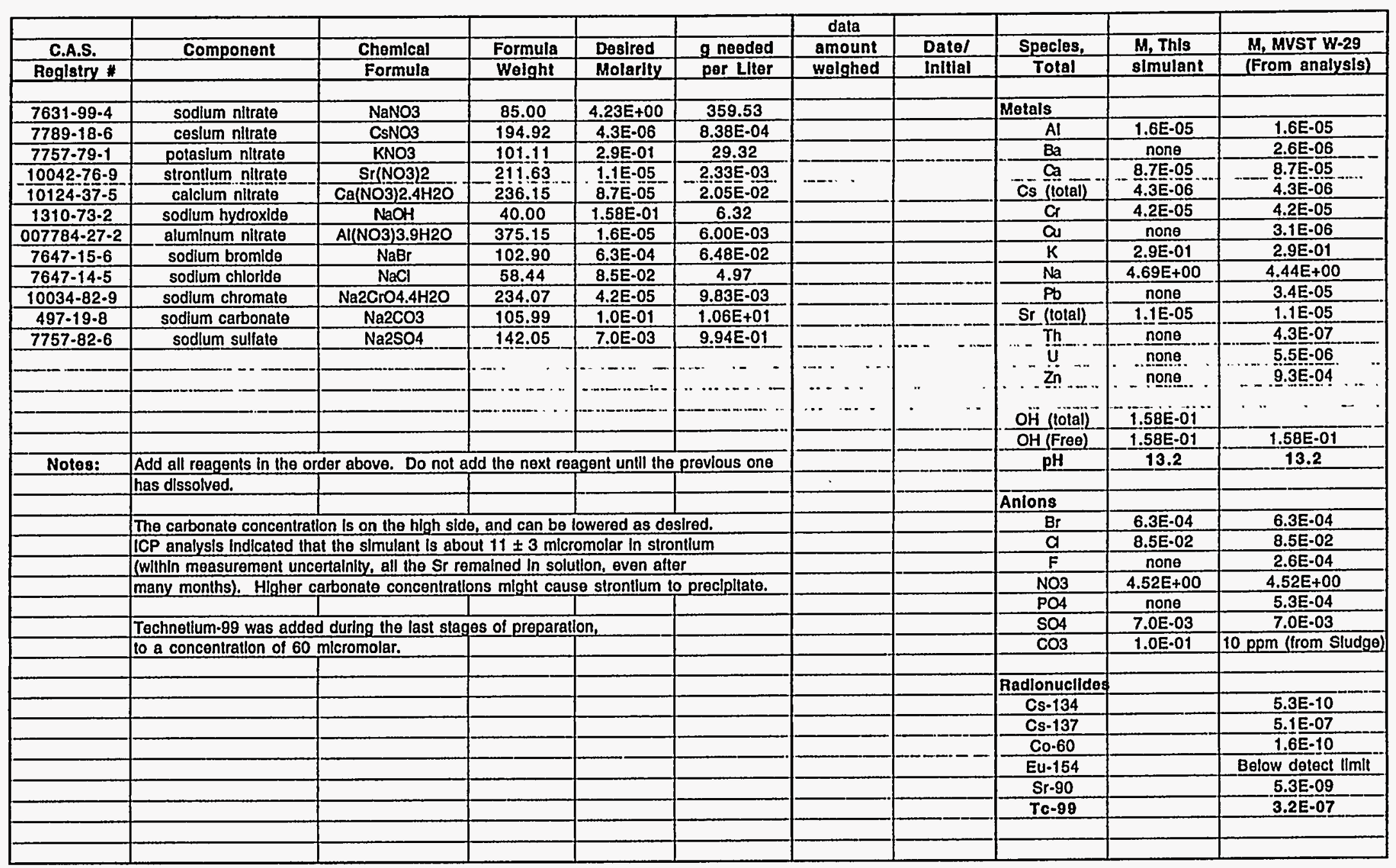




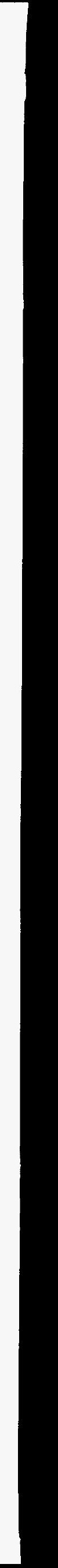




\section{INTERNAL DISTRIBUTION}

$\begin{array}{rll}\text { 1. } & \text { E.C. } & \text { Beahm } \\ 2 . & \text { J.F. } & \text { Birdwell } \\ \text { 3. } & \text { W.D. } & \text { Bond } \\ \text { 4-14. } & \text { P.V. } & \text { Bonnesen } \\ \text { 15. } & \text { D.A. } & \text { Bostick } \\ \text { 16. } & \text { G.M } & \text { Brown } \\ \text { 17. } & \text { J. C. } & \text { Bryan } \\ \text { 18. } & \text { C.F. } & \text { Coleman } \\ \text { 19. } & \text { J.L } & \text { Collins } \\ \text { 20. } & \text { D.L } & \text { Davidson } \\ 21 . & \text { G.D. } & \text { Delcul } \\ 22 . & \text { B.Z. } & \text { Egan } \\ 23 . & \text { T.J. } & \text { Haverlock } \\ 24 . & \text { R.D. } & \text { Hunt } \\ 25 . & \text { R.T. } & \text { Jubin } \\ 26 . & \text { J.M. } & \text { Keller } \\ 27 . & \text { T.E. } & \text { Kent }\end{array}$

\author{
28. D.D. Lee \\ 29. A.P. Malinauskas \\ 30. C.P. McGinnis \\ 31-45. B.A. Moyer \\ 46. D.J. Presley \\ 47. R.A. Sachleben \\ 48. F.V. Sloop \\ 49. B.B. Spencer \\ 50. P.A. Taylor \\ 51. J.S. Watson \\ 52. T.D. Welch \\ 53-54. ORNL Laboratory Records \\ 55. ORNL Laboraory Records, RC \\ 56. ORNL Patent Section \\ 57. Y-12 Technical Library \\ Document Reference Center \\ 58. Central Research Library
}

\section{EXTERNAL DISTRIBUTION}

59. J.N. Appel, Westinghouse Hanford Co., P.O. Box 1970, MS G3-21, Richland, WA 99352

60. V.S. Armstrong, Galbraith Laboratories, P.O. Box 51610, Knoxville, TN 37950

61. M. Attrep, Jr., Los Alamos National Laboratory, P.O. Box 1663, MS J514, Los Alamos, NM 87545

62. R.M. Counce, Department of Chemical Engineering, University of Tennessee, Knoxville, TN, 37996

63. M.L. Dietz, Argonne National Laboratory, Chemistry Division, Bldg. 200, 9700 South Cass Ave., Argonne, II 60439-4831

64. T.A. Fryberger, Pacific Northwest National Laboratory, Battelle Boulevard, P.O. Box 999, Richland, WA 99352

65. K.D. Gerdes, Department of Energy, Trevion II, Germantown Road, Germantown, MD 20583

66. J.G.H. Geeting Battelle Pacific Northwest National Laboratory, Battelle Boulevard, P.O. Box 999, MS P7-19, Richland, WA 99352

67. M.J. Gula, Eichrom Industries, Inc., 8205 S. Cass Avenue, Suite 107, Darien, II 60559

68. H. Harmon, Westinghouse Savannah River Co., High Level Waste Manangement Division, Bldg. 719-4A, Rm. 136, Aiken, SC 29802

69. B.P. Hay, Battelle Pacific Northwest National Laboratory, Battelle Boulevard, MX: K6-82, Richland, WA 99352

70. E.P. Horwitz, Argonne National Laboratory, Chemistry Division, Bldg. 200, 9700 South Cass Ave., Argonne, II 60439-4831

71. S.R. Izatt, IBC Advanced Technologies, Inc., P.O. Box 98, 856 East Utah Valley Dr., American Fork, Utah 84003 
72. S. Kilambi, Commodore Membrane Technologies, 1579 Worthington Club Dr., Westerville, OH 43081

73. W.K. Kot, Quince Diamond Executive Center, 555 Quince Orchard Road, Suite 500, Gaithersburg, MD 20878-1437

74. W.L. Kuhn, Battelle Pacific Northwest National Laboratory, Battelle Boulevard, P.O. Box 999, Richland, WA 99352

75. J.P. LaFemina, Pacific Northwest Laboratory, P.O. Box 999, MSIN K2-25, 999 Battelle Blvd., Richland, WA 99352

76. J.D. Lamb, Department of Chemistry, 207 ESC, Brigham Young University, Provo, UT 84602

77. R.A Leonard, Chemical Gechnology Division, Argonne National Laboratory, 9700 South Cass Avenue, Argonne, IL 60439

78. G.J. Lumetta, Battelle Pacific Northwest National Laboratory, Battelle Boulevard, P.O. Box 999, P7-25, Richland, WA 99352

79. R.L. Miller, Los Alamos National Laboratory, CST-11, MS J514, Los Alamos, NM 87545

80. B.J. Mincher, LITCO, P. O. Box 1625, Idaho Falls, ID 83415-7111

81. J.O. Moore, USDOE-OR, Waste Management Bldg., 3 Main Street, Oak Ridge, TN 37830

82. J. Noble-Dial, USDOE-OR, Waste Management Bldg., 3 Main Street, Oak Ridge, TN 37830

83. R.K. Quinn, Battelle Pacific Northwest National Laboratory, Battelle Boulevard, P.O. Box 999, Richland, WA 99352

84. R.B. Robinson, Dept. of Civil Engineering, 73 Perkins Hall, University of Tennessee, Knoxville, TN 37996

85. R.D. Rogers, Northern Illinois University, Department of Chemistry, Dekalb, IL 60115

86. N.C. Schroeder, Los Alamos National Laboratory, Chemical Science and Technology Division, P.O. Box 1663, MS J514, Los Alamos, NM 87545

87. T.L. Stewart, Battelle Pacific Northwest National Laboratory, Battelle Boulevard, P.O. Box 999, P7-25, Richland, WA 99352

88. J.L. Swanson, 1318 Cottonwood Dr., Richland, WA 99352

89. M.C. Thompson, Westinghouse Savannah River Co., P.O. Box 616, Aiken, SC 29802

90. T.A. Todd, LITCO, P.O. Box 1625, Idaho Falls, ID 83415

91. G.F. Vandegrift, Argonne National Laboratory, Chemistry Division, Bldg. 200, 9700 South Cass Ave., Argonne, IL 60439-4831

92. D.J. Wood, Applied Technology Department, Westinghouse Idaho Nuclear Company, Inc., Box 4000, Idaho Falls, ID 83415-5218

93. Office of Assistant Manager, Energy Research and Development, DOE-ORO, P.O. Box 2008, Oak Ridge, TN 37831-6269

94-95. Office of Scientific and Technical Information, P.O. Box 62, Oak Ridge, TN 37831 